Illinois State University

ISU ReD: Research and eData

Theses and Dissertations

8-3-2020

\title{
Men, Women And Witchcraft: The Feminist Reclamation Of The Witch In The Modern Horror Film
}

Brian Joseph Hadsell

Illinois State University, bjhadsell@gmail.com

Follow this and additional works at: https://ir.library.illinoisstate.edu/etd

Part of the Sociology Commons

\section{Recommended Citation}

Hadsell, Brian Joseph, "Men, Women And Witchcraft: The Feminist Reclamation Of The Witch In The Modern Horror Film" (2020). Theses and Dissertations. 1332.

https://ir.library.illinoisstate.edu/etd/1332

This Thesis is brought to you for free and open access by ISU ReD: Research and eData. It has been accepted for inclusion in Theses and Dissertations by an authorized administrator of ISU ReD: Research and eData. For more information, please contact ISUReD@ilstu.edu. 


\section{MEN, WOMEN AND WITCHCRAFT: THE FEMINIST RECLAMATION OF THE WITCH \\ IN THE MODERN HORROR FILM}

\section{BRIAN JOSEPH HADSELL}

\section{Pages}

The witch as a figure possesses a powerful and enduring legacy in Euro-American culture; she is both a victim of patriarchal persecution and the natural enemy of a deeplygendered society. Recent horror films that employ the witch, however, have generally done so in the form of reclaimed feminist icon: a violently retributive figure avenging the wrongs done to women both past and present. The purpose of this research is to provide insight about our acutely gendered society and culture in the times during and preceding the \#MeToo movement through a semiological analysis of three recent horror films that center on the figure of the witch: Lars von Trier's Antichrist, Robert Eggers's The Witch and André Øvredal's The Autopsy of Jane Doe. Rather than analyzing women-in-film generally or feminist films particularly, this analysis engages with the sociological, historical and filmic contexts inherent to the witch as a horror icon in order to document her changing portrayal in film. By engaging with the iconography and contexts of the witch in different ways, these three films demonstrate the changing gendered landscape of the last decade. And despite these films' best efforts to unmoor the witch from her status as a villain, the enduring legacy of the witch-as-monster has proved remarkably resistant to both recontextualization and reexamination.

KEYWORDS: film, gender, horror, semiology, witch, women 
MEN, WOMEN AND WITCHCRAFT: THE FEMINIST RECLAMATION OF THE WITCH

IN THE MODERN HORROR FILM

BRIAN JOSEPH HADSELL

A Thesis Submitted in Partial

Fulfillment of the Requirements

for the Degree of

MASTER OF SCIENCE

Department of Sociology and Anthropology

ILLINOIS STATE UNIVERSITY

2020 
(C) 2020 Brian Joseph Hadsell 
MEN, WOMEN AND WITCHCRAFT: THE FEMINIST RECLAMATION OF THE WITCH

IN THE MODERN HORROR FILM

BRIAN JOSEPH HADSELL

COMMITTEE MEMBERS

Jason Whitesel, Chair

Livia K. Stone

Li Zeng 


\section{CONTENTS}

Page

INTRODUCTION

CHAPTER I: METHODS AND LITERATURES 8

$\begin{array}{ll}\text { Semiological Methods } & 8\end{array}$

Eve, Lilith, and the Historical Construction of the Witch through Western

Religion $\quad 11$

"Here’s Looking at You:” Gender in Classic Hollywood and Horror Genre

Films $\quad 42$

The Sociological Literature of Gender and Witch Politics in the Post 9/11

$\begin{array}{ll}\text { and \#MeToo Era } & 75\end{array}$

CHAPTER II: LARS VON TRIER’S ‘ANTICHRIST’ (2009) 89

CHAPTER III: ROBERT EGGERS’S ‘THE WITCH’ (2015) 114

CHAPTER IV: ANDRÉ ØVREDAL’S ‘THE AUTOPSY OF JANE DOE’ (2016) 137

$\begin{array}{ll}\text { CONCLUSION } & 151\end{array}$

$\begin{array}{ll}\text { REFERENCES } & 157\end{array}$ 


\section{INTRODUCTION}

Films in general, and those belonging to the horror genre in particular, are often dismissed by critics in mainstream culture as escapist entertainment or lowbrow nonsense and bemoaned for "dumbing down [cinematic] content" (Bergesen 2016, 593) in the name of popular appeal. Horror movies as an element of mass culture particularly bear out that "a wider swath of potential viewers requires a wider span of cultural assumptions if all are to understand what is happening on screen" (Bergesen 2016, 593). In fact, scary movies can serve the vital "social function of speculating about societal fears and apprehensions" (Subissati 2010, ii). After all, nothing is ever "too lowly to be taken up in ritual and given lofty meaning" (Douglas 1966, 114). Regardless of its perceived baseness by the keepers of 'good taste,' cultural anthropologists understand that "the more personal and intimate the source of ritual symbolism, the more telling its message. The more the symbol is drawn from the common fund of human experience, the more wide and certain its reception" (Douglas 1966, 114). Consequently, "the more popular the movie, the more sociological and civilizational information it has to presume" (Bergesen 2016, 593).

Touching on Siegfried Kracauer's foundational notion that cinema can powerfully shape the societies about reality (Kracauer 1947) and that "the enormous potentialities of [cinematic] visualization in the formation of 'political' beliefs, or of any beliefs" (Mayer 1948, 18), it is evident that film, and particularly film genres such as horror, "serve as forms of 'cultural ritual' and the public's 'collective expression' of values" (Tasker 2015, 10). And “just as religion became the object of analysis for one of the earliest sociologists, Emile Durkheim, so [too are] the structures of contemporary mass culture $[\ldots]$ cinematic" (Pajaczkowska 2017, 302). Thus, 
"to analyze and decode cinema is to study the structures, thoughts, ideas, and fantasies of modernity" itself (Pajaczkowska 2017, 302-303).

We understand that "evolutionary models of genre are often underpinned by a sense of how the film industry works [and they] can tell us useful things about social values at any particular point" within a society (Tasker 2015, 10). In other words, the fact that horror is doing social, even political, work is nothing new, and if these films were nothing more than cheap titillation and tasteless gore, they would not continue to be "heaped with praise, [to win] awards, [and to] chang[e] minds" as they continue to echo the underlying truths of our modern society (Wilson 2020,3). Not only do "horror films reflect and refract the terrors that contemporary society faces" (West 2016, 8), but "the modern horror movie has [both] established a vocabulary for us to articulate our fears [as well as] taught us what to be scared of" (Zinoman 2011, 6). Or, as horror author Stephen King aptly put it:

the mythic horror movie, like the sick joke, has a dirty job to do. It deliberately appeals to all that is worst in us. It is morbidity unchained, our most base instincts let free, our nastiest fantasies realized... and it all happens, fittingly enough, in the dark. (King 1981, 175)

Accordingly, horror movies work by "lifting a trap door in the civilized forebrain and throwing a basket of raw meat to the hungry alligators swimming around in that subterranean river beneath" (King 1981, 175). The reason why filmmakers, audiences and even social scientists should engage with the genre is "because it keeps [the alligators] from getting out $[\ldots]$ It keeps them down there and me [safely] up here" (King 1981, 175). Therefore, horror contributes to "the various stories our culture tells itself to purify and justify the values and beliefs which sustain it" (Schatz 1981, 263). So even though "Lennon and McCartney [...] said 
that all you need is love," that only matters "as long as you keep the gators fed" (King 1981, 175).

It is generally understood by film writers and academics that "much of film scholarship is underwritten by an assumption that genres can be understood as gendered" (Tasker 2015, 64), and that "horror films [in particular] have always been highly gendered" (Langill 2014, ๆ 1) because "female figures and/or gender issues loom especially large" within it (Clover 1992, 5). Consequently, throughout the present century, gender issues have dominated the public discourse, have proliferated popular and critically lauded films and have betrayed the deepseated cultural anxieties surrounding them: from the initial emergence of the phrase "MeToo" on MySpace in 2006 (and, a decade later, the hashtag and social movement of the same name) in order "to draw attention to the prevalence of sexual harassment and assault [as well as] the social structures that enable, protect, and shield powerful figures from consequences" (Wingfield 2019, 352), to U.S. Representative Maxine Waters leading the viral charge for women to "reclaim [their] time" (Wingfield 2019, 345), to the incendiary revelations of the sexual abuses of Harvey Weinstein and other powerful men throughout society (Kantor and Twohey 2017, $\mid 5$ ) and the acknowledgement that many others "knew enough to do more than [they] did" (Kantor 2017, \2).

In much the same way that Siegfried Kracauer and Anton Kaes varyingly view Weimar era films as either being prophetic of World War II (Kracauer 1947) or symptomatic of World War I (Kaes 2009), the popularity and prescience of horror films have been strongly correlated with economic (and, subsequently, societal) strife: a trend which has been maintained across both time and space. Whether nightmarishly expressionistic silent films in 1920s Germany, the Universal monster movies in 1930s America, slashers in 1970s America, J-horror in 1990s Japan 
or the zombie resurgence throughout the world in the 2000s, different subgenres of horror film have long been associated with the social, economic and cultural anxieties of their time. And, in the 2010 s, it is evident that "the witch is having a moment" of revival (Sollèe 2017, 13). After all, "film and television are filled with tales of witches and otherworldly women, visual art and literature are plumbing the depths of pagan lore, and runaways are replete with occult symbolism” (Sollèe 2017, 13). Recently, witches have appeared in journalism (West 2017, $\mid 6$ ), in video games (e.g., Bayonetta, 2009), in tabletop roleplaying games (e.g., Night Witches, 2015), in literature (e.g., A Secret History of Witches, 2017), on television (e.g., American Horror Story: Coven, 2013-2014), or in the films of directors Lars von Trier (e.g., Antichrist, 2009), Robert Eggers (e.g., The Witch, 2015) and André Øvredal (e.g., The Autopsy of Jane Doe, 2016). It is not just that women generally are being uniquely centered at this current moment (such as Lisbeth Salander in Girl with the Dragon Tattoo books and films), but that these women - these witches - are being proliferated and recontextualized in ways that are radically at odds with their historical treatment in media.

Unlike prior iterations of the witch in popular culture, however, "for the newly appointed 'generation witch,' empowerment is central to her appeal”' (Sollèe 2017, 13). In fact, witch, author and ecofeminist Starhawk wrote that "to reclaim the word Witch is to reclaim our right, as women, to be powerful"' (Sollèe 2017, 83). Many recent iterations of the witch in popular culture generally, and in film particularly, have foregone the image of the shrunken, hook-nosed hag in dark robes and a pointed hat, speeding away on a broomstick to sacrifice an innocent child to their unholy master. Rather, these modern-day witches are often placed "in conversation with male violence, sexual or otherwise. [... and deal ] pointedly with rape culture" (Wilson 2020). As a result, these narratives "posit that the targeting of the witch is part of a continuum of 
violence fueled by the demonization of female power, the disparagement of female sexuality, and the construction of women as rapeable object[s]" (Wilson 2020, 133-134). Thus, as presented throughout the 2010s, the witch is a subversive, vengeful, feminist icon and her various narratives, "like dreams, [... can] work through [women's collective] trauma by restaging it [and $\mathrm{h}$ ]orror films in particular, with their shock effects and near-death encounters, $[\ldots]$ allow the viewer to take part in the experience of the traumatic event, but from a distance, vicariously and safely" (Kaes 2009, 51-52). Or, by contrast, "horror movies can be conceived of as collective nightmares: compiled representations of all the things that both terrify and intrigue us at the same time" (Subissati 2010,1). In either case, the "intrinsically voyeuristic and manipulative [nature of] 'horror' provide[s] a space for transforming personal drama into its performative equivalent[: a] primal scream into [the] Theatre of Cruelty, [an] Artaudesque shock therapy for complacent audiences"(Badley 2010, 146).

Of the range of visual methodologies available to sociologists, film critic James Monaco believed that "semiology is the best method for interpreting films because $[\ldots]$ films communicate meaning and semiology has the best tools for analyzing visual meaning-making" (Rose 2016, 178). Because "human culture is made up of signs, each of which stands for something other than itself, and the people inhabiting culture busy themselves making sense of those signs" (Bal 1991, 174), this allows semiology, an analytic approach that is expressly concerned with understanding the meaning of signs and what they signify, to "lay bare the prejudices beneath the smooth surface of the beautiful" and the horrific (Iversen 1986, 84).

The films herein chosen for analysis have been done so based on their appearance at the intersection of several core metrics which demonstrate their particular social importance to this resurgence of witch films more broadly. This includes, but is not limited to, their outsized critical 
value, their continued popular appeal, the apparent influence they have held over subsequent films and the general fitness of their content toward semiological analysis. Thus, in the current cultural moment that the witch uniquely occupies, the films most foundational, emblematic and conceptually interesting are Lars von Trier's Antichrist, Robert Eggers's The Witch and André Øvredal's The Autopsy of Jane Doe.

By examining the witch within its historical, social and filmic contexts - and through films that seek to reconstruct the witch by varyingly emphasizing its iconic (The Witch), indexical (The Autopsy of Jane Doe) and symbolic (Antichrist) aspects - this thesis will examine the enduring legacy of the witch-as-monster, not only in terms of documenting how its portrayals have changed over time, but also in terms of how its unique placement in opposition to oppressive patriarchal ideations have made it remarkably resistant to both recontextualization and reexamination in popular culture. This thesis will begin by outlining semiology as a vital mode of socio-filmic inquiry. It will then explore the three intersecting bodies of literature relevant to the twenty-first century cinematic witch, within which the figure of the witch is often a "peripheral topic" and in which those working within them "often hav[e] limited exposure to the interdisciplinary scholarship on the topic" (Murrey 2017, 158). These intersecting bodies of literature are the historic literature of witchcraft (as regards the witch's biblical roots and her European and American persecutions), the filmic literature of the horror genre (particularly as it relates to the multitudinous ways in which witches are cinematically constructed presently and historically, such as lack of female representation both in front of and behind the camera, Laura Mulvey's theory of the male gaze, Barbara Creed's theory of the monstrous-feminine and Carol Clover's theory of the female victim-hero, also known as the final girl) and the sociological literature of gender (especially as it regards the gendered context in the present century from 
which these witch narratives have arisen). This thesis will subsequently provide a semiological analysis of Antichrist, The Witch and The Autopsy of Jane Doe that draws upon these three literatures. The conclusion will summarize and briefly discuss other witch narratives that are also deeply relevant to this social construction of the witch but, for brevity's sake, are not its central focus. Overall, this thesis contributes to the ever-growing list of published analyses of the ongoing feminist reclamation of the witch by documenting her changing and increasingly sympathetic portrayals in horror films. In doing so, it provides social, historical and theoretical context to the ongoing gendered social concerns and anxieties experienced within society, provide insight into the power and potential activistic usefulness of the archetype of the witch in modern society (informed by its social, historical and cultural trajectories) and further connect inter-disciplinary literatures (particularly sociology and film studies) that often seem to be operating independently and ignorantly of one another. 


\section{CHAPTER I: METHODS AND LITERATURES}

\section{Semiological Methods}

As "the language of our time is increasingly a pictorial language" (Jones 1967, 8), the study of film, which "can provide the emotional impact, the specifics of human interaction, even a sense of drama that often get left out of abstract sociological thinking and writing" (Curry $1984,42)$, is uniquely positioned to reveal the social truths of the twenty-first century by "provid[ing] emotional immediacy and probing insight" to supplement the more traditionally academic concerns of sociology (Demerath 1981, 71). By examining the "points where filmic reality overlaps with a commodified social reality" (Shiel and Fitzmaurice 2003, 148), it can be understood that "film exposes the viewer to social worlds beyond the orbit of personal experience $[\ldots$ and $]$ accomplishes on an empathetic level what sociology accomplishes through historical and cross-cultural comparison: creating the capacity to understand oneself by understanding the broader social context" in which we find ourselves (Prendergast 1986, 243). And of the range of visual methodologies available to sociologists, the film critic James Monaco believed that "semiology is the best method for interpreting films because, he says, films communicate meaning and semiology has the best tools for analyzing visual meaning-making” (Rose 2016, 178). Because "human culture is made up of signs, each of which stands for something other than itself, and the people inhabiting culture busy themselves making sense of those signs" (Bal 1991, 174), this allows semiology to "lay bare the prejudices beneath the smooth surface of the beautiful" (Iversen 1986, 84). In fact, its fitness to this task is largely due "to the fact that semiology confronts the questions of how images make meaning head on [and that it] offers a very full box of analytical tools for taking an image apart and tracing how it works in relation to a broader system of meaning" (Rose 2016, 106). In doing so, it freely "draws 
upon the work of several major theorists whose impact on the social sciences since the 1960s has been immense" (Rose 2016, 106), which have classically drawn from the works of Louis Althusser, Roland Barthes, Walter Benjamin, Peter Berger, Bertolt Brecht, Michel Foucault, Jacques Lacan, Claude Lèvi-Strauss, Ferdinand de Saussure, Julia Kristeva, Judith Williamson and Carey Jewitt. It is this kind of theoretical and disciplinary flexibility that I find both methodologically compelling and, in fact, necessary for the research proposed herein.

Given that "semiology is $[\ldots]$ embedded in a rich and complex series of ideas," it has necessarily developed "an elaborate analytical vocabulary [and] a highly refined set of concepts that produce detailed accounts of the exact ways the meanings of an image are produced through that image" (Rose 2016, 106-107). Of particular importance is the concept of signs (the related concepts of signified, signifier and interpretant), as well as those of icons, indices and symbols.

In attempting to develop a system that would describe how language works, Saussure developed the concept of the sign: the most basic unit of language (Rose 2016). It consisted of two analytically distinct parts: the signified (which is a concept or an object) and the signifier (which is a sound or an image that is attached to that concept or object). For instance, linguistically, the English word baby and the Italian word bimbo are both signifieds which roughly translate to "a very young human unable to walk or talk" (Rose 2016, 113). Conversely, both words can represent vastly different signifiers, such as baby also being a term of romantic endearment or bimbo derogatorily referring to a seemingly unintelligent or sexually promiscuous woman. The relationship between signified and signifier can be simply reduced to a "thing-plusmeaning" (Williamson 1978, 17), which in turn means that "the connection between a certain signifier and a certain signified can be questioned; and the relations between signs and their signifieds can be explored" (Rose 2016, 114). Charles Sanders Pierce later elaborated on this 
dyad by adding a third component, the interpretant, which is how an observer actually reads the sign: in short, what is actually being communicated by it. As it pertains to the proposed research, this conceptual triad of meaning-making that is of foundational importance to semiology means that this methodology is uniquely situated to analyze the changing relationship between the figure of the witch (the sign) and the changing meanings that have been attached to it (its signifiers).

Starting with Pierce, three different types of signs were developed: the icon, the index and the symbol. Iconic signs hold that "the signifier represents the signified by apparently having a likeness to it" (Rose 2016, 119). Due to the inherently pictorial nature of film (Jones 1967), this kind of sign is particularly important to meaning-making within the medium, as "iconographic models of genre emphasiz[e] the continuity provided by recurrent scenes and signs" (Tasker 2015, 5). And just as "a photograph of a baby is an iconic sign of that baby" (Rose 2016, 119), so too is footage of a witch an iconic sign of that witch.

By contrast, the indexical signs are culturally-specific representations of "an inherent relationship between the signified and the signifier" (Rose 2016, 120). This kind of sign is classically seen in horror films between the witch (the signified) and menstrual blood (the signifier), thus constructing the witch as being both "woman and menstrual monster," (Creed 1993, 76). Therefore, filmic indexical signs can be seen as visual evidence of what is being represented.

Finally, symbolic signs are a conceptually more abstract type of sign. As determined by Saussure, these have "a conventionalized but clearly arbitrary relation between signifier and signified" (Rose 2016,120). Just as a baby might be used to represent the future or a black-robed figure might be used to represent death, something like ergot, a type of fungal crop-rot that has 
been closely associated with the Salem Witch Trials (Caporael 1976), can be used to represent hysteria or an apple can be used to represent the failings of Original Sin: both of which notably appear within the film The Witch.

\section{Eve, Lilith, and the Historical Construction of the Witch through Western Religion}

It is important to acknowledge from the start that the perspective and focus of this thesis is that of the hegemonic Western image of the witch: one which is deeply rooted in traditional Judeo-Christian conceptions of entwined femininity and evil, developed throughout a uniquely turbulent period of European history and was finally exported to the similarly fraught American colonies. Researchers more broadly, however, have demonstrated that these same themes have been used to depict various colonized groups as spiritually inferior and to establish ideological, moral and hierarchical frameworks to justify enslavement, colonialism and imperialism. They have, in fact, "been central to a racial system of social classification, in which the idea(s) of "the native'7 ('the savage', 'the primitive') as uncivilised, spiritually and culturally impoverished and underdeveloped is first invented and then maintained through imagined geographies of the Other" (Murrey 2017, 158). So although witches can indeed be found within the "Sumerian tales of Inanna, [the] Egyptian legends of Isis, and [the] Hindu myths of Kali” (Sollèe 2017, 21), not all of these cultures experienced the label of the witch in the same way and, in fact, "reflect divergent understandings of "witchcraft," ranging from "the divine feminine" to iconoclastic "rebel knowledge" (Murrey 2017, 166).

The Judeo-Christian tradition has more in common with the latter depiction accounts of creation, in which one could glibly surmise that "what was Lilith if not a witch that refused to bed down, missionary style, with Adam?" (Wilson 2020, 131). But after millennia of 
reinvention, reinterpretation and recontextualization from this perspective, the supernatural women of pre-Christian religions were, narrowly and popularly codified by the ways in which "women [took] on increasingly sinister roles in religious and artistic lore" (Sollèe 2017, 21). And, therefore, "by examining the misogyny that drove the witch hunts, we can illustrate the brutal origins of the sexism women still face today, and put into context feminist resistance against contemporary misogyny" (Sollèe 2017, 13-14).

The genesis of witchcraft in the Euro-American tradition - the ur-text from which all traditions of maleficarum invariably trace their lineage back to - is the Bible: specifically, from the events depicted in Genesis 3, which many scholars consider to be the "foundation text of Christian misogyny" (Faxneld 2017, 35). Its positioning as a cornerstone of both popular and academic understandings of witchcraft, as both a spearpoint for inquisitors (such as Heinrich Kramer's infamous Malleus Maleficarum) and as a shield against them (as with Jules Michelet's generally sympathetic La Sorcière), is certainly understandable. When the invention of the moveable type printing press made the mass production and mass dissemination of written texts among the lower classes possible for the first time in history, it was the Bible that ushered in this literary revolution, which profoundly influenced many now-sacrosanct writers of the Western canon, including John Milton (Paradise Lost), Geoffrey Chaucer (The Canterbury Tales), William Shakespeare (MacBeth) and Dante Alighieri (The Divine Comedy). Even into the midto-late nineteenth century, "when pioneer families went west in their prairie schooners $[\ldots]$ they generally carried only two books: the Bible and Shakespeare" (Foster 2003, 42), thus ensuring that "everyone knows the tale of the Fall of Man told in Genesis 3" (Faxneld 2017, 35).

As the first book of both the first book of the Hebrew Bible and the Christian Old Testament, Genesis recounts God's creation of the universe as well as the ancient development 
of the Jewish people. Whereas the first two chapters depict the cosmic origins of the Earth and its inhabitants, Genesis 3 concerns itself with the fall of mankind from its nascent state of Grace and lays the groundwork for the misogynist traditions that gave rise to the witch persecutions in Europe and the Americas. Theologian R. W. L. Moberly asserts that "no story from the Old Testament has had a greater impact upon the theology of the Christian Church and the art and literature of Western civilization" (Faxneld 35). And "if we read the Bible as normative social literature," as cultural historian Riane Eisler does, "the absence of the Goddess is the single most important statement about the kind of social order that the men who over many centuries wrote and rewrote this religious document strove to establish and uphold" (Sollèe 2017, 22).

In Genesis 3, the progenitor couple, Adam and Eve, are instructed by God that they may do as they please in the earthly paradise that He has created for them: anything, that is, except eat the fruit from the Tree of the Knowledge of Good and Evil, for if they do, the pair "shalt surely die" (Genesis 2:17). Despite this divine warning, however, Eve is drawn in by the Edenic serpent, a creature identified by later theologians as the devil himself. He goads her into eating the fruit by coyly asking her "did God really say "you must not eat from any tree in the garden" (Genesis 3:1); when she corrects him by repeating God's decree that they may merely not eat of that one particular tree and explains the consequences for doing so (that is, death), he reassures her that she "shall not surely die." Rather, he insists that "the day [she] eat thereof, then [her] eyes shall be opened, and [she] shall be as gods, knowing good and evil" (Genesis 3:4-5). Convinced by the serpent's reasoning, Eve eats the fruit, then gives some to Adam and convinces him to eat it as well. Suddenly gifted with the tree's promised knowledge of good and evil, the fog of innocence is stripped from their minds, and they learn of shame, of their nakedness and of the extent of their wrongdoing. They hurriedly cover themselves with makeshift clothing and, 
overcome by guilt for what they had done, "hid themselves from the presence of the Lord God amongst the trees of the garden" (Genesis 3:8) when God next walked among them. When God eventually discovered their disobedience, he severely punished the couple. Casting them out from the Garden of Eden, it was decreed that he would endlessly toil in the fields for the scarcest of sustenance, that she would suffer terribly in throngs of childbirth and that both would grow old and frail and eventually die (Genesis 3:16-19).

Although a surface-level reading of the text would scarcely imply an inherent misogyny to the faith - it was, after all, the Serpent that tempted Eve, both she and her husband ate equally of the fruit and both of them shared equally of God's wrath - centuries of theological texts, traditions and interpretations have recentered the narrative entirely on the duplicitousness of Eve. In such readings, she both betrayed God and debased her husband (a pious man whose only real shortcoming was foolishly listening to his wife's wicked suggestion); thus, through her witchlike subversion of the natural and intended order laid out by God, Eve's actions introduced sin and hardship into the world. By extension, subsequent readings of Genesis 3 have intoned the persistence of these same failings of character in the ensuring generations of men and, especially, women. Rachel Havrelock observed that "how things began becomes the justification how they must be" (Faxneld 2017, 35) and others have noted that Eve's biblical beginnings, as much as broader "misconceptions of sexual difference and procreative power[, has resulted in] the male subordination of females [that is] at the very base of how our society operates and how we view the world" (Gerould 2002, 689). In Eve's wake, the "prevailing archetypes of womanhood in the Bible become virgin, obedient wife or deviant whore" (Sollèe 2017, 21). Thus the ill-begotten beginnings of Genesis 3 have long lent themselves to easy readings to the moral frailness and 
innately destructive tendencies of women: reasons widely cited throughout history for both female subservience and patriarchal domination of the social world.

Genesis 3 has, in practice, been used by Christians as "a social charter, which affects all women due to the fact that Eve, the woman, is the first in the tale to transgress" (Faxneld 2017, 35). Eve as a Judeo-Christian equivalent to the Greeks' Pandora, as the font of all worldly suffering and the devastator of a primordial golden age that has since passed into myth, is an oftcited parallel in rabbinic literature (Lachs 1974, 342). And because of Eve's allegiance to the Edenic Serpent, all women are seen to share in her sinful nature, duplicitous intent and particular closeness to Satan; Eve was, after all, the first to transgress, the second to tempt and, ultimately, the impetus for all the antediluvian suffering to come. This holds true even in the history of Marian theology (the biblical study of Mary, the virgin mother of Jesus), whose scholarships has often been a source of pain and insecurity for women because of "the feelings of failure, impurity and inability to achieved the unachievable ideal" of virginal motherhood (Soskice 2001, 120). And given the long-standing tradition of Jewish suffering in the annals of both scripture and history - from Egyptian enslavement to the biblical Exodus to countless other, similarlypatterned subjugations, diasporas, holocausts and injustices - the significance of women's perceived moral shortcomings has had especially far-reaching consequences, both into and beyond the bevy of Euro-American witch trials.

As is the case for many popular assertions that have often been attributed to the Bible, "the later idea of Eve as a temptress luring Adam to his doom does not really appear explicitly in Genesis," rather, "she simply gives some of the fruit to Adam, who is with her, and he eats [it]" (Faxneld 2017, 37). Although part of Eve's divine punishment for her transgressions was that "thy desire shall be to thy husband, and he shall rule over thee" (Genesis 3:16), it was not until 
subsequent generations of scholars, theologians and writers, "draw[ing] mainly from each commentator's own presuppositions and cultural expectations" (Faxneld 2017, 37) about the place and grace of women, that this explanation of mankind's existence in an imperfect and oftentimes cruel world took on more pointedly gendered meanings. As early as the books of the New Testament, the text of Genesis 3 has been reinterpreted as a divinely inspired warning of the frailties of womankind. In Paul's letter to Timothy, for instance, “Eve's actions in the Genesis 3 are used as a justification for why women must remain silent and submissive" (Faxneld 2017, 37). Paul argues that "Adam was not deceived, but the woman being deceived was in transgression" (1 Timothy 2:12-14). And, because of this biblically transcribed transgression, Paul commands his adherents to "suffer not a woman to teach, nor to usurp authority over the man, but to be in silence" (1 Timothy 2:12-14). It is also important to note than while God later forgave Adam for his transgressions in Eden (Leviticus 29:1), "no such forgiveness [was ever] extended to Eve" (Kvam et al. 1999, 96), thus cementing the primacy of women's wickedness, furthering their distance from God, gravitating them towards the devil and laying the conceptual groundwork for their easier recruitment to witchcraft. Therefore, Eve's legacy as the prototypical female, from which all antecedent women derive their supposed failings, is secured within the early Church, and women's prescribed silence before men signifies their impotence within a male-dominated social order that was becoming increasingly invested in women's social roles and the social importance of gendered anatomy.

In fact, such misogynist teachings can be found throughout the New Testament. Although the book of Ephesians merely dictates that husbands should love their wives "even as Christ also loved the church, and gave himself for it; that he might sanctify and cleanse it with the washing 
of water by the word" (Ephesians 5:25-26) - explicitly placing the man in the Christ-like role of spiritual savior and filial lord over his wife - the Bible pointedly asserts that:

wives [should] submit to [their] own husbands, as unto the Lord. For the husband is the head of the wife, even as Christ is the head of the church: and he is the saviour of the body. Therefore as the church is subject unto Christ, so let the wives be to their own husbands in every thing. (Ephesians 5:22-24)

This same sentiment is later echoed in the biblical passage commanding "wives [to] submit [themselves] unto [their] own husbands, as it is fit in the Lord" (Colossians 3:18), which itself parallels related imperatives for "children [to] obey [their] parents in all things" (3:20) and for "servants [to] obey in all things [their] masters according to the flesh" (3:22). Similarly, it is decreed that women ought to be "teachers of good things [...] to be sober, to love their husbands, to love their children, to be discreet, chaste, keepers at home, good, obedient to their own husbands [and] that the word of God be not blasphemed" (Titus 2:3-5). And although they are biblically prescribed to be teachers, they are always to defer to their husband's authority, as scripture commands:

women [to] keep silence in the churches: for it is not permitted unto them to speak; but they are commanded to be under obedience as also saith the law. And if they will learn any thing, let them ask their husbands at home: for it is a shame for women to speak in the church. What? Came the word of God out from you? Or came it unto you only? (1 Corinthians 14:34-36)

Taken together, these texts create a foundational expectation of female subservience to male authority, places women within an authoritative hierarchy somewhere between adult men and 
their children and establishes women as the passive recipients of divine knowledge rather than as active participants in its dissemination.

Women's studies scholar Katharine M. Rogers contends that “St. Paul's doctrines wielded an enormous influence on Christian culture," which subsequently provided a convenient supply of divinely inspired misogynistic texts for any Christian writer who chose to use them" (Faxneld 2017, 37). In fact, "the foundations of Christian misogyny - its guilt about sex, its insistence on female subjection, its dread of female seduction - are all in St. Paul's epistles" (Faxneld 2017, 37). And because of the Bible's ubiquitous stature in Western culture and society, "his statements on female subjection were still being quoted in the twentieth century by opponents of equality for women" (Faxneld 2017, 37). Owing to "phrasings like [these] and the ways in which they have been used to serve patriarchal ends, [...] it [is] easy to see why some feminists would later view God as [both] the protector of the patriarchy" (Faxneld 2017, 37), if not the explicit enemy of women in general.

Even later authors would pick up on these New Testament themes of Eve, as the typical woman, being the chief-most transgressor of the Edenic couple and, like Pandora, a woman "who unleashed misery in the world through her curiosity" (Faxneld 2017, 39). As if intent on proving Rogers's assertion that Paul's scriptural letters were as deeply misogynistic as they were influential on descendent generations of Christian thinkers, John Chrysostom, an important fourth century priest, concerning the aforementioned letter in 1 Timothy, considered that:

the woman taught once and for all, and upset everything. Therefore he [Paul] says. "Let her not teach." Then does this mean something for the rest of womankind, that Eve suffered this judgement? It certainly does concern other women! For the female sex is weak and vain, and here this is said of the whole sex. (Faxneld 2017, 40) 
Chrysostom contends that her instruction, taught with the aid of the forbidden fruit, was in the ways of good and evil. Her actions taught shame (for their nakedness), suffering (for their crimes) and all the miserable ways of the world (from their banishment). Her lessons were faithlessness and lies, heresy and rebellion. She was not then "a teacher of good things" (Titus 2:3) as the Bible prescribes, a notion which is historically recapitulated in the sixteenth and seventeenth centuries when keepers of uniquely female knowledge, such as midwives, were among those often accused of witchcraft (Davidson 1995, 257). In this context, it is not so hard to make the leap from Eve's wrongdoings in the Garden to the later commandment that "if [women] will learn any thing, let them ask their husbands at home" (1 Corinthians 14:35); thus Eve's own lesson from Genesis 3 was deference to her husband in all things, as God sentenced that "he shall rule over [her]" (Genesis 3:16) for her crimes against Him.

One of the most influential and oft-quoted of these post-scriptural authors was Tertullian, a second century priest whose writing "holds up Eve as an image of all women" (Faxneld 2017, 39). In one especially influential passage, he asks of women:

Are you not aware that you are each an Eve? The essence of God on this sex of yours lives on in our own time, the guilt must then, of necessity, live on also. You are the devil's gateway. You first plucked the forbidden fruit and first deserted the divine law.

You are she who persuaded him whom the devil was not brave enough to attack. (Faxneld 2017, 39-40) Tertullian's most evocative phrase in this passage, his description of women as "the devil's gateway," has become particularly well-cited throughout the succeeding two millennia. It has been historically used as both "a tool of patriarchal oppression and as a feminist portrayal of tyrannical Christianity (Faxneld 2017, 40). And although Tertullian may have been more critical 
of Adam elsewhere in the body of literature that he produced over his sixty-five years, none of that critical assessment of that second Edenic transgressor is present in this passage. Rather, Adam is portrayed more as gullible than outright sinful: as a morally resolute individual who was more than a match for the Serpent's silver-tongued advances. In fact, "the devil was not brave enough to attack" him (Faxneld 2017, 40), and in his roundabout fashion had to deceive him through Eve, who Adam once intimately referred to as the "bone of my bones, and flesh of my flesh" (Genesis 2:23): his wife and partner who he was naturally disposed to trust.

As it so happens, Saint Augustine of Hippo, one of Christianity's foremost theologians, agrees with this sentiment: that Adam was too strong to succumb to the Serpent's advances and that he needed a circumlocutory route toward his corruption. It is, after all, why Satan started "with the lower member of that human couple in order to arrive gradually at the whole" (Faxneld 2017, 40). After all "he did not think that man was readily gullible" (Faxneld 2017, 40), whereby the comparatively 'lower' woman was. Augustine, however, goes even further than Tertullian by positing that, whereby man was incorruptible, woman had "a certain love of her own power and a certain proud self-presumption" (Faxneld 2017, 40). By this reasoning, Eve was corrupt even prior to eating the fruit. She was vain and proud and envious of the powers reserved by God for himself - all three of which number among the especially grievous Seven Deadly Sins - and it was only through her failings that Adam was able to be similarly brought low. Even Martin Luther, whose faith was largely antithetical to the inviolable Catholic Church, insisted that "if [the Edenic serpent] had tempted Adam first, the victory would have been Adam's," who would have then "crushed the serpent with his foot" in retaliation (Faxneld 2017, 41). These, then, are in keeping with the Aristotle construction of "the female [as] a misbegotten male" (Bucholz 2009, 26) and of Heinrich Kramer's construction of "women [as natural] instruments of Satan 
[because] they are by nature carnal and a structural defect rooted in the original creation" (Miles $2008,80)$. It therefore stands that a long and unbroken line of deeply-gendered religious, historical and philosophical thinking in Europe had constructed women as morally corruptible, spiritually weakened and intellectually naïve, and therefore more prone than men are to satanism in general and witchcraft in particular.

Because of this debasement innate to womankind, Eve was something both more and less despicable than Satan himself: "a temptress and cause of sin, a "chaos agent" who threatens male hierarchies" (Faxneld 2017, 40) in ways that even the devil himself was powerless to do on his own. By describing Eve in such vilified terms, in which her disobedience to both God and her morally superior husband became the principle sin, Charles Ess argues that Augustine "makes obedience to (patriarchal) authority the highest good, no matter if said authority happens to be God, king, or husband," and thus he "sacralize[s] both a patriarchal relationship between the sexes... and the hierarchical politics of monarchy and empire" (Faxneld 2017, 40-41). This, in turn, established that it is anarchical agents such as demonesses, Satanists and witches that exist in opposition to both patriarchal and monarchal authority.

Eve, however, was not the only, or even the first, scriptural depiction of women's innate profanity. According to the Jewish tradition, Adam had a first wife, Lilith, who was created alongside him on the sixth day and who predated Eve's arrival by some heretofore undisclosed period of time (Faxneld 2017, 56). According to this account, itself largely typified by the anonymous, possibly parodic, Alphabet of Ben Sira, Adam and Lilith were not a happily married couple. Since both man and woman were made of the Earth, Lilith considered herself to be Adam's equal, and refused to submit to Adam by lying beneath him during sexual intercourse. This, naturally, violated the rabbinic doctrine that "the male dominant position in intercourse, as 
in married life, [is] a prerequisite of man's primacy in creation" (Faxneld 2017, 57). The strain on their marriage eventually grew too great to bear, and she willing fled the Garden of Eden, traveling beyond the Red Sea. Even when God sent a trio of angels to retrieve her, Lilith insolently refused the command and instead bent her considerable powers to causing sickness in infants. Following this failed first experiment of womankind, God, in keeping with the traditional Genesis story, made Eve out of Adam's rib, rather than the Earth itself. In so doing, the primacy of Adam (and thus man) was secured and Eve (and, by extension, all women) were beholden to their authority as God's most senior creation. And because woman is canonically established to have been derived from man, she is granted "secondary ontological status [to him]. She is two steps removed (being both corporeal and female) from the immortal image of God found in Genesis 1" (Kvam et al. 1999, 42). To this end, turn-of-the-century abolitionist minister Moncure Daniel Conway contends that Eve was made “out of Adam's rib in order that there be no question of her dependence, and that the embarrassing question of woman's rights might never be raised again" (Faxneld 2017, 61). Eve, then, as with every subsequent generation of womankind, was divinely beholden to male authority, which itself is derived from male primacy. Any "improper" deviation from that, such from those accused as witches throughout history, was to be met with divine retribution.

Later writers, both within and without the Jewish community, would adapt, borrow and elaborate on this basic premise of an ancient femme fatale and tormentor of children. Some versions attribute Lilith's willfulness and power to laying with demons, while others place her as the bride of 'the Great Demon' Samael (later Satan). She was the sometimes-sexual assailant of Adam in the wilds beyond Eden, would frequently lay with men who went to bed alone and sicken, kidnap or kill children left unprotected by rabbinical magics. In The Coming of Lilith, an 
essay anthology written by Jewish theologian Judith Plaskow, Lilith "becomes a strong, independent woman and a sister for Eve in Plaskow's [...] symbolizing feminist religious sisterhood and grounding Plaskow's own theological development" (Stenger 2006, 290). Even today, Lilith's legacy persists in terms of how “the Roman Catholic Church's understanding of marriage as sacramental combines with physically rooted imagery of women and men to argue for naturally ordered relationships supporting procreation, chastity, fidelity, and women's subordination" (Stenger 2006, 290). Lilith, then, has been varyingly constructed as the mother of demons, the ancestor of apes, the commander of succubi and the progenitor of witches (Faxneld 2017, 55-61).

It is in this last regard that Lilith enjoys her most lasting impact in gentile theology. Much of what grew into commonly accepted knowledge of witches originated with Jewish depictions of Lilith. Like the witches of later eras, she was wed to Satan, who granted her supernatural powers that put her on par with men. Like those same witches, she upended the established sexual order, asserting herself to be her husband's equal rather than his deferent partner (something more than a child, but less than man). Mirroring rabbinical accounts of Lilith, descriptions of demons and witches " "near the mountains of darkness, where they have sexual intercourse with Samael' [...] strongly resemble the concept of the witches' sabbath in Christian culture" (Faxneld 2017, 58), directly linking with Lilith as a sort of proto-witch who simultaneously represented "female divinity, female ferocity, and female transgression[ ... but] most of all, she is misunderstood" (Sollèe 2017, 15). Historian Caroline Ford's Divided Houses: Religion and Gender in Modern France demonstrates that otherwise pious women in nineteenthcentury France not only felt empowered by "the possibility of serving society as teachers, nurses, or charity workers but also occasionally in challenging the authority of family, church, and state 
and in claiming individual rights of conscience, free movement, and decisions about property" (Stenger 2006, 290), activities that are traditionally disassociated from hegemonic ideas of "proper womanhood." Lilith therefore created a heretical blueprint, a kind of dark feminism (Hurwitz 1992), for later dispossessed women to follow in the pursuit of greater power and freedom than was afforded to them within God's church.

What was notably absent in these Biblical and early Christian accounts of deviant, sometimes supernaturally-empowered and almost always Satanically-inspired women, however, was anything even remotely resembling our modern conceptions of witchcraft. Eve may have been "the devil's gateway" (Faxneld 2017, 39-40), but she was hardly some satanic sorceress who bewitched men and blighted crops, although both her tempting of Adam with the forbidden fruit on the Serpent's behalf and God's subsequent punishing decree that "cursed is the ground for [Adam's] sake; in sorrow shalt thou eat of it all the days of thy life; Thorns also and thistles shall it bring forth to thee; and thou shalt eat the herb of the field" (Genesis 3:17-18) comes curiously close to that commonplace assessment of witches. The extra-scriptural accounts of Lilith are likewise bereft of iconographic details common of latter-day witches, although, like Eve, her animosity towards God and children, her congress with demons, her marriage to Satan and her assortment of supernatural abilities seem to lay a loose foundation for the kinds of women who would arrive in later centuries. There is, of course, no dearth of malevolent females in the Bible; but even so, the most well-known reference to witchcraft in that text, "thou shalt not suffer a witch to live" (Exodus 22:18), is buried in the middle of a long string of dozens of commandments, stretched out over multiple chapters and, in effect, acting as a half-forgotten coda to the better-known Ten Commandments brought down by Moses from Mount Sinai in 
Exodus 20. In the Bible itself, however, there was neither a broomstick nor black book to be found.

In fact, "it was not until the fifteenth century that [the] stereotype of the diabolical and conspiratorial witch was fully developed" (Waite 1999, 155). After "the Black Plague had wiped out over one third of Europe and Christianity had been molded a sharp duality between God and the Devil," and after centuries of existing at the peripheries of ecclesiastical thought, thenceforward "the stage was properly set for the witch's debut" (Sollèe 2017, 22). Taken as a whole, these period accounts broadly describe:

The stereotyp[ical] witch [as] an independent adult woman who does not conform to the male idea of proper female behavior. She is assertive; she does not require or give love (though she may enchant); she does not nurture men or children, nor care for the weak. She has the power of words - to defend herself or to curse. In addition, she may have other, more mysterious powers which do not derive from the established order. All women threaten male hegemony with their exclusive power to give life; and social order depends on women conforming to male ideals of female behaviour. The identification of any woman as a witch will, therefore, set against her not only males, but also conforming females and their children. (Larner 1994, 253)

Thus, as can be witnessed in more modern systems of oppression, the same people whose very existence as vulnerable targets for persecution within this repressive social order are themselves strongly incentivized to maintain it, therefore positioning themselves above the offending witch and within reach of the many boons varyingly dispensed and withheld by those in positions of greater power. 
By the fifteenth century, "nearly all believed, that God had created the universe, ordered it, and was active in its daily workings. In other words, the world was a physical manifestation of God's will" (Bucholz 2009, 23): perfect, inviable and immaculately hierarchical. Everything, in short, was as it ought to be, as it always was and as it always would continue to be. Referred to as the Great Chain of Being, everything, and everyone, was hierarchically ranked within it: starting with God in Heaven, then descending through the ranks of angels, man, animals, plants and minerals before finally coming to rest with the damned in Hell. And, indeed, there were subrankings within each of these greater, cosmological categories. Within the rank and file of man, for instance, the head position was owed to the divine right of kings, which bestowed authority to "the ruler of the kingdom, the fount of justice and honor [and] God's lieutenant on earth" (Bucholz 2009, 24). Immediately beneath his royal personage were the nobles, which comprised of "50 or 60 families" who were "ready to assist him in his rule" (Bucholz 2009, 24), themselves ranked in order of dukes, marquesses, earls, viscounts and barons. Further below them were the gentlemen, then the yeomen, the husbandmen, the cottagers and the laborers, in that order. Even European emigrants in later centuries would adhere to this hierarchical model, in which the "family itself represented a covenant, with parents and householders bound to 'wives, and children, and servants, and kindred, and acquaintances, and all that are under [their] reach[']" (Reis 1997, xiii). This created a singular continuity of absolute and unquestioned authority, bestowing the unqualified rule of law to the male head-of-household who ruled over his family like the state-in-miniature in accordance with the perceived proper order of the universe. Any deviation from this divinely ordained order, however - such as the rebel body of a witchy woman challenging the sacrosanct male authority (Federici 2004) - cast the entire system into abject chaos. 
According to Shakespeare's play Troilus and Cressida, under God's stately watch, "the heavens themselves, the planets, and this centre, / Observe degree, priority, and place, / Insisture, course, proportion, season, form, / Office and custom, in all in of order" (Bucholz 2009, 26). But amidst the corrupting influence of Satan, witches and the other enemies of God, Shakespeare's approach to the Trojan War in Troilus and Cressida also emphasizes that "the planets, / In evil mixture, to disorder wander, / What plagues, and what portents, what mutiny, / What raging of the sea, shaking of earth, / Commotion in the winds, frights, changes, horrors / Divert and crack, rend and deracinate / The unity and married calm of states / Quit from their fixture" (Bucholz 2009, 26-27). Shakespeare's three weird sisters, like Thomas de Quincey's three ladies of sorrow and Dario Argento's three mother, famously reciting “'fair is foul, and foul is fair', [make] reference to a 'hurlyburly' with its suggestion of misrule and topsyturveydom" (Clark 1980, 129). The offending women they describe, which can take the form of either demonesses or witches, are described as a noxious, lowly creature that promotes a chaotic and disorderly inversion of the divinely inspired ranking within which all life is supposed to reside.

Witches, therefore, existed in direct opposition to what the established rule of order was supposed to be, as "the nature of Satan, the character of hell and, above all, the ritual activities of witches shared a vocabulary of misrule" (Clark 1980, 121). And, "like all manifestations of misrule [witches represent] that [proper, orderly] world mirrored in reverse" (Clark 1980, 129). For instance, one of the most iconic powers of the witch, that she could "change [herself] and other into animals" (Clark 1980, 126), was profane precisely because it existed in violation of the sacrosanct hierarchies God set in place to bring order to the world: transubstantiating higher beings (humans) into lesser ones (animals). The Great Chain of Being, after all, was exactly what it claimed to be: a chain, not a ladder, and therefore disallowed the possibility of anything 
changing its position along it. It could therefore be reasonably assumed from a contemporaneous vantage point, that "the witches have power to turn the world upside down at their pleasure" (Clark 1980, 126). Further echoing these apocalyptic visions of a world turned upsidedown by witchcraft, another observer, Nicholas Rèmy, a $16^{\text {th }}$ and $17^{\text {th }}$ century magistrate who boasted of having condemned and burned witches, opined that among the dangers inherent to witches is that:

there is nothing to hinder a Demon from raising up mountains to an enormous height in a moment, and then casting them down into the deepest abysses; from stopping the flow of rivers, or even causing them to go backwards; from drying up the very sea (if we may believe Apuleius); from bringing down the skies, holding the earth in suspension, raising foundations solid, raising the shades of the dead, putting out the stars, lighting up the very darkness of Hell, and turning upside down the whole scheme of this universe. (Clark 1997, 126)

Recalling the terrifying Night on Bald Mountain sequence from Disney's Fantasia (1940) to many modern readers, whose music and animation depict Satan presiding over a witch's sabbath, Rèmy's description provides a cataclysmic urgency to the need counter the misrule that these despotic forces represented to the Early Modern period and uphold God's stately and eternal order.

In summarizing the wide historical arc of witchcraft, $19^{\text {th }}$ century author and women's suffragist Matilda Joslyn Gage identified three core themes of the European and American witch hunts, which bear out broadly within the literature available in the 1800s. Accordingly, these are:

First: That women were chiefly accused. 
Second: That men believing in women's inherent wickedness, and understanding neither the mental nor the physical peculiarities of her being, ascribed all her idiosyncrasies to witchcraft.

Third: That the clergy inculcated the idea that woman was in league with the Devil, and that strong intellect, remarkable beauty, or unusual sickness were in themselves proof of this league. (Sollèe 2017, 51-52)

Although theologians "may have professed publicly that the sexes were equal before God," excepting their differing placement in the Great Chain of Being that is, "they were not equal before the Devil" (Reis 1997, 261). As with Lilith before the Fall, the devil preferred female companionship. It was widely "believed that Satan attacked the soul by assaulting the body" (Reis 1997, 262) and that by damaging or otherwise weakening the body, he could gain access to the divine essence within (either by possession or conscription to witchcraft). And because “women's bodies were [viewed as being] weaker, the Devil could reach women's souls more easily and breach these 'weaker vessels' with greater frequency" (Reis 1997, 262). This, perhaps, is why eighty percent or more of accused witches were female, although the "male suspects appear to have been treated with the same harshness as females once they reached the courts" (Larner 1994, 255). Therefore, before both God and the earthly courts of the faithful, the perceived physical frailty of women doubled as a spiritual weakness: a direct avenue through which they might become corrupted by both the Devil and his ilk.

It stood to reason, then, at least by way of late-Medieval and Early Modern thinkers, that “a woman's feminine soul, jeopardized in a woman's feminine body, was frail, submissive, and passive - qualities that most [...] thought would allow her to become either a wife to Christ or a drudge to Satan" in equal measure (Reis 1997, 262). In that the trajectory of women's lives was 
at this time considered as either "sign[ing] a pact with Satan [or] wait[ing] quiescently for Christ, [society] effectively demonized the notion of active female choice" (Reis 1997, 262). She was, in fact, "damned if she did and damned if she didn't" (Reis 1997, 262), because any route she took in life made her as susceptible to the guiles of Satan as Eve was before her. "If," for instance, "her soul waited longingly for salvation in Christ, such female yearning could evoke the image of an unsatisfied woman vulnerable to Satan; if," however, "a woman's soul acted assertively rather than in passive obedience, by definition it chose the Devil" (Reis 1997, 262). And even if she focused on worldly life - on marrying a husband and bearing his children - she would eventually fall under witchy suspicion, given that "a disproportionate number of accused witches were over forty years of age, which coincides with waning fertility, the criterion by which a woman's worth was measured in early modern society" (Sollèe 2017, 24). Regardless of her choices and thus constructed, women were impossibly constrained by "a gendered ideology and society that conceived of women, ironically, as closer both to God and to Satan" (Reis 1997, 266). Contemporary feminist scholars, however, understand this as the Madonna-Whore dichotomy which polarizes women's lives: catching them between a state of childlike innocence (for which their doe-eyed gullibility in the face of obvious deception is to blame) and one of active wrongdoing (for which their inherently wicked nature in the face of worldly temptation is to blame). Either way, the woman is always deemed to be at fault.

An additional dimension to the topsyturvydom of witchcraft is how, like Lilith before them, witches posed a specifically sexual danger to the men in the surrounding community. But whereas Lilith, the woman, simple wouldn't submit to rabbinically sacrosanct sexual positions that both favored and empowered Adam, the man, the distinctive iconography and beliefs surrounding witches spoke to a deep-seeded castration anxiety within the male sex. The Malleus 
Maleficarum (literally, 'the witch's hammer), whose "tone is one of fire and brimstone" (Wilson 2020,133), was a particularly lurid inquisitor's handbook that contained detailed instructions on how one could identify, interrogate and ultimately destroy suspected witches. In the wake of the printing revolution of the mid-1400s, when sensational "religious propaganda about heathen servants of Satan began to replicate like a viral meme" (Sollèe 2017, 23), this treatise on witchcraft proved to be particularly "instrumental in legitimizing the persecution of those accused of witchcraft" (Wilson 2020, 133). The Malleus Malefcarum became emblematic of the increasingly malevolent shift in the church's attitude toward witchcraft and, "significantly, it cemented the association between heretical practices, witchcraft, and the devil [and] associating evil with women specifically" (Wilson 2020, 133) by reframing the "isolated misfits with weird ways that could heal or harm [into heretics in league with the devil, opposed to the rule of God on earth[, that] were seductive[,] immoral, and received their powers as gifts from Satan" (Sollèe 2017, 24). This, in turn, represented "a pulling together of misogynist attitudes from many different sources and centuries" (Sollèe 2017, 24) into an ideology that could be weaponized against women. As documented in the Malleus Maleficarum, it was believed that witches would: sometimes collect male organs [i.e., penises] in great numbers, as many as twenty or thirty members together, and put them in a bird's nest, or shut them up in a box, where they move themselves like living members, and eat oats and corn, as has been seen by many and is a matter of common report. (Oldridge 2008, 247)

In one particularly telling account, the Malleus Maleficarum describes one-such man who suffered a witch's penectomy. Partly reading like a satirical and ribald tale (with some textual congruities with depictions of Lilith in Alphabet of Ben Sira), the man, having: 
had lost his member $[\ldots]$ approached a known witch to ask her to restore it to him. She told the afflicted man to climb a certain tree, and that he might take whichever member he liked out of a nest in which there were several members. And when he tried to take a big one, the witch said, "You must not take that one," adding, "because it belonged to a parish priest." (Oldridge 2008, 247)

The antagonist of this anecdote, here presented as an absolutely truthful account of what witches are capable of, is actually doubly damning for its male victim. In the first, he has been penectomized by a witch, who has profaned the inherent order of the universe as conceived of by The Great Chain of Being by disregarding the primacy of man in an explicitly phallocentric world.. When he asks her for his 'member' back, it is revealed that she has so many such organs from so many men that she cannot possibly identify his penis among the gathered multitude (itself an implicit sleight on his manhood by way of how unremarkable his particular appendage was). To make amends, she allows him to take whichever one he wants and, fittingly, he chooses the biggest one he can find, only for her to infringe on his dignity as a man yet again by informing him that that penis was not his, but rather a priest (a man who, adding insult to injury, would have taken a vow of celibacy and have had no sexual need for it). Taken together, this tale demonstrates that witchcraft is a multi-faceted affront to the patriarchy: one that attacks men physically (the amputation), psychologically (the incessant taunting) and spiritually (by supplanting man's supposed place of God-given superiority). Likewise, it constructs female liberation as the antithesis of male virility, such that female power is naturally counterbalanced by male neutering: a symbolic affront to a rigidly gendered social order.

These traditions in the Christian West came along gradually and piecemeal: cobbled together from multiple, often contradictory texts, superstitions, political ideologies, philosophic 
beliefs and straight-up misogyny. Indeed, it is true that "the case that the witch-hunt was a woman-hunt is a strong one" (Larner 1994, 254). From the mid-1400s to about 1700, an estimated 40,000-60,000 people were tried, convicted, tortured and executed for the crime of witchcraft in both Europe and the Americas (West 2019, 4). Because the stereotypical witch was female, approximately 80 percent (and sometimes as high as 95-100 percent) of accused witches were women. Typical readings of this centuries-long persecution understandably equate it to outright gynocide, as was the case "in twelfth-century Russia, [when] the authorities in one district became so anxious about the prevalence of witchcraft [that they] began to round up the entire female population" (Larner 1994, 254). So while some scholars argue that to equate "the witch-hunt was a woman-hunt [ $\ldots$ is] simply incorrect [and that the crime of witchcraft] was [merely] sex-related [and] not sex-specific" (Larner 1994, 255), most take the stance that "to discuss witches without addressing the woman-as-witch mythos would be to ignore a robust canon of art, literature, and scripture that conflates femininity with devilry" (Sollèe 2017, 22) and the innumerable ways in which women were disproportionately affected by the persecution of and hysteria surrounding witchcraft. After all, explains Carol F. Karlsen, "the history of witchcraft is primarily a history of women" (Sollèe 2017, 22). However, it is true that a multitude of cultural, social and, yes, sexual factors contributed to the accusation, prosecution and punishment of presumed witches throughout history.

The long and troubled history of the world starting in the Medieval Era (476-1453), through the Early Modern Era (1485-1740) and into the so-called Long Nineteenth Century (1789-1914) gave rise to the popular eschatological view in Catholic France, Lutheran Germany and Calvinist England that "witcheraft flourished because the world was in a state of terminal decline" almost since its inception (Clark 1997, 137). Eve's transgressions in the Garden of Eden 
traded in an earthly paradise for the tremulous toil of the mundane world. Following the biblical flood, humans no longer lived for hundreds of years, nor amongst the angels, demons and other fantastical creatures common to the antediluvian period (Faxneld 2017, 57).

The aftershock of the fall of the Roman empire was the Medieval, or Dark, Age: a millennia-long period marked by plague, famine, war, political strife and hardships not conceived of since that first Edenic Exodus at the dawn of time. In the century immediately preceding the advent of the Early Modern period, "three different royal houses had ruled England. Each had a disputed succession and each had fallen with the murder of its king and head" (Bucholz 2009, 32). And although the resolution of the pandemonic War of the Roses ended with the ascension of Henry VII to the throne, a man who would peaceably "rule England for nearly 25 years and die in his bed, safe in the knowledge that his son, also named Henry, would succeed to a more or less united, loyal and peaceful realm supported by a full treasury" (Buchlz 2009, 32), the thirty-eight year reign which followed was nothing short of catastrophic, resulting in the rise of heretical protestant sects, religious persecution, an irreparable schism with the Catholic Church, a bitter loss of territory to rival states and acute anxiety over royal succession (as the new Henry lacked a legitimate male heir through the majority of his reign). And, somehow, the years immediately following Henry VIII's death were even worse, between the regency of the child-king Edward VI, the disputed nine-day reign of Lady Jane Grey, the ascension of "Bloody" Mary Tudor as sovereign, the utter exhaustion of English material and political capital by her husband Phillip II of Spain and the terroristic dread posed by Mary Queen of Scots, all leading up to the comparatively amicable (although nonetheless still contentious) reign of Elizabeth I. It is no wonder, given this context, that many who lived through these 
tumultuous times adopted an 'apocalyptic' view of history (Clark 1997, 137) that emphasized the first sin of womankind as the impetus for all the misery that eventually followed.

Despite the omnipresent dread of Medieval and Early Modern existence and "contrary to popular belief, witchcraft accusations were not very common during the Middle Ages" (Clark 1997, 137). In fact, there was not even a legal "statute against the practice until 1542" (Bucholz 2009, 190), during the last five years of Henry VIII's rule. Prior to 1542, witchcraft was a crimen exceptum - that is to say, an exceptional crime prosecuted outside of standard legal conventions - and, given the particular nature of the transgressions in question, they were often impossible to witness firsthand (Sollèe 2017, 25). Ironically, as Anne Barstow notes, women's testimony, both as forced confessions and as criminal accusations, was only made legally admissible in order to try and convict accused witches. Thus "European women first emerged into full legal adulthood as witches [and were] first accorded independent legal status [from their husbands or other male relatives] in order to be persecuted for witchcraft" (Sollèe 2017, 26). However, "between about 1560 and 1640" - that is, between the coronation of Mary I and the outbreak of the English Civil War - "there was an epidemic of witchcraft accusations and prosecutions in England" (Bucholz $2009,190)$ that spread and was recapitulated with "monotonous regularity across Western Europe, featuring sex with the Devil, harm to women in childbed, and threats to fertility [...] all issues which touch centrally on women's experience" (Sollèe 2017, 27). The trajectory of early gains in women's rights was therefore inextricably linked with the trajectory of women's persecution by the state, both of which were bound to the unique experiences inherent to women's lives during this period.

Of the eighty-year height of witch trials and persecution, however, the most "critical decades [were] the 1540 s to 1560 s" after which came a gradual "waning of large-scale heresy 
prosecution" (Waite 1999, 155) and such concerns were confined to more provincial settlements, where, uniquely, "many accusations of witchcraft were between women" (Larner 1994, 255). Although numerous theories have been posited by historians of subsequent generations as to why this rash of persecutions and hysteria occurred during this period - including religious anxiety (and outright rivalry) among Catholics (Clark 1997, 140-141), Lutherans (Rowlands 1996, 149) and Anabaptists (Waite 1999, 154-155), concern over women's changing place in the world (Larner 1994), professional rivalries between male-dominated doctors and female-dominated midwives (Davidson 1995, 257), as a general exercise in state-making (Williams 1999, 183) and as evidence that the state's control of women's 'rebel bodies' was an essential aspect of early capitalism (Federici 2004) - one commonplace and invariable theme linking these various strains of research together is the fact "that the medieval Church did indeed link heresy with demonism, that heretics were accused of crimes with close similarities to witchcraft, and that the first 'new' witches of the fourteenth century were assimilated to the 'old' heretics of the twelfth and thirteenth" (Clark 1997, 141). As a result, witchcraft maintained its apocalyptic continuity with the supposedly terminal state of decline of the world (Clark 1997, 137) and coalesced a whole constellation of unique fears under a singular and intensely gendered banner.

In using these ad-hoc processes of identifying prior generations' witches among otherwise disparate castes of heretics, criminals, dissidents and other malcontents, a new class of witchcraft prosecutors, who were comprised of opportunistic zealots, religious fundamentalists and militant inquisitors, were able to create an unbroken continuum of existential dread throughout recorded history. After all, "those who were prosecuted for witchcraft were not, except during certain mass panics, randomly selected" (Larner 1994, 255), no more so than other criminals were chosen for prosecution. As a matter of course, "the cursing and bewitching 
women were the female equivalent of violent males. They were the disturbers of social order; they were those who could not easily cooperate with others; they were aggressive" (Larner 1994, 255). In other words, "witches, like male bullies, were not "nice people"” (Larner 1994, 255). Witches were, in fact, highly conspicuous transgressors of the established patriarchal social order and their punishment as witches doubled as punishment for failing to conform to the dictates of that very same patriarchal regime. It is no wonder, then, that "women who went to the stake during the witch-hunt went cursing, often for the [very] crime of cursing” (Larner 1994, 254). After all, the crimes that these women were both charged with and convicted for were obvious for everybody to see, and any protestations that they made to the contrary were simply more evidence to be used against them to prove their guilt.

The fear of witches was not contained to Europe, however. When that continent's population began to transplant itself across the ocean, they took with them their generational beliefs in God, the Devil and witchcraft. What is so immediately notable about the American tradition of witchcraft, emblematized by the infamous Salem witch trials, is just how much of a historic outlier it proved to be in the larger arc of witch persecutions. Taking place 50 years after the end of the epidemic inquisitions in Europe, and 130 years after the height of the frenzy in the $1560 \mathrm{~s}$, it is one of the last such persecutions anywhere. Although colonial existence in the Americas was unquestionably hard living, it was not so categorically different from life in Europe at the time. In fact, following the Great Migration of 1630-1642:

a balanced ratio between the sexes, the persistence of patriarchal control and the commitment to family and community, the comparative health and longevity of the population, and the relatively short duration of the migration (which meant that New England's subsequent population growth would occur through natural increase) all 
contributed to making New England more stable and more like old England than any other early North American colonial settlement. (Reis 1997, xii)

These Calvinist migrants abandoned "the English church [that] they considered corrupt, [and] cultivated a more vital, primitive faith" (Reis 1997, xiii)) than that of their forebears and set about to establish "a city upon a hill, [with] the eyes of all [the] people [of the world] upon [them]" (Bremer 2005, 171). As part of this pious pursuit, they "abolished certain Anglican religious rituals, and rejected the hierarchical ecclesiastical structures of the establishment" in favor of a "family [which] itself represented a covenant, with parents and householders bound to 'wives, and children, and servants, and kindred, and acquaintances, and all that are under [their] reach[']" (Reis 1997, xiii). Owing to these generally congenial factors, three subsequent generations of colonists existed more-or-less harmoniously with one another at a time in which "women played critical - and, most likely, satisfying - economic roles within the family, even as that family defined and confined them" (xii) to be no more than "“deputy husband[s]" (xiii) in their homes and communities.

Central to Calvinist theology is the notion of predestination, the belief that "salvation and damnation were foreordained by God, [rather than being] chosen by individuals [...] and only God knew who would end up in heaven or in hell" upon their death (Reis 1997, 1). But the faithful "did not simply wait for God to reveal their fates to them on Judgment Day" (Reis 1997, 1). Rather, they looked for signs of God's blessing on Earth and sought to prove their worthiness of salvation through hard work and sacrifice, both of which were indicative of their assured place in God's heaven and eternal grace. To the modern observer, this recalls sociologist Max Weber's understanding of the "Protestant work ethic," which stressed the virtues of hard work, discipline and frugality, as well as their resulting material rewards, as a means of "economic supermen" 
like J. P. Morgan, J. D. Rockefeller, Jay Gould and others 'legitimat[ing] themselves in personal and social life" (Weber 1946, 308-309). However, "Puritan anxiety owed less to the unattainability of heavenly glory than to the likelihood of hellish horror," and their convictions "made salvation an uncertain reward for even the most righteous, but it surely damned those who followed the devil's path" (Reis 1997, 4). Simply put, although the damned could surely never regain their lost seat in paradise, "sinners could indeed work their way to hell" (Reis 1997, 4). Of foundational importance "to this cycle of anxiety and assurance" of one's predestined but unknown fate in the afterlife "was the very real dread of the devil," who could corrupt and even possess the righteous, compelling them to sin against their better natures, and "the imminent possibility of damnation[,] made certain by complicity with Satan[, ... followed by their deserved tumble into an agonizing hell” (Reis 1997, 1). It was therefore both unknown and unknowable whether one ranked among the saved or the damned in God's estimation at any point of time. And, given that even those predestined for a heavenly afterlife might still fall due to the machinations of the devil, everybody existed in state of constant apprehension over whether they could correctly interpret the cryptic signs of either God's momentary pleasure or displeasure to ascertain their ultimate fate in death.

While there had been earlier (and equally aberrant) witch trials in Connecticut and Massachusetts (Reis 1997, 7), these were comparatively small, isolated and inconsequential. The eventual persecutions in Salem in 1692, however, "took up where the European witch trials left off [decades prior] and featured a familiar confluence of circumstances" (Sollèe 2017, 34). Drawing on the same socio-cultural environment of existential fear, religious fatalism and material strife, the Salem witch trials were shocking only insofar as they were otherwise so far 
removed from the earlier European witch persecutions, rather than owing to any escalation in persecutorial tactics by the American colonists.

In early 1692, nine-year-old Betty Parris and her eleven-year-old cousin Abigail Williams fell inexplicably ill, suffering from "fits" and seizures. After observers ruled out potential medical causes for the ailments, the community concluded that the devil was to blame. Whether motivated by a sincere belief in witchcraft, by "political or familial revenge, whether they simply continued to play a game that had gotten out of hand, whether they pursued a strategy to deflect suspicions from themselves or whether they calculated fraud" (Reis 1997, 6) against their neighbors, Abigail Williams, Betty Parris and others continued to suffer from their bizarre ailments and accuse their neighbors of bewitching them.

What distinguished "the Salem episode [...] from earlier witchcraft accusations [in America was not] the intensity of belief but rather [...] the official response to the accusations" (Reis 1997, 8). Whereas "previous governors had been more cautious about jailing and trying witchcraft suspects, and their reticence had perhaps allowed potentially inflammatory outbreaks to die out" (Reis 1997, 8), Salem's new governor, Sir William Phips, unlike his predecessors, immediately set up a special court to quickly resolve the disturbance. Headed by "the colony's staunchest believer in the devil's ability to recruit witches," lieutenant governor William Stoughton, the court consequently ignored even "the clergy's [taciturn] advice to proceed with caution $[\ldots]$ and [ the court subsequently] encouraged testimony that sent many to their death" (Reis 1997, 9). Had any one of these unique circumstances been deterred by either prosecutorial precedent or clerical authority, it appears likely that the Salem trials would have flared out as comparatively harmlessly as the earlier cases in Connecticut and Massachusetts. 
As in the earlier European trials, "forced confessions, torture, and strip searches for the Devil's mark or an extra teat for an animal familiar to suckle all made an appearance, along with revelations of witches' sabbath[s], riding on broomstick[s], and signing the Devil's book" (Sollèe 2017, 37). After the hysteria subsided in May 1693, approximately two hundred individuals were accused of practicing witchcraft, thirty were convicted, nineteen had been executed and five had died after months of languishing in jail (Sollèe 2017, 36). All told, "fourteen women, five men, and two dogs were executed" (Sollèe 2017, 33) after little more than a year of adjudications.

Although Puritans, like their theological counterparts in Europe, "may have professed publicly that the sexes were equal before God [...] they were not equal before the devil" (Reis 1997, 2). American women, like those in Europe before them, were seen as "[more] vile and evil creature[s]" by nature, who were just as "hopelessly unworthy of Christ's love" as their European kin (Reis 1997, 2-3). They were thus innately more susceptible than men to Satan's charms. This misogynistic belief was equally shared by both the men and women of the community and was so deeply entrenched in the female psyche in particular that "women easily blurred the line between ordinary sinning, which necessitated [only] repentance, and the more egregious [and unforgivable] act of signing the devil's book and becoming a witch" (Reis 1997, 2). This, in turn, accounts for the higher rate at which women were accused of, confessed to and were convicted for practicing witchcraft: trends that have been consistently borne out over the centuries-long history of witch persecution.

Perhaps because "the uniquely American witch hunt straddles both history and mystery, and [owing to the fact that] despite a bounty of studies on the subject, there is no single explanation as to what stirred the pot in Salem village" (Sollèe 2017, 34), the Salem witch trials have cemented a lasting, iconic and sometimes contradictory status in popular culture. In her 
2015 book The Witches: Suspicion, Betrayal, and Hysteria in 1692 Salem, Pulitzer Prize-

winning author Stacy Schiff enumerates the most commonly attributed causes to the Salem witch trials, an event that she refers to as "our first true-crime story," which includes "generational, sexual, economic, ecclesiastical, and class tensions; regional hostilities imported from England; food poisoning; a hothouse religion in a cold climate [historically, witchcraft accusations tended to spike in late winter]; teenage hysteria; fraud, taxes, conspiracy; instability; trauma induced by Indian attacks; and [...] witchcraft itself" (Schiff 2015, 4-5). The fact that many of these potential causes have been implemented (either explicitly or implicitly) by recent witch films ranging from actual sorcery in The Lords of Salem (2013) to ergotism (which Schiff identifies as "food poisoning") in The Witch (2015) to generalized female persecution in The Autopsy of Jane Doe (2016) - speaks to the event's darkly enduring legacy.

\section{"Here's Looking at You:" Gender in Classic Hollywood and Horror Genre Films}

Film has long had a gender problem. This should come as no surprise, as "cinema and gender are concepts with a long and complicated relationship that extends to every aspect of filmmaking - production, representation, exhibition, spectatorship, reception, and distribution" (Hole et al. 2017, 1). From the very beginning "the medium has reflected and constructed ideals of both femininity and masculinity $[\ldots$ and $]$ over the course of the twentieth century, cinema has not only reiterated raced and classed gender norms, but constructed them as well" (Hole et al. 2017, 1). This rocky relationship is further compounded when viewed through the lens of genre, especially the horror genre where "female figures and/or gender issues loom especially large" (Clover 1992). This mercurial web of relational meanings is perpetually created, questioned and revised, and has in fact "perpetually shifted in relation to emerging practices, technologies, and 
recognition of the limitations of the prevailing intellectual paradigms at any given moment" (Hole et al. 2017, 1). Gender, thus, is inescapably entwined with the horror film, both as a site of reflexive repetition and as one of contentious reinvention.

Edgar Allen Poe, for instance, famously asserted that the death of a beautiful women "is the most poetical topic in the world" (Poe 2004, 535), a claim that appears foundational to many of the genre's later entries. Famed Italian giallo director Dario Argento went even further, insisting that he "like[s] women, especially beautiful ones. If they have a good face and figure, [he] would much prefer to watch them being murdered than an ugly girl or man" (Schoell 1985, 35). Even though Carrie author Stephen King intended his debut novel to depict "an uneasy masculine shrinking from a future of female equality" (King 1981, 171), Carrie director Brian De Palma, who believed that "women in peril work better in the suspense genre," delivered a film more in line with The Perils of Pauline, in which "if you have a haunted house and you have a woman walking around with a candelabrum, you fear for her more than you would a husky man” (King 1981, 41). Most extreme of all, however, was British emigre Alfred Hitchcock, who insistently "follow[ed] the advice of the playwright Sardou. He said, 'Torture the woman!' The trouble today is that we don't torture women enough" (Spoto 1983, 483). And, given the ways in which many of these men have treated women both in their work and in their lives, they seem to have taken this advice to heart.

In the horror genre, these misogynistic ideations have calcified into the traditional trappings of the cinematic witch. Forever cast as the antagonist of the films that feature her, the witch's outward appearance is designed to express her internal moral failings, such as the Wicked Witch's sickly green skin (The Wizard of Oz, 1939), Mother Markos' infirmed and haggard appearance (Suspiria, 1977), the skeletal guise of Mater Tenebrarum (Inferno, 1980), 
the twisted, demonic visage of Eva Ernst (The Witches, 1990), the burn scars of Bonnie Harper (The Craft, 1996) or, at the height of her vengeful rampage, the pig's blood coating Carrie White (Carrie, 1976). The filmmakers invariably frame these sinistrally and at a dehumanizing distance: showing them in profile (Suspiria), from extreme angles (Carrie) or in heavy smoke or shadow (The Wizard of $\mathrm{Oz}$ ). In some instances, the witch is never afforded even a cursory depiction, instead only appearing off-screen to torment her victims from the unseen margins of the film (The Blair Witch Project, 1999). When they do appear on-screen, however, they are arrayed with the stereotypical iconography of occultism - such as flying broomsticks (The Wizard of $\mathrm{Oz}$ ), dark pointed hats (Hocus Pocus, 1993), Christian paraphernalia (Carrie) or the appearance of Death itself (Inferno) - and can only be defeated through some means of purification, such as water (The Wizard of Oz), fire (Suspiria), sunlight (Hocus Pocus) or the innate goodness of the soul (The Craft). And, in keeping with the genre's fixation on female protagonists and the witch's historical fixation on children as her victims, the characters that the cinematic witch invariably torments are comprised mostly, if not exclusively, by women and children.

The horror genre, however, is merely one facet of the larger film industry, where similarly negative portrayals of women on-screen and rampant sexual imbalances off-screen are commonly cited failings of the industry as a whole (Bechdel 1985). This was famously lampooned by cartoonist Alison Bechdel in a 1985 strip of her comic Dykes to Watch Out For entitled "The Rule." In “The Rule," two women discuss the possibility of going out to see a movie, erstwhile walking past a movie theater whose hyper-masculine offerings include The Mercenary (spoofing 1982's First Blood), The Barbarian (spoofing 1982's Conan the Barbarian) and The Vigilante (spoofing 1971's Dirty Harry). Jadedly, one of the women 
explains that she only goes to see movies that meet three seemingly-simple criteria: "One, it has to have at least two woman in it who, Two, talk to each other about, Three, something besides a man" (Bechdel 1985, 1). Although ostensibly easy to meet, the woman reveals that the last movie that she saw which met all three criteria was Alien (1979) six years prior, and that was because the only two women in the movie had a conversation about the titular alien, whose biology is so utterly incompatible with humans so as to effective render it sexless. Others have even taken the alien's non-maleness a step further, into being actively, monstrously feminine (Creed 1993, Freeland 1996). The punchline to "The Rule," then, is the matter-of-fact observation that the only ostensibly women-centered films being made are few, far between and inherently monstrous.

This, in turn, speaks to the inherent shortcoming of the comic strip's titular rule, later and more popularly referred to as The Bechdel Test: it is not so much an indicator of any individual film's representational power or feminist ideations, but rather a macro-level indicator of systemic patterns of preferencing the male over the female in film. While it may be an indicator of “movies with an independent female presence" (Lindner et al. 2015, 408), it is better seen as a quantitative diagnostic of the industry as a whole rather than as a qualitative assessment of this or that film in particular. After all, many films which are lauded for their powerful, progressive depictions of femininity and female characters (e.g. 1928's The Passion of Joan of Arc and 1991's Terminator 2: Judgment Day) fail the test, while many films that have been decried for their retrograde portrayals of women ultimately pass it (e.g., 1978's Debbie Does Dallas and 1993's The Bikini Carwash Company). In fact, much of the "prevailing scholarship in this area has examined the extent to which women are portrayed on screen in scripted entertainment, in ways that are stereotypical, from oppressive gender roles to overt sexualization, in disparate 
entertainment storytelling types" (Chattoo 2018,374) and has generally concluded that "there has been improvement over recent decades" (Chattoo 2018, 374). This holds true both in terms of there now being an increased number of films which pass the Bechdel test as well as the fact that Sweden adopting the test as part of their film rating system (Lindner et al. 2015). Despite these advances, however, the dominant trend in terms of film production continues to be that "the balance of negative portrayals persists when it comes to representation of women in entertainment narrative" (Chattoo 2018, 374). So while some demonstrable gains offer a degree of encouragement about the direction that the film industry continues to move toward, it still holds true that films in general sideline female characters within their narratives and minimize their importance within their overwhelmingly male-dominant casts.

In recent years, about 50 percent of movies pass the Bechdel Test (Bechdeltest.com 2019). Those number can vary wildly depending on the methodologies used to select the given sample of movies: from a slim majority of 53 percent (Hickey 2014, $\uparrow 11$ ) to a chasmically low of 36 percent (Sharma and Sender 2014, $\uparrow 6$ ), the test reinforces the reality that "the majority of popular movies lack an independent female presence" of any kind (Lindner et al. 2015, 420). And "to the degree to which institutions of mass communication influence behavior and attitudes, consistent repetition of such themes can be expected to encourage the maintenance of women's subordinate position in society" (Tuchman 1978, 150). According to this line of reasoning, it can be understood that:

by consistently underrepresenting women in media industry roles, both on screen as characters and behind the scenes in decision-making creative positions, a dominant male ideology is reinforced $[\ldots]$ Such a pattern is cyclical, perpetuating long-standing patterns 
of inequity in media industries, as well as audience understanding of cultural voices and a lens worthy of consideration. (Chattoo 2018, 374)

While it is true that even when controlling for variables such as genre, critical appraisal, being released under an arthouse label, being a sequel, and including a popular star, "movies with an independent female presence," in other words, movies which pass the Bechdel test, "tend to have smaller production budgets and consequently earn less money" (Lindner et al. 2015, 422), thus reinforcing popular perceptions about female-centered films being less profitable than malecentered ones because the "“conventional wisdom' is that girls will watch movies with male or female leads, but boys won't watch movies with female leads" (Myers 2009, $\mid$ |8). This, however, tells only a partial truth, because "given two otherwise equivalent movies with the same budget, audiences do not appear to penalize those with a female presence" (Lindner et al. 2015, 423). Therefore, "the best predictors of box office performance were upstream effects-decisions made by key film industry gatekeepers about which projects to greenlight and how big of a production budget to grant—rather than downstream effects like consumer perception" (Lindner et al. 2015, 410). In other words, a film's initial popularity (measured by its box office earnings upon release to the public) can be more readily attributed to the promotional efforts of generally male film producers and promoters than by the presence or absence of an independent female presence within the film itself.

While the performance of this or that movie at the box office - or, by extension, with critics or with industry award bodies - seems like an idle occupation with the bottom lines of corporations and the exorbitantly wealthy filmmakers they employ, there are deeper and more far-reaching consequences that stem from the rewards (or punishments) given in this milieu. It has long been observed that "representation ... signifies social existence; absence means 
symbolic annihilation" (Gerbner and Gross 1976, 182), meaning that the types of characters, narratives and storytellers who are privileged and platformed in society are empowered by it: given cultural weight and canonized into the 'wide and certain' ranks of mainstream society. Or, as another critical observer noted:

viral media coverage, diversity inclusion and representation matters because when we praise and reward certain stories or images, whether by big box office or gold statuary, we reveal what we as a society value, the kinds of people we find interesting, the characteristics we revere and revile. We show the paths we hope to choose or avoid and the lessons we have learned, or not learned, from history. (McNamara 2016, 99 ) Representation matters, in other words, because it promotes a world view: both the filmmaker's in particular and society's more broadly. It varyingly values and devalues entire castes of people and shapes how those groups are perceived in general.

Even queer cinema skews towards valuing (implicitly white, albeit gay) men, as the male-domination of the film industry carries strong implications for lesbian and trans cinema as well. When asked in a 2012 interview why the New Queer Cinema - a film movement that began in the early 1990s and which eventually lead to the creation of films such as Brokeback Mountain (2005), Milk (2008), The Kids Are All Right (2010) and Blue Is the Warmest Color (2013) in recent years - is dominated by male filmmakers, B. Ruby Rich explained that it was because:

gay men are still men, whereas lesbians are still women. The run up to the Oscars [in 2012] resulted for some reason in the 'discovery' of how few women have been nominated for the award and how low the numbers of women in the industry [are] - even [in] the independent world. Lesbians though are in even worse positions than 
heterosexual women in the film biz, since they aren't seen as available bedmates $[\ldots]$ and since the craft guilds are still so gender-bound. Editing is the great exception because it's close work in dark rooms dedicated to helping the guy look good - a fit job for a woman. (Petro 2017, 17)

This final point in particularly recalls legendary film editor and longtime Martin Scorsese collaborator Thelma Schoonmaker's famous remark when she was asked how it was possible that such a nice lady like her could edit all of Scorsese's violent gangster film; in response, she said "ah, but they aren't violent until I've edited them" (The People Pill 2020, $₫ 15$ ). Whether it is Thelma Schoonmaker to Martin Scorsese or Sally Menke to Quentin Tarantino or Polly Platt to Peter Bogdanovich, women filmmakers have always been shunted from the limelight and made to work in service to their male colleagues' artistic visions at the expense of their own.

The marginalization of women in the film industry is nothing new and has not substantively improved in the last decade. When announcing the Academy Awards' 2020 Best Director lineup, for instance, announcer Issa Rae quipped "congratulations to those men" before looking, stone-faced, directly into the camera, not-so-subtly referring to the men-only lineup of director nominees despite the lauded work of directors Greta Gerwig (for Best Picture nominee Little Women), Lulu Wang (for The Farewell), Lorene Scafaria (for Hustlers), Céline Sciamma (for Portrait of a Lady on Fire) and Mati Diop (for Atlantics), all of whom made headlines for their willful exclusion in the category in the following weeks. When an unnamed male member of the Academy's producer's branch explained why he was voting the way that he was for the Oscars this year, he first addressed a performance that was not even nominated, Jennifer Lopez in Hustlers (2019) - a film that, like recent Best Picture nominee (and Best Adapted Screenplay winner) The Big Short (2015), detailed the economic fallout of the 2007 Subprime Mortgage 
Crisis, only this time from the perspective of female sex workers of color rather than that of white male financiers - bluntly exclaiming "Fuck J.Lo. I'm allergic to that movie. It isn't a movie about 'empowering' women; it's a movie about slipping asshole men roofies and fucking jacking them. Roger Corman made better stripper films" (Feinberg 2020, \13). Even more damning, however, is the graphic manner in which this same Academy voter expressed why he voted for actress Margot Robbie - who portrayed a compliant victim of Fox News mogul Roger Ailes's sexual predations in the film Bombshell (2019) - for the same category instead, stating "sure I have a crush on her, but she is also so accessible as an actress" (Feinberg 2020, $\llbracket 13$ ). This, in turn, speaks to systemic patterns of racism and sexism that are rampant in the film industry and elsewhere: one that privileges the work (and cinematic depictions) of sexually compliant white women while simultaneously excoriating sexually unavailable (or sexually dominant) women of color.

This gendered reality of cinema, like the concept of gender itself, "is so much the routine ground of everyday activities that questioning its taken-for-granted assumptions and presuppositions is like thinking about whether the sun will come up" (Lorber 1994, 1). This not only includes the presence or absence of independent female characters, but the very language being used to convey meaning in films These audio-visual cues are, by and large, uncritically taken as a given of the medium - the fade-ins and zoom-outs, match-cuts and parallel edits, the subtle lingering on an attractive female face and the leering close-ups on an exposed female form - with little attention to how gender "is constantly created and re-created out of human interaction [behind the camera and] out of [the permeating realities of] social life" off-set (Lorber 1994, 1). How gender performative acts manifest in moviemaking is, however, crucial to understanding the ways in which film both reflects and reinforces the lived social realities of 
gendered persons in society. The effect of the peculiarities of film and filmic language on society is that, like education, it reproduces the cumulative advantages and disadvantages that already exist in the broader society (Bourdieu 1984). Gender habitus, like social-class "taste," can be seen, at least in part, as "a product of [the] upbringing and education" (Bourdieu 1984, 1) that a lifetime of viewing film and media texts (e.g., dialogue within a play text) inculcates in audiences.

Male-defined notions of women's roles in film, or femininity defined from a male vantage point or gaze, extrapolates to woman's history and the specific symbolism of women as witches, even in modern-day cinematic representations, being controlled, documented, and visualized by men. It is particularly important to understand that all "documentation of witchhunts comes from the persecutors, not the accused. Indeed, there are no primary sources penned by women (let al.one women accused of witchcraft)" (Wilson 2020, 134). As a consequence, witch and witch-hunting narratives told by women and utilizing a woman's uniquely informative perspective have been denied to audiences historically, and continue even into the present day, where the majority of witch narratives (particularly cinematic ones) are penned and directed by men. Indeed, it has been noted by journeyman filmmaker Anna Biller, whose film The Love Witch (2016) came out of the same moment in time as the witch films of Lars von Trier, Robert Eggers and André Øvredal, not only that "very few films are feminist" (Biller 2018, $\uparrow 1$ ), but that earlier "women's films" of the 1930s were free from "a certain type of violence and aggression towards women that we are so familiar with today," which she identifies as resulting from "the backlash against the second wave feminist movement and the lifting of censorship codes, both of which happened at precisely the same time in the 1960s" (Biller 2018, q2). Despite the sympathetic (even, arguably, outright feminist) treatment of the figure of the witch in these 
recent films, all three films that are of primary interest to this thesis - Antichrist (2009), The Witch (2015) and The Autopsy of Jane Doe (2016) - are exclusively written and directed by men; in addition, two of them track the exploits of male protagonists who are, in varying ways, being tormented by female antagonists This is, of course, reflective of the problematic gender imbalance in the film industry more widely. According to 50/50 by 2020, an intersectional initiative put forward by the Times Up movement (itself an offshoot of \#MeToo) that seeks to achieve gender parity in all aspects of film and television production, upwards of 96 percent of film directors and 76 percent of film and television writers are male (5050 by 2020). Of the other high-profile witch films that Antichrist, The Witch and The Autopsy of Jane Doe generally represent, only one - Anna Biller's The Love Witch (2016) - can be said to be the product of a female filmmaker.

Understanding that "the specifically cinematic formal language of film must [...] be examined for [its] 'invisible' ideological effects” (Hole et al. 2017, 2), Laura Mulvey proposed her theory of the male gaze, which has since become foundational to the understanding of how films frame their subjects and guide their viewers through their narratives. Mulvey asserts that the language of cinema was developed by men, with men as their implicit subject matter and men as their presumed audience and, consequently that film language itself is inherently phallocentric. Film, in both conception and execution, is therefore inextricably structured by and entwined with "the unconscious of patriarchal society" (Mulvey 1975, 711). In other words, film becomes an avenue in which audiences take viewing pleasure in patriarchal ideology.

Men are the active subjects of a film's narrative action; they are subsequently depicted via the tenets of basic film language (e.g., the staging of a scene, the placement of the camera, the editing together of individual shots and the costumes that they are placed in) as powerful, 
capable and actualized within the world of the film. They make decisions, they take meaningful actions and they are granted agency within the narrative.

Women, however, are men's mirrored opposite. They are passive where the male is active, dependent where he is powerful and placed as if by chance where her foil moves where he pleases. And just as the male is the subject of the film, she is forever marked as spectacle - as window dressing - no different from any other special effect used to draw in a matinee crowd. In so doing, this gaze "reflects, reveals and even plays on the straight, socially established interpretation of sexual difference which controls images, erotic ways of looking and spectacle" (Mulvey 1975, 711). Mulvey's theory describes gender-binary relations of looking and appearing in front of the camera and audiences.

This binary of sexualized social functionality, however, is not an equitable one. The camera, and thus both film language and film as an artistic medium, preference the male perspective and depictions of maleness. Men have been and continue to be the functional default within film. Between 2007 and 2016, for instance, only 30.5 percent of all speaking characters less than a third of everybody given voice on the screen - were women and, on average, male actors outnumber female actors by a ratio of 2.3:1 (New York Film Academy 2018). In addition, nearly five times as many women wore revealing clothing compared to men and nearly three times as many women were shown partially naked compared to men, belying a disturbing continuity as regards sexual titillation and objectification throughout film history (New York Film Academy 2018).

Thus, "to be male is not to be 'sexed'; to be 'sexed' is always a way of becoming particular and relative, and males within this system participate in the form of the universal person" (Butler 1990, 113). By extension, women are portrayed as aberrant at best, and deviant 
at worst. They are othered as a consequence of the supposedly "natural" (that is, male-centric) laws of the films in which they are placed.

It holds true even in the specific context of the horror film, where "female figures and/or gender issues loom especially large" (Clover 1992, 5), that the default category of person is male. As in other genres, "the majority of the $[\ldots]$ protagonists are still male, rendering them the 'structuring norm' of the genre" (Amadou 2011, 94). Logically extended, it is clear that "heterosexual masculinity [is] a structuring norm in relation to [...] images of women [and] it has to that extent been profoundly problematized" (Neale 1993, 9). Thus "masculinity becomes the structuring norm of other genders, as it is the universal that defines difference" (Amadou 2011, 97). Mulvey's theory describes gender-binary relations of looking and appearing in front of the camera and audiences

Laura Mulvey's view of the male gaze insists that the camera through which we view the world of the film - that voyeuristic window which grants us invisible access to the intimate, presumed-private lives of others - is, in conception and design, sexualized as male. Acting in the manner of visually recording women as spectacle, sociologist Norman Denzin (1995) equates the male gaze to the Peeping Tom in the cinemization of everyday life; the Peeping Tom leers at women in the exact same fashion as the men who filmed them and the presumed male audience who paid to witness their spectacle. Given, as sociologist Émile Durkheim teaches us, that the most important aspects of a culture are symbolically reproduced and ritualistically enacted within it, so too does Mulvey credit that, "in a world ordered by sexual imbalance," does:

the determining male gaze project its phantasy on to the female figure which is styled accordingly. In their traditional exhibitionist role women are simultaneously looked at and displayed, with their appearance coded for strong visual and erotic impact so that 
they can be said to connote to-be-looked-at-ness. Woman displayed as sexual object is the leit-motif of erotic spectacle: from pin-ups to strip-tease, from Ziegfeld to Busby Berkeley, she holds the look, plays to and signifies male desire. (Mulvey 1975, 716) "What counts," Mulvey insists, "is what the heroine $[\ldots]$ represents. She is $[\ldots]$ the love or fear she inspires in the hero [...] who makes him act the way he does. In herself the woman has not the slightest importance" (Mulvey 1975, 717). Thus, in film, women are reduced to their symbolic functions, rather than existing for their own sake.

It is in this manner that literary theorist Roland Barthes fetishistically describes silent movie star Greta Garbo; or, rather, he describes the function of Greta Garbo's face on screen as a kind of philter that makes men fall ruinously in love with her image. During the height of her popularity, "capturing the human face [...] plunged audiences into the deepest ecstasy[:] one literally lost oneself in a human image as one would in a philtre" (Barthes 1957, 471). Rather than performing the ordinary functions of a face - such as conveying emotion, elucidating understanding, forming connective bonds with others - it "represented a kind of absolute state of the flesh, which could be neither reached nor renounced" (Barthes 1957, 471). The face of Garbo, then "partakes of the [...] rule of Courtly Love, where the flesh gives rise to mystical feelings of perdition" (Barthes 1957, 471). In other words, putting Garbo in front of a malecoded camera lens allows for a male viewer's gaze to reduce her entire being down to just a face and a sex object for the sole purpose of eliciting male pleasure.

For Barthes, Greta Garbo is not an actress; she is not a human being with a unique combination of hopes, desires and talents that connects her with the human condition. Neither is she what she pretends to be: that is, the characters that exist within her movies, each just as intimately and complexly drawn as herself. Rather, she is a thing to be gawked at: "an admirable 
face-object $[\ldots]$ not drawn but sculpted in something smooth and fragile, that is, at once perfect and ephemeral" (Barthes 1957, 472). Parallel to sociologist Max Weber's ideal types, Barthes describes her as the "Platonic Idea of the human creature $[\ldots]$ the essence of [a] corporeal person, descended from a heaven where all things are formed and perfected in the clearest light [...] not to be degraded [...] not to have any reality except that of its perfection" (Barthes 1957, 473). In this manner, Barthes joins Poe, de Palma, Hitchcock and Argento in viewing the women of the screen less as people and more as objects of pure titillation: unfeeling lust-objects upon which men can project their basest fantasies (whether it is his sexual desire or his sexual violence).

Similar to the ways in which Barthes can draw out the momentary glances of the face of Garbo - a functional object of sexual desire to be imposed upon as spectacle for male fetishism into an extolling treatise on an ideal type of human beauty, so too does the male gaze of the camera draw out the passive spectacle that it creates of women. Inherently, this "split between spectacle and narrative supports the man's role as the active one of forwarding the story, making things happen. The man controls the film phantasy and also emerges as the representative of power" (Mulvey 1975, 717). And, true to form, the woman, his opposite, once more acts as his perfect foil: stalling, rather than advancing, action - drawing out long moments so as to allow the male gazers (which here includes the male characters, the functionally male camera and the presumably male audience) to 'take it all in:' that is to say, to get a better look at her. Because, by this logic, that is all that she is worth.

In more traditionally sociological terms, the framing of women on screen is how film constructs, or does, gender (West and Zimmerman 1987). It is "a routine, methodical, and recurring accomplishment" (West and Zimmerman 1987, 126) that is perpetually negotiated, 
depicted and ultimately earned on screen, calcified in plain view of its audience. In as much as doing gender is "a complex of socially guided perceptual, interactional, and micropolitical activities that cast particular pursuits as expressions of masculine and feminine "natures"' (West and Zimmerman 1987, 126), Mulvey's understanding of the male-coded gaze of the camera in the male-coded medium of film functions identically.

For a film to do gender interactively, it must, as Mulvey asserts, "reflect $[\ldots]$ reveal $[\ldots]$ and even play $[\ldots]$ on the straight, socially established interpretation of sexual difference which controls images, erotic ways of looking and spectacle" (Mulvey 1975, 711). This gendered production is, after all, "a situated doing, carried out in the virtual or real presence of others," such as the film's audience, "who are presumed to be oriented to its production" (West and Zimmerman 1987, 126). That is to say, the masculine-oriented action, through the lens of the masculine-oriented camera, produces an expected, appropriately gendered presentation of its characters for pleasure of the masculine-oriented audience. Thus do audiences "organize their various and manifold activities to reflect or express gender, and they are disposed to perceive the behavior of others," such as the characters presented in the film, "in a similar light" (West and Zimmerman 1987, 127). Movies cater to the gender mindset of viewers living in a patriarchal society; they $r$ aspire to redefine the audience's point of reference, meaning gender ideologies are not constituted by the film alone, but result from an interaction between film and viewer.

Just as West and Zimmerman assert that doing gender is "unavoidable because of the social consequences of sex-category membership" (West and Zimmerman 1987, 145) so too does Mulvey contend that "the built-in patterns of pleasure and identification impose masculinity as the "point of view"' (Mulvey 1981, 12) of any given film and inherently precludes the possibility of its opposite: of a so-called female gaze. She contends that, owing to the fact that 
the language of cinema was developed with the intentionality of masculinity - that is to say, by men and for the expressed pleasure and consumption of other men - it is inherently baked into the narrative DNA of film to be thusly a masculine-coded artform. Accordingly, from the traditionally Mulveynian perspective, the consequences of reversing the gendered scripts that have informed the last 125 years of cinema - including "the allocation of power and resources" (West and Zimmerman 1987, 145) within the film industry and via the channels of traditional theatrical distribution - are simply too dire to ever succeed. From this view, even films with few (or even no) male characters, or films with only peripherally important male characters to adopt the active narrative role by "forwarding the story, making things happen [and] control[ing] the film phantasy" (Mulvey 1975, 717) in contrast with the films' female characters, nevertheless fall under the purview of the male gaze, as they still employ the same filmic techniques in their construction, still operate in the same channels of distribution and exhibition and still exist in dialog with the expressly male-coded moviegoers. And given that "the meanings derived from the [film] are constantly negotiated by audiences, created within a context, or additional milieu, of the viewer and the viewed" (Willis 2008, 244), the male gaze remains the dominant lens by which the text of the film is necessarily understood. Indeed, it reasons that: on-screen representation of gender stereotypes and other negative patterns are not ad hoc but rather are created systemically as a consequence of power in media content production; thus, if more women are in decision-making roles in the creation and production of mass media content, then portrayals will change. (Chattoo 2018, 374) For decades, gender negotiations in film have been decidedly dominated by men both in front of and behind the camera. Their central positions both in front of and behind the camera allow them to construct and contextualize gender in whatever way they deem fit, which has historically been 
accomplished by sedating, sexualizing and sidelining female characters and centering male characters as the active and driving forces of film narrative.

Despite the theoretical dominance of the concept of the male gaze in the film industry, many have challenged the strict, traditionalist understanding of the gaze as both inherently and inviably male (to say nothing of being both white and heteronormative as well). Director Pedro Almodóvar, for instance, has been telling stories through a queer and frequently female lens since the early 1980s, telling stories fronted by women (e.g., The Flower of My Secret, 1995) and gay characters (e.g., Pain and Glory, 2019), lesbian characters (Pepi, Luci, Born, 1990) or transgender characters (e.g., All About My Mother, 1999) or in which the male characters are either absent (e.g., Women on the Verge of a Nervous Breakdown, 1988), dead (e.g., Volver, 2006) or have adopted atypical gender roles (e.g., Talk to Her, 2002). With Juno (2007), director Jason Reitman and writer Diablo Cody depict a fully modern conception of young female sexuality. In the film, the title character exhibits "agentive presence [...] in her resolve about what she wants" (Willis 2008, 243) and achieves sexually; this is depicted via an early sex scene in which "the audience observes $[\ldots]$ the boy $[\ldots]$ through the perspective of the [eyes of a girl]" who is "symbolically exhibiting control of the situation, the physical positioning of her body indicat[ing] an assertive stance" (Willis 2008, 246). Compared to Juno's male sex partner, who is depicted as both passive and pliant in ways that bely the typical Mulveyian framing of his gender, Juno is framed as a figure of active sexual agency. Director Steven Soderbergh's Magic Mike (2012) unflinchingly follows the exhibitionist work and interior lives of a group of attractive, muscular, male strippers, framing them in such an explicitly sexual manner so as to leave no question that the assumed audience for the film was decidedly not comprised of heterosexual males. By contrast, director Lorene Scafaria's Hustlers (2019) reveals the work and 
domestic lives of female strippers in such sensitive and nonexploitive terms as to target an explicitly female audience. And, of course, there are countless slasher films from the 1970s, 1980s and 1990s, whose heroines triumphantly "exercise [...] the 'active investigating gaze' normally reserved for males $[\ldots$ by] aggressively $[\ldots]$ look[ing $]$ for the killer $[\ldots]$ and then at him" (Clover 1992, 48). In fact, Norman K. Denzin notes that audiences do more than take mere "morbid pleasure in looking at the sordid, private activities of others" (Denzin 1995, 5). Rather, audiences typically adopt a broader "cinematic gaze, visual and auditory at the core, [which allows viewers to] instantiat[e] and defin[e] the medical, psychiatric, military, criminological, ethnographic, journalistic and scientific gazes that Foucault $[\ldots]$ locates at the center of today's disciplinary societies" (Denzin 1995, 15). Instead of only taking "morbid pleasure in looking at the sordid, private activities of others" moviegoers are afforded access to "the clinical gaze of medicine, psychoanalysis and science $[\ldots]$ the investigative gazes of the police state $[\ldots]$ the informational gaze of news reportage $[\ldots]$ the erotic, violent gaze of Peeping Toms $[\ldots$ and $]$ the inquisitive, assertive peering gaze of the tourist" (Denzin 1995, 5). Thus, despite its narrowlydrawn application by Mulvey herself, which is necessarily "straitjacketed [to] association[s] between males and the pleasures of looking or spectatorship" (Freeland 1996, 629), her work has contributed to the development of multiple, intentionally different theoretical 'gazes' in a vast variety of contexts which, among others, includes the postcolonial gaze (Said 1978), the oppositional gaze (Hooks 1992), the queer gaze (Gamman \& Evans 1995) and the imperial gaze (Kaplan 1997).

In the same context of classic Hollywood films that birthed the ideation of the male gaze comes an auditory understanding of the sublimation of the feminine in service to the masculine, as "the common practice of assigning leitmotifs or themes to different characters [in a movie 
resulted] in the differential treatment of female and male protagonists" (Vernon 2017, 49) throughout mid-twentieth century cinema. However, as with the cinematographic and editing cues of films during this same period that were explored by Laura Mulvey, writer Heather Laing recognized that "the film scoring style of the 1940s [ultimately] burdens female characters with a Romantic relationship to music that carries with it both psychological and physical implications" (Laing 2007, 10). Whereas the male protagonist would be afforded his own unique musical theme to positively identify him to the audience, the female protagonist's theme typically doubled as the "love theme" representative of the pair's union. It is precisely this asymmetrical treatment of gendered music and the doubling of the female-coded theme with the love theme that "suggests that [the female lead] has no existence beyond her relationship with her male partner" (Vernon 2017, 49), "establishe[es] a musical identity for [the male lead] that cannot be reduced in the same way" (Buhler 2014, 367) as the female lead's and reproduces the larger society's patriarchal point of view within the world of the film. Thus music can be seen as existing as a part of a longstanding artistic tradition in which it is established as:

the most highly gendered and specifically "feminine" of the different components of cinema sound. [...] harken[ing] back to the long-standing Western suspicions of music that conflate[d] its supposed[ly] abstract and non-referential nature and lack of fixed meanings with fears of (feminine) disorder, and emotional and sexual excess. (Vernon 2017, 48)

Issues abound with regard to film background music in relation to gender and sexuality wherein the cinematic use of silence, sound effects and musical scores have been repeatedly patterned to build a sonic landscape that is reflective of the stylized repetition of gender norms and categorizations. 
These early theories pertaining to the gendered qualities of cinematic sound "effectively assume[d] the subordinate role of sound, as manifest[ed] in the female voice" (Vernon 2017, 52) and emphasized its role as "a fetish within dominant cinema, filling in for and covering over what is unspeakable within male subjectivity" (Silverman 1988, 38). In this sense, sound, in all of its forms, can be seen as an "'acoustic mirror" to the male gaze" (Vernon 2017, 52). Further echoing Mulvey's assertion that there cannot be a feminine alternative to the male gaze, Kaja Silverman maintains that, even when using her own voice to assert her own point of view: women's words are shown to be even less her own than are her "looks." They are scripted for her, extracted from her by an external agency, or uttered by her in a trancelike state. Her voice also reveals a remarkable facility for self-disparagement and self-incrimination. [...] Even when she speaks without coercion, she is always spoken from the place of the sexual other. (Silverman 1988, 31)

Women, in other words, are always already speaking with voices which are not their own. Certainly, though, our theoretical understanding of sound has evolved just as our theoretical understanding of the male gaze has in the decades since these notions were first introduced. And just as modern-day directors such as Almodóvar, Reitman, Soderbergh and Scafaria are challenging the notion of a monolithic, unchanging and inherently male gaze, so too are modern-day mélomanes - that is to say "directors for whom music functions as an 'integral aspect' of directorial style" (Vernon 2017, 50) - challenging the notion of a monolithic, unchanging and inherently male soundscape (Gorbman 2007, 151). Directors as varied and farreaching as Pedro Almodóvar, Jean-Luc Godard, Aki Kaurismäki, Spike Lee, Sally Potter, Quentin Tarantino, Agnès Varda and Wim Wenders (Gorbman 2007, 150-151) are among those that have been infusing sonic personality and differentiated auditory characterizations into their 
films, in many cases as a direct response to the static musical treatments of studio-era American films.

Working out from this perspective, French composer and sound theorist Michel Chion identified that the historically devaluated stature and feminized associations of filmic sound, which are inherently devoid of the same levels of scrutiny afforded to the visual and implicitly masculine elements of film, are a rich "territory of freedom" (Vernon 2017, 47) within which filmmakers are free to experiment and subvert dominant aesthetics and ideologies. After all, "sound stands opposed to vision in an implicitly gendered hierarchy that associates rational knowledge and the mastery afforded by the distance between viewer and object of vision within the sense of sight," and, by that same measure, associates "sound within its elusive yet enveloping presentness with "the emotional and the intuitive"” (Vernon 2017, 47); in other words, sound, with all of its feminine associations, is allowed to be more abstract, more intuitive and more experimental than the assumed-to-be more concrete and documentarian machinations of the visual. Calling it "a fluid and musical domain rich in meanings and pleasures" (Vernon 2017, 47), Kathleen Vernon frees up earlier theories of cinematic sound that famed Russian director Sergei Eisenstein and his contemporaries called "a double edged invention [whose] application," both lamentably and predictably, largely followed "along the line of least resistance" (Eisenstein et al. 1928, 316): that is to say, most movies merely use sound for the conveyance of spoken dialog rather than artfully using it to further the deeper meaning-making of the medium.

Decades after Eisenstein's lament, however, cinematic sound had developed into a robust component of filmic analysis. Indeed, through the present day, academics have associated the aural with the feminine, with French psychoanalyst Guy Rosolato connecting it with the 
"sonorous envelope [...] of the mother's womb" (Vernon 2017, 48) and others, like feminist scholar Hélène Cixous, identifying it as the inherently feminine "expression of sexuality that exceeds the codes and classifications of rational thought" (Vernon 2017, 48). Some have even gone so far as to privilege music and sound as "an alternative to the image-centered theories of cinema narration dominated by the structuring male gaze" (Vernon 2017, 48): a literal inversion of male-coded filmic meaning-making that, like the witch herself. recalls "a 'hurlyburly' with its suggestion of misrule and topsyturveydom" (Clark 1980, 126). Claudia Gorbman asserted that music, generally, supplies "a necessary emotional, irrational, romantic, or intuitive dimension" (Gorbman 1987, 79) to the otherwise 'objective' facets of filmmaking, washing audiences in a sonorous "bath or gel of affect" that ultimately "renders the individual an untroublesome viewing subject: less critical, less 'awake"' (Gorbman 1987, 5). Many others, however, such as Mary Ann Doane and Caryl Flinn, explicitly warn of the dangers of essentializing the auditory elements of film and thus to consigning them "to a space beyond signification" (Vernon 2017, 48) and, consequently, beyond semiological analysis.

It should come as no surprise, then, in light of its gendered stature within filmmaking, that music has come to be associated with the idea of the monstrous-feminine. After all, "music's sensuous sounds were said to give it the capacity to 'penetrate the ear and 'ravish' the mind"' (Vernon 2017, 48), evoking classical notions of Greek Sirens, whose seductive singing drove men to their deaths while at sea. More recently, this traditional has been maintained by films centered on the witch: whether expressed via the coven-run dance academy in Suspiria (1977, 2019), the sea-witch Ursula's theft and weaponization of Ariel's voice in The Little Mermaid (1989), Winifred and Sarah Sanderson's songs - "I Put a Spell on You" and "Sarah's Theme" that are varyingly used to bewitch Salem's parents and to steal their children in Hocus Pocus 
(1993), the discordant track that the lords of Salem (in fact, a modern-day coven of witches) use to exact their vengeance on the descendants of their accusers in The Lords of Salem (2013) and the unnerving hymnal-esque "Open Up Your Heart (And Let the Sunshine In)" used to herald the protagonists' doom in The Autopsy of Jane Doe (2016). Thus, given their association with cinematic witchcraft - as both a sorcerous and sonorous means of enchanting a witch's victims and heralding her arrival and ascent - deliberative, malevolent or otherwise 'witchy' use of music in film indexically signifies the presence of witchcraft.

In an April 2015 interview, Laura Mulvey referred to her seminal essay 'Visual Pleasure and Narrative Cinema" as "a political intervention" rather than as an academic treatise: one that was "primarily influenced by the Women's Liberation Movement" (Amsterdam University Press) and was informed by an activistic reading of the works of psychoanalyst Sigmund Freud. Emerging from a unique historical moment in which "women [were] collectively speaking about and analyzing their experience[s] as it intersected or was in tension with [the] major intellectual currents of the time" (Hole 2017, 461), the essay acted as "a manifesto, a call to arms and part of a larger history of feminist polemics and manifestos" (Petro 2017, 15) that, according to Mandy Merck, stretches from "Mary Wollstonecraft's Vindication of the Rights of Women to Emma Goldman's 'The Tragedy of Women's Emancipation' to Shulamith Firestone's The Dialectic of Sex to Mary Daly's Gyn/Ecology" (Merck 2007, 7). These revolutionary sentiments were later echoed within the horror genre by Get Out (2017) writer-director Jordan Peele who, following the Hollywood Foreign Press Association's decision to nominate his film in the "Best Motion Picture: Musical or Comedy" category, argued that there was nothing funny about his film. Rather, he argued that "Get Out is a documentary" and that "the movie is an expression of my truth, my experience, [and] the experiences of a lot of black people, and minorities. Anyone who 
feels like the other” (Kohn 2017, \6). In much the same way, recent witch horror films have not terrified audiences so much by deviating from a presumably ideal status-quo, but by depicting the real and lived-in (or at least broadly representative of the real and lived-in) experiences of women to a knowing public that recognizes those experiences. In his review for Lars von Trier's Antichrist, even Pulitzer Prize-winning Chicago Sun Times film critic Roger Ebert could not help but compare the film to a documentary, charging that while "feature films may be fiction, $[\ldots]$ they are certainly documentaries showing actors in front of a camera" (Ebert 2009, $₫ 8$ ). Horror, then, emerges from the reproduction of societal norms rather than from their violation, in "challenging normative identities that continue to limit women in the present and to truncate the scope of how the politics; is defined" (Hole 2017, 461). In other words, the "horror" of it all lies in the normative forces that produce marginalization, and anti-oppressive horror films can help expose those minoritizing forces occurring within larger social contexts.

Famously speaking to the social construction of gender, French philosopher Simone de Beauvoir astutely observed that "one is not born, but rather becomes, a woman" (de Beauvoir 1949, 267). Three quarters of a century later, we understand that "so too are monsters made, [and] not born" (Wilson 2020, 181), with both femininity and monstrosity oftentimes being constructed simultaneously. According to Barbara Creed, "the monstrous is produced at the border of which separates those who take up their proper gender positions from those who do not" (Creed 1993, 11). Therefore, women "provide a proximal conduit for [the fearful] projections" (Wilson 2020,182) of the wider, deeply patriarchal society. In fact, "women are so regularly aligned with the monstrous $[\ldots]$ that they are often not depicted in exaggerated form in horror texts, their mere female bodies being enough to construe monstrosity" (Wilson 2020, 182). Witches especially require no such embellishments to convey monstrosity, as their power 
to shock and terrify has traditionally come as much from their supernatural powers as it has come from their otherwise inconspicuous presence within a community and the terror that naturally results from it.

First proposed by Creed in her seminal book of the same name, the monstrous-feminine builds upon Adrienne Rich's assessment that the female body "the terrain on which patriarchy is erected" (Rich 1976, 55) by presenting an ideal type of cinematic femininity that "is constructed as an abject figure because she threatens the symbolic order $[\ldots]$ draw $[i n g]$ attention to the 'frailty of the symbolic order' through her evocation of the natural, animal order and its terrifying associations with [...] death" (Creed 1993, 83). Hearkening back to a pre-medieval understanding of the body, where the processes surrounding conception and birth were unknown and "there was [the] suspicion that [for] the male species everything is on the exterior [...plainly] laid out [and] underst[oo]d [...] But when you're a woman, everything happens internally" and is therefore unknowable (Subissati and West 2014). Women, then, are horrific specifically because they are constructed in opposition to this presumed masculine default: inverted, yonic and possessed of an "enterable but unseeable inner space" (Clover 1992, 18).

Horror, in turn, is so impactful with moviegoers owing to how "the metaphoric architecture of [the female body itself...] has for so long been a fixture in the production of the uncanny" (Clover 1992, 18). This monstrous creature, then, instinctively driven to reproduce and utterly bent toward the destruction of the sacrosanct order, is "'horrific' in the sense of being allengulfing, primitive, and impure or defiled by bodily fluids" (Freeland 1996, 630). Perhaps unsurprisingly given the decidedly negative construction of femininity historically, "all human societies have a conception of the monstrous-feminine, of what it is about a woman that is terrifying, horrific, [and] abject" (Creed 1993, 1) that is shared "irrespective of language, 
geography and religion" (Santos 2017, xv). Going back to "the devouring sea-hydra and Charybdis, each said to consume passing ships, [and the] land-dwelling libidinous women reported to have a taste for male genitalia, female monsters [have been] characterized as a particular threat" (Wilson 2020, 8). Thus from Eve to Lilith, from the Gorgons to the Sirens and from Baba Yaga to Kuchisake-onna, stories told the world over have reaffirmed the inherently monstrous, bestial nature of womankind, whether represented by a fantastically mutilated spirit or a perfectly normal, "leaky, shape-shifting, bleeding and birthing female body" (Wilson 2020, 182).

For witches in particular, "the symbolic function of women's menstrual blood is of crucial importance" (Creed 1993, 77) as it, in connection to women's more visible function in reproduction, "[is their] one real power" (Subissati and West, 2014). In Carrie (1976), perhaps the horror genre's most iconic witch, blood is both the literal and symbolic root of her powers: the crimson wells from which her strength as a woman, and as a witch, spring. Varying contexts of blood symbolism as "dangerous" or "defiling" become embodied by the witch / Carrie as a practitioner or transmitter of "blood magic" or by persecutors of her shameful onset of menarche, e.g., "menstrual blood, pig's blood, birth blood, the blood of $\sin$ and the blood of death [... and $]$ also the blood which flows between mother and daughter and joins them together in their lifeand-death struggle" (Creed 1993, 77), each usage conveying its own symbolic meaning. All of these different associations with blood, however, ultimately seek to convey and reinforce her status as a "monstrous figure with supernatural powers and a desire for evil" (Creed 1993, 76). By tapping into the wider social understanding of "the debased meaning of woman's / pig's blood in order to horrify modern audiences $[\ldots$ the film] perpetuates negative views about women and menstruation [which] is also central to the film's discourse on the abject" (Creed 
1993, 80) that "helps to construct Carrie as monstrous" (Creed 1993, 81). This tradition of blood symbolism in the horror genre, and particularly in witch films, continues to the present day, evidenced in films like The Love Witch (2016), Revenge (2017), Suspiria (2018) and Midsommar (2019).

It has long been the case that menstrual blood and other feminine fluids have been the subject of abjection - which Julia Kristeva explains is the subjective, corporeal horror that "is immoral, sinister, scheming, and shady: a terror that dissembles, a hatred that smiles, a passion that uses the body for barter instead of inflaming it, a debtor who sells you up, a friend who stabs you" (Kristeva 1982,4) - throughout the religious world. These kinds of "pollution beliefs [are often] used in dialog of claims and counter-claims to status" (Douglas 1966, 3). These claims include the commonly held belief in non-industrial cultures (as well as in conservative sexual education programs) that "each sex is a danger to the other through contact with sexual fluids," that this usually engenders danger to "males [from] females [and that] such patterns of sexual danger can be $[\ldots]$ interpreted as symbols of the relation between parts of society, as mirroring designs of hierarchy and symmetry which apply in the larger social system" (Douglas 1966, 4). After all, gender "has long served as a basis to identify others as monstrous. [...] Repeatedly associated with excessive, dangerous consumption (particularly of the cannibalistic variety) as well as perverse sexuality (particularly of the emasculating or castrator variety), such associations buttress the 'necessity' of patriarchal rule" (Wilson 2020, 7). Such prejudicial associations with abject fluids (vital, sexual or otherwise) serve to stigmatize the "dirty" female body and idealize the "clean" male body in the wider culture.

Similar to how "all bodies are materialized through discourse" - that is to say, in the way that bodies are socially constructed - "constructions of the monstrous rely on naming certain 
bodily forms deviant, deformed, and/or freakish" (Wilson 2020, 10). This is in keeping with Aristotle's proclamation that "the birth of females [is] the most common deformity" (Wilson 2020, 10), in fifteenth century witch inquisitor Heinrich Kramer's assertion that "Women are by nature instruments of Satan - they are by nature carnal and a structural defect rooted in the original creation" (Miles 2008, 80) and in horror-suspense film director Brian De Palma's suggestion "that female frailty is a predicate of the suspense genre [and that ...] the lack of a phallus, for Lacan the privileged signifier of the symbolic order, is itself horrifying" (Clover 1992, 50). Women, and particularly witches, have commonly been constructed in such terms. Even historically, "the monsterization of women [was] 'a prerequisite to the conquest and colonization,' [with] Christopher Columbus and Amerigo Vespucci's reports of cannibal warrior women [resulting in an] allegory of the New World as a monstrous female" (Clover 1992, 7-8): an image that would persist through the Salem witch trials, three waves of feminist activism, and into the current \#MeToo moment.

Perfectly coalescing into the figure of the witch, women have been "aligned with the irrational, the grotesque, the abject, the polluting, the natural world, and the body (rather than the soul), [and] linkages between the female and the monstrous have imbued the patriarchal imaginary throughout recorded history" (Wilson 2020, 182). Spanning not just cinema, but also "mythology, folklore, and religion from around the globe, the woman as monster is called upon to explain original sin, blamed for disease and species mutations, accused of corrupting man, birthing degenerates, and unleashing evil upon the world" (Wilson 2020, 182). So framed, witches, who represent both "female independence and sexual independence [are constructed as] frightening because [they liberate] us from oppressive structures and [the need] to rely on a patriarchal system to grant us power" (Sollèe 2017, 56). Although a witch's mere presence is 
enough to instill panic into normative members of society, the fact that these women are also believed to possess any number of deviant physical features to complement their deviant ideologies - signs that additionally serve as "paradigmatic element[s] in the oppression of $[\ldots]$ women" more broadly (Shildrick 2002, 1) - is particularly upsetting. Such anatomical alterations can include the presence of supernumerary nipples and devil's marks, a shrunken and haggard appearance and the Wicked Witch's unmistakable emerald complexion.

Since the medium's creation in 1895 , film has proven to be "both a perfect and a bizarre vanguard in [the] war for culture change. Perfect because its reach is so vast, its influence so potent; bizarre because [it is] how a great many toxic ideas embed themselves inside us in the first place" (West 2019, 72). Whereas traditional models of thinking have posited that to "consum $[\mathrm{e}]$ horror $[\ldots]$ is to revel in male power and female victimhood, to find pleasure in female death, to perpetuate ideas of the feminine as monstrous, dangerous, inferior, and ultimately other" (Wilson 2020, 2), it is more to the point that "the genre regularly features women who endeavor to break free of patriarchy's stranglehold, to destroy white supremacist sentiment, [and] to claim sexual agency" (Wilson 2020, 2-3). In fact, the oftentimes tumultuous status of the witch within popular culture sometimes results in texts "[holding] her up as a feminist hero, while others [play] upon her classic monstrosity" (Sollèe 2017, 113). Indeed, what hangs in the balance between the witch presented as a monstrous victim and the witch transformed into a feminist hero will take scholars a long time to process, and some will continue their film critiques unfazed by the winds of change brewing beneath the surface of contemporary horror.

Even today, decades after this generally progressive trend in the genre was first observed, many feminist scholars and activistic onlookers persist in "underestimat[ing] the horror genre's] 
subversive potential" (Pinedo 1997, 71), to languish in the "many examples of the genre [that] eroticize violence, solidify the woman-as-evil-monster equation, and sideline women (both in front of and behind the camera)" (Wilson 2020,2) and to insist "that horror's satisfactions begin and end with sadism" (Clover 1992, 19). Playing into classic conceptions of femininity in the horror genre, they insist that "the horror film [...] expresses female desire only to show how monstrous it is" (Clover 1992, 47). However, "what filmmakers seem to know better than film critics is that gender is less a wall than a permeable membrane" (Clover 1992,46) that allows audience members to identify with characters, whether monstrous, heroic or something inbetween - of any gender. Therefore, while many horror films do often present women as inherently monstrous - even in films, like Carrie, that are centered around their interior lives and lived experiences - they just as often frame "females and femininity as not only monstrous, but also powerful, as able to kill the patriarchal beast" (Wilson 2020, 2). In fact, horror was once said to be "the most important of all American [film] genres and perhaps even the most progressive, even in its overt nihilism" (Wood 1978, 28) precisely because horror films "often present unpopular - even radical - views addressing the social, political, racial, or sexual inequalities, hypocrisy in religion or government" (Vale and Juno 1986, 5). Despite, horror films' frequently shocking, controversial or otherwise extreme content, they are uniquely positioned to challenge the status quo and bring forward radical ideological change in filmgoers.

By the start of the current century, it became clear that "not only could cinema articulate the desire for a better world, its complex ways of interpreting and representing [the world] could also produce critique and new ways of seeing" (Mulvey 2004, 1287), revealing significant "overlaps between the feminine and the monstrous [that] can be highly productive" (Shildrick $2002,29)$ to feminist causes precisely because "the cinema doubled as a major means of 
women's oppression through image and as a means of liberation through transformation and reinvention of its forms and conventions" (Mulvey 2004, 1287). Monster narratives, like those presently being told of the witch, "regularly redeem creatures that have historically been constructed as diabolical, horrific, and/or irredeemably other" (Wilson 2020, 9). In fact, "a substantial body of theory celebrate[s] the 'promises of monsters' [...] in various ways, [which includes authors such as] Margrit Shildrick, Sara Ahmed, Jeffrey Jerome Cohen, Rosi Braidotti, Donna Haraway, and Simon Bacon" (Wilson 2020, 9). And just as recent witch films offer a wide range of political and gendered perspectives that can either hinder or hinder feminist causes, so too are their monstrous protagonists "just as capable of shoring up inequitable systems of power as they are at destabilizing them" (Wilson 2020, 11).

Not only do horror films, particularly those "from the post-millennial period[,] present females as fully human, heroic, powerful, wise, and complicated as their male counterparts - and as flawed" (Wilson 2020,184), but also audiences are invited to actively oppose patriarchal, oppressive male "monsters" villainized as witch hunters and tormentors. More so than those of other genres, these movies offer a rare cultural space that trains its viewers to empathize with the (usually female) victims, to believe their stories and to rally to their defense against their (usually male) tormentors. Consequently, scholars have noted how "the monstrous feminine serves as a powerfully political metaphor for our time" (Wilson 2020,181) and that, particularly within the context of the horror genre, political "resistance is often fomented using the tools of the marginalized - the tools of those deemed to be monstrous" (Wilson 2020, 243). Whereas earlier and less charitable readings of the monstrous feminine emphasized its perceived misogynistic overtones, recent reappraisals of the construct understand that it can also serve are an empowering force within the horror genre. 
This reappraisal of the monstrous feminine falls in line with what some observers have noted as a "rebirth of various tropes that had lain nearly dormant for decades, including zombies and vampires" (Hayt 2017, 131) being reimagined as explicitly social, cultural and political critiques of the immediately post-9/11 world. Others have noted however, that for this very reason "the witch as a figure is arguably harder to reclaim than either the zombie or the vampire for the precise reason [that] witches are primarily coded female" (Wilson 2020, 14), and thus coded as being essentially, rather than incidentally, monstrous. And while filmmakers have attempted to reframe "the kidnapping of babies, killing of innocents, and the hexing of the living [as being the result of] the oppressive contexts in which these witches reside rather than in any natural wickedness" (Wilson 2020, 14), witches have been met with mixed success across the multiple mediums in which they have been presented. Still, just as "both [zombies and vampires] have been co-opted away from horror and turned into teen melodrama in various ways" (Hayt 2017,131 ), so too have witches been successfully brought into that fold with popular narratives such as The Chilling Adventures of Sabrina (2018) and Charmed (2018).

The witches of film, however, present themselves within a much murkier and much more morally complicated paradigm than those presented in other media. Witches of television, such as on the aforementioned The Chilling Adventures of Sabrina and Charmed, frequently frame witchcraft itself as "a patriarchy-busting practice [wrapped in] light, comedic tones and [with] scripts featuring knowing winks to popular culture" (Wilson 2020, 142-143). Witches of literature, such as in Louisa Morgan's A Secret History of Witches and Beth Underdown's The Witchfinder's Sister, "shine incisive light on the periods in which the witch-hunts occurred both in Europe and the United States," varyingly framing the accused as "a positive figure not deserving of persecution [and] those who hunt the witch, whether figuratively or literally, [...] as 
villains" (Wilson 2020,134-135). But witches of film are not depicted in such black-and-white terms. These are deeply wronged women that bear their fresh wounds and psychic scars inside of them, where they can fester, unseen, for a lifetime. These are women who embrace, fully, the historic and cultural legacy of the witch: from its earliest propaganda to its most commercial iconography. Retributive to the core, these witches raze towns, incite violence, abduct infants, destroy families, slaughter innocents, possess the righteous, drive men insane, consort with demons and sign the devil's black book. In Antichrist (2009), the woman protagonist accidentally disfigures her son, attributes his death to her motherly negligence and mutilates her husband; in The Witch (2015), Thomasin kills her mother, conscripts with the devil and joins a coven celebrating a witch's sabbath; in The Autopsy of Jane Doe (2016), the titular Jane Doe torments, tortures and gruesomely kills a pair of innocent men performing her autopsy. Rather than repudiating the notion of witchcraft as villainy, they operate from the logic of 'in for a penny, in for a pound' (or, alternatively, 'they can only burn me once') and 'mak[e] a case for executing witches in ways reminiscent of Malleus Maleficarum" (Wilson 2020, 164.). With a malevolent smirk, they seem to say "sure, if you insist, it's a witch hunt. I'm a witch, and I'm hunting you" (West 2017, $₫ 6$ ). The films that these characters inhabit are not constructed for "safe" consumption, they are made to burn the unjust world down around them.

\section{The Sociological Literature of Gender and Witch Politics in the Post 9/11 and \#MeToo Era}

Gender has long been one of the essential control mechanisms of the patriarchy and has been weaponized against gender non-conforming persons throughout history. In the post-9/11 and \#MeToo era especially, the various ways that gender manifests itself - including via film have been used as a means of victimizing and withholding power from women by those in 
positions of authority. This, in turn, speaks to Andrew Tudor's position that "fictions are understood and experienced in variable cultural settings, read by different audiences in different ways and can only be explored for their social significance by seeking to understand them in those contexts" (Tudor 1989, 211). In fact, engaging films in this manner necessarily contributes to a "sociological knowledge of film [that] would surely [include] a body of 'true' statements about the role of the institution [of film] in society, its effects, the organizational context within which it operates, the nature, attitudes, and preferences of its audience, and the interrelations between these and endless other factors" (Tudor 1974, 15). Or, as Joseph Nye, who pioneered the theory of soft power in the 1990s, argues, "in an Information Age in which credibility is the scarcest resource, the best propaganda is not propaganda" because "there is little $[\ldots]$ audience for brittle propaganda (Nye 2012, $\uparrow 7-8$ ) and "the absence of propagandistic intent [in cultural artifacts make them] more compelling and authentic" to the viewer (Kaylan 2019, $₫ 6$ ). In other words, the ways in which audiences engage with and understand specific texts depends on the specific contexts in which they are produced, exhibited and received and that the most potent texts are those which organically either challenge or reinforce the social (and, in this case, gendered) norms of society.

Gender is the most consequential way in which our society is structured and "is so much the routine ground of everyday activities that questioning its taken-for-granted assumptions and presuppositions is like thinking about whether the sun will come up" (Lorber 1994, 1). It is "a routine, methodical, and recurring accomplishment" (West and Zimmerman 1987, 126) that is "constantly created and re-created out of human interaction, out of social life, and is the texture and order of that social life" (Lorber 1994, 1). Consequently, gender as "a complex of socially guided perceptual, interactional, and micropolitical activities that cast particular pursuits as 
expressions of masculine and feminine "natures"” (West and Zimmerman 1987, 126) means that individuals "organize their various and manifold activities to reflect or express gender and they are disposed to perceive the behavior of others in a similar light" (West and Zimmerman 1987, 127). Gender crucially impacts people's livelihoods and life chances, such as access to education, healthcare and economic and social well-being. Because "gender, like culture is a human production that depends on everyone constantly 'doing gender"” (Lorber 1994, 1), and because doing gender is "unavoidable because of the social consequences of sex-category membership" (West and Zimmerman 1987, 145), it is constantly and insidiously reinforced at every level of society, and those who violate its expected norms are summarily punished for their deviations via "the allocation of power and resources not only in the domestic, economic, and political domains but also in the broad arena of interpersonal relations" (West and Zimmerman 1987, 145). Sociologically speaking, gender functions as a controlling category.

Particularly during times of great societal change, "female subjects that challenge the obedience, passivity, and purity expected of them are [...] cast as monsters in the popular imaginary" (Wilson 2020, 183). And the twenty-first century is, if nothing else, a tumultuous moment of societal change wherein the nexus between monstrosity and the representation of "female subjects" continues. Opening with the devastating September 11 terrorist attacks, which triggered an ongoing series of regional conflict in the Middle East and, in the United States, the post-9/11 political fallout ushered in an era defined by "corporate capitalism, neoliberalism, and techno-globalism[, in which] women [are] once again being hunted as witches" (Wilson 2020, 183) and "framed as the locus of both disease, and of impending social disaster" (Jones 2011, 40) for failing to adhere to the idealistic standards of "return[ing] to the home, pleas[ing] their partners, eschew[ing] birth control, avoid[ing] getting raped" - because, after all, rape is 
invariably framed as the woman's fault for inspiring - "[and] rais[ing] good consumer children [...] all while making sure to keep their bodies tight, trim, and beautiful" (Wilson 2020, 183) for the flesh-and-blood male gaze. These gender stereotypes and mixed messages reinforced in the post-9/11 discourse, in turn, were met with \#MeToo movement insistence that sexual and gender-based violence marks the everyday lives of women - especially Black women and girls and young women of color from low-wealth communities, some of whom are queer, trans, and/or disabled - further buttressed by revelations of sexual improprieties of multiple highprofile producers, executives and entertainers in the entertainment industry (e.g. Harvey Weinstein, Roger Ailes, Woody Allen, Louis C. K., Bill Cosby, Kevin Spacey), government officials (e.g. Donald Trump, Brett Kavanagh) and clergymen (e.g., John Geoghan, John Hanlon, Paul Shanley, Robert V. Gale, James Talbot).

Just as "the early modern witch hunts served in part to discipline and punish female bodies" (Sollèe 2017, 43), so too have these sexually insidious and deeply gendered conflicts increased in frequency, intensity and consequence as embattled (or implicitly threatened) men in power sought to enact patriarchal vengeance on women over the last decade in particular and graphic examples of these backlashes abound in recent history. In 2012, for instance, after Georgetown University student Sandra Fluke testified in a congressional meeting on birth control in favor of contraception access, conservative talk radio host Rush Limbaugh lasciviously announced on his show that "if we are going to pay for your contraceptives, and thus pay for you to have sex, we want something for it, and I'll tell you what it is [...] We want you to post the videos online so we can all watch" (Sollèe 2017,28). That same year, Republican senator Rick Santorum further opined that birth control is "not okay" and that it is a "license to do things in the sexual realm that is counter to how things are supposed to be" (Sollèe 2017, 41). Also in 
2012, Republican Congressman Todd Akin explained his belief that a woman could not become pregnant due to being raped, and thus that abortion rights should not be extended to the victims of rape, because, contrary to the way that the female body actually works, "if it's a legitimate rape, the female body has ways to try to shut that whole thing down" (Sollèe 2017, 42). In 2015, after non-profit women's healthcare provider Planned Parenthood was falsely accused of illegally harvesting and selling aborted fetuses on the black market, Texas Governor Rick Perry stated that the disproven accusations were "a disturbing reminder of the organization's penchant for profiting off the tragedy of a destroyed human life" (Sollèe 2017, 42). In March 2016, during that year's presidential election, Republican presidential nominee (and now President) Donald Trump argued that there should be "some form of punishment" (Sollè 2017, 42) for women seeking abortions and vice-presidential nominee Mike Pence stated outright that the Roe v. Wade decision should be "consigned to the ash heap of history where it belongs" (Sollèe 2017, 43). During that same election cycle, Democratic presidential nominee Hillary Clinton was often referred to as "the Wicked Witch of the Left" (Sollèe 2017, 57). Rush Limbaugh, again, referred to her as "a witch with a capital B" (Sollèe 2017, 58) and 2016 Republican National Convention speaker (and later failed politician) Antonio Sabàto Jr. asserted that if you "give her a broom so she can fly away, the witch" (Sollèe 2017, 58). Even during the Democratic primaries, some supporters of rival Democratic hopeful Bernie Sanders held signs up reading "Bern the witch" (Sollèe 2017, 58) in clear reference to former secretary of state Hillary Clinton.

And then, suddenly, it was October 2016, and by New York Times writer Lindy West's assessment:

we were doing so well [...] Thanks to decades of bloody, incremental, hard-won victories by generations of activists and organizers, the traditional presumption of white male 
authority had grown translucent, vulnerable. The term feminist was no longer so stigmatized that teenage girls were afraid to assert their innate equality and celebrities were afraid to utter it in interviews. Marriage equality passed [...] Black Lives Matter forced the facts of radicalized police violence through the generally impenetrable psyches of Middle Americans [...] We were just a hairsbreadth from electing the United States' first female president to succeed the United States' first black president. Justice Antonin Scalia passed away unexpectedly and, despite Mitch McConnell's best efforts at subverting democracy, she was going to name his replacement. (West 2019, 7-8) Based on the metrics available at the time, Hillary Clinton was almost certain to be elected president despite the allegations of influence-peddling by her family's foundation and the reopening investigation into her use of a private e-mail server.

But then, only a month before election night and two days before a presidential debate, the now-infamous recording of Donald Trump from a 2005 Access Hollywood segment surfaced in the media. In it, after a tittering of sexist remarks between him and host Billy Bush (first cousin to then-Republican President George W. Bush), Trump brazenly admitted to (presumably multiple accounts of) sexual assault:

You know, I'm automatically attracted to beautiful [women] - I just start kissing them, it's like a magnet. Just kiss. I don't even wait. And when you're a star, they let you do it. You can do anything. Grab them by the pussy. You can do anything. (West 2019, 11-12) After Trump's vulgar descriptions of sexually assaulting women were revealed by the Access Hollywood recording, a damaged, but ever-defiant Trump dramatically escalated his personal attacks on the Clintons as he sought to deflect the political fallout before a critical debate. 
In the brief and ineffectual apology that followed the scandal, Trump dismissed it as "locker room banter" (Fahrenthold 2016, $\mid 21$ ) and pivoted to accusing former President Bill Clinton of rape and Hillary Clinton of covering it up by "bull[ying], attack[ing], sham[ing] and intimidate[ing] his victims" into silence (Fahrenthold 2016, $₫ \mid 3$ ). Accordingly, "every woman knows a version of Donald Trump" (West 2019, 12). He is the ur-text of modern misogyny and emblematic of the Western tradition of sexual antagonism:

He's the boss who thinks you owe him something; the date who thinks that silence means "yes" and "no" means "try harder"; the stranger who thinks your body's mere existence constitutes an invitation to touch, take, own, and destroy. He's every deadbeat hookup, every narcissistic loser, every man who's ever tried to leverage power, money, fame, credibility, or physical strength to snap your boundaries like matchsticks. He is hot fear and cold dread in the pit of your stomach. He's the man who held you back, who never took you seriously, who treated you like nothing until you started to believe it, who raped you and told you it was your fault and whose daddy was a cop, so who would believe you anyway. (West 2019, 12)

He is, in short, "rape culture's blathering id" (West 2019, 12). And, mere days after the release of the infamous Access Hollywood tape, in which Donald Trump admitted to sexual assault, "Hillary Clinton [...] was required to stand next to him on a stage for a presidential debate and remain unflappable while being held to an astronomically higher standard and $[\ldots]$ his followers persisted in howling that sexism was a feminist myth" (West 2019, 12). In time, Clinton would describe the Trump administration's e-mail probe as a "witch hunt" against her, while Trump, seeking to control the narrative, would describe the special counsel's investigation into Russian interference in the election or the impeachment inquiry as a "witch hunt" against him. 
In October 2017, almost to the day, the story broke credibly implicating Hollywood mega-producer Harvey Weinstein of repeatedly sexually assaulting women in the industry and ruining the careers of those who successfully fought against his advances, practices which had been open secrets in the American film industry for years (Kantor and Twohey 2017, $₫ 5$ ). Owing to his close working relationship with Weinstein over the entirety of his career, writer-director Quentin Tarantino tellingly admitted to reporters that he "knew enough to do more than [he] did" (Kantor 2017, $\mid 2$ ). Less than a year later, Tarantino would be embroiled in his own controversy when Uma Thurman, another one of Weinstein's assault victims, revealed that Tarantino had dismissed her accusations of Weinstein to him prior to (and again in) 2001 and, during the filming of the Kill Bill (2003-2004) movies, dismissed her safety concerns about shooting a particular scene that resulted in a car crash that nearly killed her and left her with a "permanently damaged neck and $[\ldots]$ screwed up knees" (Dowd 2018, $₫ 55$ ).

Felony allegations against Weinstein, “or, more accurately, the fact that an undeniable number of high-profile victims came forward and the allegations actually stuck[,] formed the keystone of a collective grassroots awakening known as the "Me Too" movement" (West 2019, 14). In its earliest form as part of a Post-9/11 cultural milieu, the phrase "Me Too" was used by activist Tarana Burke on MySpace in 2006 in order "to draw attention to the prevalence of sexual harassment and assault [as well as] the social structures that enable, protect, and shield powerful figures from consequences" (Wingfield 2019, 352), although it failed to garner much widespread attention until nearly a decade later. In 2014, a video recording of comic Hannibal Buress' standup routine castigated Bill Cosby for his long-but-underrecognized history of sexual assault allegations went viral, raised awareness of the exact same issues raised by Tarana Burke years prior and allowed them to find purchase in mainstream discourse (Dalton 2018, $\uparrow 4$ ). This cultural 
cavalcade later culminated in the 2017 revelations of, 2018 arrest for and 2020 conviction for sexual assault by Hollywood producer Harvey Weinstein. Fueled by past and present revelations of sexual violence by not just Bill Cosby and Harvey Weinstein, but Donald Trump, Brett Kavanaugh, Roger Ailes, Woody Allen, Louis C. K., Kevin Spacey, Roman Polanski and numerous priests in the Catholic Archdiocese of Boston as well - "\#MeToo has exploded into a large-scale cultural reckoning that so far has not remotely faded" (West 2019, 14). Even in 2020, the specifically gendered issues raised by \#MeToo have continued to gain traction.

Even outside of the realm of politics, witch hunt rhetoric is employed by men as both a defense of male colleagues' predatory behaviors against women and as an attack on the very women seeking justice against those same men's behavior. Austrian director Michael Haneke whose films, like the acclaimed Funny Games (1997), are often reminiscent of the provocative films of Lars von Trier in terms of their extreme and unmitigated violence - opined in 2018 that \#MeToo was spear-heading a "witch hunt" informed by a "new puritanism coloured by a hatred of men" that "should be left in the Middle Ages" (Mumford 2018, $₫ 1-2$ ); he added an additionally racial dimension to his comments by accusing the movement of terrorizing artists with a "crusade against any form of eroticism" (Mumford 2018, q2). Actor Liam Neeson, while defending fellow actor Dustin Hoffman from allegations of molesting a costar every night during the 1983 Broadway production of the play Death of a Salesman, called \#MeToo "a bit of a witch hunt" (Pasquini 2018, $\llbracket 1$ ) and insisted that he believed Hoffman's denials because actors in a play "do silly things" on- and off-stage (Pasquini 2018, $₫$ |8). Perhaps the most egregious comments, however, came from Monty Python cast member-cum-director Terry Gilliam, who has frequently been subject to scrutiny for his seeming impropriety with women. Speaking to Newsweek in 2020, Gilliam brazenly stated "yeah, I said \#MeToo is a witch hunt. I really feel 
there were a lot of people, decent people, or mildly irritating people, who were getting hammered. That's wrong” (Rahman 2020, $\mid 4$ ). More than simply dismissing such predatory behavior, Gilliam went on to outright defend such practices via victim-blaming, saying that “there are many victims in Harvey's life and I feel sympathy for them, but then, Hollywood is full of very ambitious people who are adults and they make choices” (Rahman 2020, ๆ5). The evocation of witch hunt rhetoric to describe holding sexual predators accountable in general and to the activism of \#MeToo in particular is inviably "at odds with the usual deployment of the phrase, one which is associated with 'hunting' those who threaten established authority" rather than those who themselves represent the established authority (Wilson 2020, 132). Further, such usage of the phrase to both condemn activists seeking social retribution, if not social revolution, while simultaneously enabling the misconduct of deeply misogynistic and predatory men "goes against actual history [as] it was not those in power who bore the brunt of witch hunts (as Trump's[,] Allen's [and others'] use of the phrase suggest), but most often the marginalized" (Wilson 2020,132). Such linguistic appropriations by these accused and convicted sexual predators is, by its very nature, a deeply insidious tactic that recenters women's sexual assault narratives on their abusers and reframes them as the victims of those interactions.

Even director Lars von Trier has not been able to cleanly support \#MeToo. The Danish filmmaker has long been an intensely controversial figure that, paradoxically, is both frequently accused of misogyny and also responsible for creating films that are arguably sympathetic to women's causes (if not being outright feministic in their own right). When confronted with the accusations that he had sexually assaulted actress Björk on the set of his film Dancer in the Dark (2000) in 2018, his dismissive response altered between complaining how he had already "denied it, but no one wrote it" because " $90 \%$ of the journalists [that he] spoke to believe that [he 
had] harassed Björk" (Sharf 2018, ๆ2). His version of the encounter is that following an emotionally intense scene with the actress, he was "obviously" overcome with the paternalistic need to hug her, and that "if she thinks a hug is harassment, then I think I will not be able to succeed without touching my actors. I did not touch her in the wrong places, I think" (Sharf 2018 , $\mid 2)$. Like the "witch hunt" narratives of other accused men, von Trier's version of events posits that more than just doing his job as a director, he was being an altruistic figure on set that was tending to her "obvious" emotional needs and that any impropriety on his part was a mistake on her part ("if she thinks a hug is harassment") that jeopardizes his ability to do his job in the future ("I will not be able to succeed without touching my actors"). In addition, he insists that it was not the lack of consent that was at issue with their interactions, but whether or not he did or “did not touch her in the wrong places" (Sharf 2018, \2). Even so, actress Björk’s rendering of events is a radical departure from the saintly recollection of von Trier, remembering that:

after each take the director ran up to me and wrapped his arms around me for a long time in front of all crew or alone and stroked me sometimes for minutes against my wishes [...] While filming in Sweden, he threatened to climb from his room's balcony over to mine in the middle of the night with a clear sexual intention, while his wife was in the room next door. (Sharf 2018, $\uparrow 4$ )

This inexcusable behavior detailed by Björk is further compounded by additional reports that have come out regarding Zentropa Entertainments, the Danish production studio that Lars von Trier co-founded with producer Peter Aalbaek Jensen. Jensen's response to Björk's accusations were to discredit her, reporting that the film's production was "fraught with tension" and that he “blamed Björk for being difficult on set” (Sharf 2018, \3), therefore reinforcing von Trier’s victim narrative. Following an investigation into multiple sexual assault and abuse allegations 
leveled at Zentropa by the Danish government, including that "Jensen would 'spank' trainees as punishment (Jensen later confirmed this in an interview with Danish Radio 24/7)" and that he and other high-ranking men in the company fostered an “'ingrained' culture of abuse at the studio" (Pulver 2018, $\{3$ ). Notably among those accusing the company (and Jensen in particular) of sexual impropriety is Meta Louise Foldager Sørensen, who co-produced Antichrist with Jensen. Although the Danish Working Environment Authority concluded in its investigation of Zentropa that the company had "taken enough steps to reform its practices and created a new code of conduct for its employees," Jensen, who owns $25 \%$ of the company, admitted that "he was 'not familiar' with the company's new guidelines and habitually refused to obey what he described as "boy scout rules"” (Pulver 2018, $\uparrow 4$ ). He freely admitted that he has "been slapping the asses of guys and girls at [Zentropa] for 20 years," and although he insisted that he "never tried to fuck anyone [, because] that is seen differently [now] than it was [5], 10, 15 years ago ... So I'll stop slapping asses" (Pulver 2018, $\uparrow 2$ ). Like von Trier and other men that have been credibly accused of (and in some cases have even admitted to) committing acts of sexual assault, his statements serve to justify his behavior by dismissing his accusers, belittling his actions and drawing a line in the sand between what he frames as "appropriate" and "inappropriate" forms of sexual assault.

Although Lars von Trier ostensibly supports the \#MeToo movement in his public statements, even those statements coinciding with questions about his assault allegations, and although many of his films convey narratives that appear to be supportive of the autonomy and interior lives of women, as well as be sympathetic to the injustices done to them, von Trier's behavior is powerfully indicative of a pre-\#MeToo film industry, where powerful men use their wealth and stature to insulate themselves from what should be the consequences of their 
untenable actions. In fact, von Trier calls the social movement "a brilliant idea" and "very important," that is, "if it’s used the right way" (Sharf 2018, $₫ 6$ ): the "right way," seeming to mean "not against me." Blockbuster film fans may similarly recall accusations made against Joss Whedon by ex-wife Kai Cole: that he used his marriage to her and his professed feminist ideals "as a shield, both during and after [their] marriage, so no one would question his relationships with other women or scrutinize his writing as anything other than feminist" (Cole 2017, \8). In both instances, male filmmakers with a strong interest in presenting nuanced female characters on-screen fail to live up to the ideals that are otherwise realized in their films. Taken together, all of these men's comments (Haneke's, Neeson's, Gilliam's, von Trier's, Jensen's, Whedon's and others') coalesce to reinforce an environment of predation and fear for women, shield men from the consequences of their predatory behavior and systemically benefit men at the expense of women's mental, emotional and professional well-being.

Since 2017, \#MeToo's stature has only risen in the popular consciousness, creating a space in which "victims strid[e] bravely and angrily out of the shadows to tell their stories of exploitation, predation, terror, abuse, derailed careers, and sabotaged potential $[\ldots]$ as well as [build] bridges across industries and socioeconomic strata to demand meaningful, widespread, systemic change" (West 2019, 14-15). In fact, "the reason \#MeToo has been so terrifying to so many people," particularly for rich, powerful, white men like Harvey Weinstein and his ilk, "is that we got a quick glimpse of what history is going to say about us. For just a moment, we could see the curvature of the earth" (West 2019, 17), and it did not include men like him; or, rather, it did not include men like him in unassailable positions of absolute power and authority. Thus "like the inquisitors, witch finders, and civilian accusers of yore, Republican lawmakers [and media personalities] and their ongoing attacks against sexual and reproductive health place a 
woman's right to bodily autonomy perpetually under siege" (Sollèe 2017, 43) and even the most cursory reading of history exposes how 'the 'sluts' seeking birth control and basic reproductive freedoms [today] are hardly [any] different from the Satanic witch midwives of yesteryear" (Sollèe 2017, 43). Amy Kremer, co-founder of the Women Vote Trump PAC, told MSNBC in 2018 about her take on left-wing attacks on conservatives, saying that "it is a scary time right now" (Chiu 2018, $\mid 2$ ) and that "now you've got witches that are placing a hex on Brett Kavanaugh” (Chiu 2018, ๆ5). Not unlike historical moments chronicled earlier in this thesis, contemporary Republican lawmakers have launched a political witch-hunt on women's freedoms with accusations of witchcraft used against powerful and outspoken women 


\section{CHAPTER II: LARS VON TRIER'S ‘ANTICHRIST’ (2009)}

Much scholarship has been made concerning Lars von Trier's heatedly controversial film Antichrist in the decade since its release. Possibly owing to being the first film released in this cycle of witch cinema, possibly owing to how densely layered with meanings and allusions its unfolding narrative is, it has been scrutinized from innumerable angles with very little consensus seeming to have been made. The film has been "criticized by feminists for its perceived misogyny" (Buch-Hansen 2011, 115), praised for wielding its "misogyny as a critique of Western hegemonic patriarchy" (Pettibone 2013) and generally dismissed for how its “'Dionysian wisdom, even in its most chocking forms, remains the lesser evil' (Maffesoli, 102)" even though its contentious narrative "may cause panic and transgress boundaries" (Thomsen $2009,10)$. The only consistent through line in scholarly considerations of the film is that "in spite of, or perhaps because of, the eschatological signification of its title" (Zolkos 2011, 177) - which has the additional distinction of replacing its final " $\mathrm{t}$ " with the female pictogram - Antichrist invites viewers to consider themes of religion and gender in tandem with its profoundly violent, psychosexual narrative.

Structured more akin to a work of literature than a work of cinema, Lars von Trier's Antichrist is divided into six discreet sections: a Prologue, Chapter 1: Grief (Mourning), Chapter 2: Pain (Chaos Reigns), Chapter 3: Despair (Gynocide), Chapter 4: The Three Beggars and an Epilogue. Aesthetically distinct from the four chapters which follow it, the Prologue is composed of a single, stylistic montage. Shot in crisp black-and-white photography and emphatic slow-motion and scored against a rapturously melancholic arrangement of Handel's Lascia ch 'io pianga, whose fatalistic lyrics - which include the lines "let me weep over my cruel fate / and sigh for my lost freedom" and "may the pain shatter the chains / of my torments just out of 
mercy" - portend the doom depicted in the film's beginning and ending segments. As He and She engage in impassioned sex, their son Nic, a small and precocious child, escapes from his crib and wanders their home. After seeing his parents copulating, the child turns to and approaches an open window whose inbound breeze and idyllic snowfall seems to beckon to him. He climbs to the window and throws himself out of it precisely as his parents climax in the other room.

Chapter 1 opens with the boy's funeral procession, during which She collapses. Hospitalized and medicated for depression for over a month, She leaves the hospital after He gets into an argument with her physician and insists that He can treat her more effectively despite only being a cognitive psychotherapist (rather than a medical doctor). At home, He forces She to throw out her medication and take He on as her therapist. Sinking deeper into a debilitating depression and medicating herself with sex - so much so that He's dual roles as her therapist and lover interminably blur together to the point of indistinguishability, with sexual activity transitioning into, interspersed during and ultimately ending many of their therapeutic sessions He concludes that the cause of her unwellness lies in Eden, their idyllic cabin in the woods where She spent the previous summer writing her thesis and caring for her now-dead child, and also concludes that the best form of treatment for her malady would be immersion therapy in Eden. As they near Eden from the surrounding forest, She, who has been increasingly anxious as they near their destination, naps while He sees what at first appears to be a perfectly healthy deer wandering the forest. As it turns from him, however, its bloodied, half-birthed, stillborn offspring dangles limply from its body.

Chapter 2 begins with them arriving in Eden and alternating between She's reluctant therapy, bouts of her worsening depression and anxiety and He's witnessing of further, ominous disruptions of nature. During one exercise, where She is made to travel between two stones, a 
dead chick falls out of the sky and is swarmed by ants before a hawk snatches it and tears hungrily into it. She describes how, while working on her thesis (a history of women's persecution entitled Gynocide), she thought that she heard her child crying in the woods, only to find him quietly playing by himself in a shed, the unsettling admission of which causes her to attack He (She screams "we shouldn't have come here. You were just so damned arrogant"). After She concludes that "Nature is Satan's Church" and flees into the woods, He goes after her and finds a feral, gutted fox hungrily disemboweling itself, which tells him "chaos reigns" in a low human voice, deliberately echoing Chapter 2's title.

In Chapter 3, He finds a ladder while She sleeps and uses it to access the cabin's attic, where he finds her thesis and researched splayed out throughout the room and that her manuscript rapidly degrades from easily-read script to illegible scribbles. He confronts She with more therapy, taking on the guise of Nature (who wants to "hurt [She] as much as [it] can" as it can best be understood as "the nature of all human beings"). She reveals that, in true Nietzschean fashion, she had gazed into the abyss (Nietzsche 2020, 86) of human (more specifically male) cruelty while writing thesis and has internalized the messages of the very same misogynistic propaganda that she was researching (that "if human nature is evil, then that goes as well for the nature [of women: female nature]"). This revelation culminates in desperate, emotional sex where She fervently demands that He hit her; although He initially refuses, causing She to leave. He finds her again, furiously masturbating underneath a great gnarled tree, and acquiesces to her violent requests as she speaks passionately of the power of witchcraft and the camera reveals the tangled arms of corpses buried beneath the tree stretching out from its roots. Later, She discovers the coroner's report from their child's autopsy and He reveals that She had unknowingly deformed their son's feet by putting his shoes on the wrong feet for the entire summer that She 
and Nic were previously in Eden. Realizing that what She truly fears most is "Me" (meaning herself), She furiously attacks him and accuses him of trying to leave her. After transitioning again into sex, She dismounts from He and smashes his testicles with a nearby piece of wood, causing him to pass out. Despite his unconsciousness, She masturbates He to a bloody orgasm. She then slowly hand-drills a hole into He's calf and affixes a whetstone to it like a shackle, throwing the wrench she used to tighten it with under the cabin. He wakes in catastrophic pain and, unable to unfetter himself, drags himself into a foxhole under the roots of an old tree as She desperately looks for him. While there, He disturbs a buried crow, whose caws draw She to his hiding place and who proves undaunted by He's increasingly frantic attempts at bludgeoning it to death.

Night falls in Chapter 4 as a now-calmed She digs He out and brings him back to the cabin. She cannot find the wrench to free him and He meekly lies beside her on the floor. She warns him that "when the three beggars arrive, someone must die," referencing both the three animals that He had encountered in Eden and their representative constellations from She's research. She begins to cry, but admonishes herself for it (saying "a crying woman is a scheming woman. False in legs, false in thighs, false in breast, teeth, hair and eyes"). Procuring a pair of scissors from the other room, She doffs her pants and masturbates herself using He's limp hand. Thinking of the first sex scene from the prologue, she castrates herself with the scissors, screams (drawing the attention of the deer) and passes out. He wakes at night and sees the three beggars' constellations. The deer and then the fox enter the cabin. The crow caws beneath the floorboards, breaks through the floor and joins the others, revealing the discarded wrench beneath the house. She wakes as He works to remove the whetstone from his leg and attacks him. He violently counterattacks, throwing her hard against the wall and strangling her, intercut with the visual 
signifiers of her grief (the deer), her pain (the fox) and her despair (the crow) until She dies. He burns her body in the brush outside and leaves Eden. As he does so, the forest floor is transformed into a twisted mass of female corpses, recalling the bodies shown to be beneath the tree in Chapter 3: the apparent aftermath of a gynocidal holocaust.

The Epilogue aesthetically mirrors the prologue, in that it is shot in black-and-white and musically scored once again to Lascia ch'io pianga. He slowly limps away from Eden. Scavenging for berries in the forest, He finds a jet-black feather and then its source: the spectral forms of the three beggars still gathered beside him. According to She's portents in Chapter 4, "someone must die." He stands, noticing for the first time that the women he had left behind in Eden have followed him beyond its borders. He is soon fully encased within a slowly closing circle of women clambering toward him from all sides like an inexorable tide - unmistakably the witches whose persecutions were detailed in Gynocide - whose masses of flesh swallow him against the still landscape.

Always known for being something of a provocateur - a feature that would culminate in his infamous expulsion from the Cannes Film Festival in 2011 and his incendiary return to in 2018 - Lars von Trier's Antichrist catapulted his reputation for producing viscerally challenging films to even greater heights than before. Borne of the same depressive episode that would go on to inspire Melancholia (2011) and Nymphomaniac: Vol. I (2013) and Vol. II (2013), Antichrist was von Trier's attempt to make a film "for a wider audience, a horror film ... in the style of [1994's] The Kingdom [ ... a] kind of an Antichrist ... based on the theory that it was not God but Satan who created the world" (Badley 2010,140). Proving to be his most contentious film to date, the film triggered "involuntary gasps, groans, yelps, laughter, and alleged fainting followed by hooting and booing amid scattered applause" (Badley 2010, 141-142) in its Cannes audience 
and, elsewhere, "walkouts, vomiting ([in] Toronto), a seizure ([in] New York) [...] an unremitting onslaught of polarized reviews [... and] protests and calls for bans in France and Poland" (Badley 2010, 143). Throughout its storied run at and beyond film festivals, reactions to the film ran the critical gamut, from the Chicago Sun Times' Roger Ebert praising it for its courage in documenting "our fear that evil does exist in the world, that our fellow men are capable of limitless cruelty, and that it might lead, as it does in the film, to the obliteration of human hope" (Ebert 2009, $₫ 10$ ) to Hollywood Elsewhere's Jeffrey Wells rebuking it as "an outand-out disaster" whose dedication "to the late Russian director Andrei Tarkovsky [would quite possibly inspire his] rotted and decomposed body [to claw] its way out of the grave to stalk the earth, find an axe and slay Von Trier in his bed" (Wells 2009, \7), although it is perhaps perfectly encapsulated in The Guardian's Xan Brooks's review, whose title, delicately poised between impassioned adoration and righteous excoriation, asked "Antichrist: a work of genius or the sickest film in the history of cinema" (Brooks 2009). Thus, Antichrist's foremost aim, to excite and polarize its audience members by way of their visceral reactions to the violent and violating extremities of its narrative, was easily achieved.

Less a taken-at-face-value chiller and more of a "psychological thriller that evolves into a horror film," Antichrist intentionally acted as "a glimpse into the dark world of [von Trier's] imagination: into the nature of [his] fears, into the nature of [his] Antichrist" (Badley 2010, 141). Due to its graphic depictions of violence and sex, the evident anger directed toward traditional institutions of social order (such as the church, the medical profession and the patriarchy as a whole) and the ways in which all three graphically intermingle into the bloody extremities of its climax, the film seems to stem from the same wellspring of cinematic extremism as filmmakers of the so-called New French Extremity, which have been a presence in European horror films 
since the late 1990s. Indeed, there are many comparisons to be made to films like 2002's In My Skin (in which a minorly "disfigured" women becomes obsessed with freshly probing her old wounds), 2003's High Tension (where repressed female sexuality is expressed via a sexually violent, sadomasochistic serial killer) and 2007's Inside (where a woman who is about to give birth is gruesomely attacked by another woman trying to violently extract her child on Christmas Eve). In much the same fashion as those films did, Antichrist "sees art-house and [horror] converge to mediate on the most horrific aspects of life and what remains after those social veneers are stripped away" (West 2016, 10). Of von Trier's expansive filmography, Antichrist is the film "that comes closest to a scream" (Romer 2009, $₫ 32$ ).

Drawing upon the traditions of both "pornography as well as horror," with graphic closeups of unsimulated sexual penetration scored against rapturously melancholic opera music, hematospermia (bloody ejaculate) and multiple instances of genital mutilation and disfigurement, Antichrist "produced a sadomasochistic frisson intensified by Gainsbourg's visceral, taboobreaking embodiment of aggressive female sexuality" (Badley 2010, 147). In addition, it represented both von Trier's "return to the dark expressionism" (Badley 2010, 140) and the "oneiric logic, hypnotic expressionism, and technical virtuosity of his earliest films" (Badley $2010,144)$ as well as a "blend[ing] his early and late styles and themes and [... breaking them] down into an intricate code" (Badley 2010, 144). Unlike previous von Trier films, “"horror' [...] offered a range and a vocabulary of understated frissons and excoriating extremes yet is capable of modulating from raw naturalism via the uncanny and the fantastic into surrealism, where all such distinctions might break down" (Badley 2010, 145). The extreme nature of Antichrist, then, is not beside the point of the film so much as it is the point of the film. From its pornographic titillation to its horrific set pieces, the very nature of Antichrist's overriding narrative and 
aesthetic palette are deliberately deployed to both express and explore the violence underscoring He and She's gendered understanding of the world around them and, by extension, our own understanding of it. By employing the conventions of genres as volatile as horror and pornography, Antichrist is able to do so much more acutely and with much greater nuance than any of von Trier's previous films.

Unlike many films in the last decade that prominently feature the witch, Antichrist brokers predominantly on the level of indexical, and especially symbolic, signs. Outside of an isolated and unexplored reference to She's academic thesis in Chapter 1 and the scattered appearances of the three beggars throughout the various chapters, there is no direct reference to witchcraft in the film until the discovery of her thesis on the $18^{\text {th }}$ century witch hunts, Gynocide, at the beginning of Chapter 3. And though that chapter does indeed explore her internalization of misogynistic anti-witch (and thus anti-woman) propaganda (such as the Malleus Maleficarum), it is not until Chapter 4, with the gathering of the three beggars in Eden and quite possibly the appearance of the witch coven in the Epilogue that anything definitively supernatural occurs. Even the fox speaking in Chapter 2 is so utterly unlike anything that comes immediately before or after it that the event could easily be taken as an abstract metaphor for the increasing topsyturveydom of what has been transpiring in Eden rather than as a literal plot-point to be taken as a face-value occurrence. Before the unnerving events in Eden coalesce into a concrete threat later in the movie, what is presented is merely a series of disorienting subversions of the presumed natural order and He's failed attempts at treating his wife's psychoses with therapy alone.

Indeed, there is only a single iconic sign to be found within the film, that is to say a sign in which "the signifier represents the signified by apparently having a likeness to it" (Rose 2016, 
119). In a fairly literal form, the viewer sees the iconic coven of women closing in on $\mathrm{He}$ at the film's ultimate conclusion. It is the only instance of the witch-as-a-witch, the only example of a firmly established "iconographic [...] continuity provided by recurrent scenes and signs" (Tasker 2015 , 5). It is only these unambiguous witches, and only at those final moments within the narrative, that the film directly, unequivocally signifies a witch. This in turn puts the film, like the comparatively much more conventional The Autopsy of Jane Doe (2016), in line with horror film scholars Andrea Subissati's and Alexandra West's idea of the "secret witch film" (Subissati and West 2018), where the presence of witchcraft remains obfuscated for much of the film's runtime and operates more as a narrative twist than as an ongoing narrative feature. This differs, from a more traditionally straightforward witch narrative, such as the television series American Horror Story: Coven, which deals with literalized, iconic witches from the outset of its narrative. Both The Witch (2015) and The Autopsy of Jane Doe depict far more definitively supernatural goings-on than Antichrist does, with The Witch broadcasting that plot detail in its very title. Antichrist, however, operates as a "psychological thriller that [gradually] evolves into a horror film" (Badley 2010, 141) as it transitions from its more mundane beginning to its more surreal conclusion. The film's meanings predominantly exist within increasingly complex layers of symbolism and abstraction, as opposed to simple, surface-level associations.

Antichrist's first indexical sign - which indicates "an inherent relationship between the signified and the signifier" (Rose 2016,120) and thus acts as visual evidence of what is being represented - comes near the end of Chapter 1, when He and She travel by train to Eden. In this momentary break before She's immersion therapy begins in earnest, He mentally prepares her for the experience he hopes for her to have once they arrive there. With hypnotic intensity reminiscent of the rhythmic narration of Europa (1991), He mentally guides She, who moves in 
slow-motion similar to in the Prologue, through the surrounding forest and into Eden. At one point He instructs her to "lie down on the grass" on the path outside of their cabin. Following his instructions, She lays down on her back in the grass - eyes shut, arms outstretched, palms turned upward, drowning in green - a pose that is immediately reminiscent of John Everett Millais's 1851 painting Ophelia. Referenced again and even more centrally in Antichrist's thematic follow-up, Melancholia (2011) - a film whose poster and opening shot recreate the image of the drowned Ophelia - the painting depicts the aftermath of Ophelia's suicide from Shakespeare's Hamlet. In the play, Ophelia, the spurned lover of the titular prince of Denmark, goes mad with grief and drowns herself, and has since become one of literature's most iconic depressives. The semiological relationship between She (the signified) and Ophelia (the signifier), visually reinforces her construction not just as a depressive, but as one capable of taking violent action as an extension of her malady.

This indexical sign is not the only way in which the film visually constructs She as a depressive, however. It has been well documented by psychologists that those suffering from depression often experience the passage of time differently than those who do not, that "patients with major depressive disorder (MDD) commonly report the sense that time is passing very slowly" (Ahmadi et al. 2019, 672). In fact, "the perception of a monotonous environment and the psychological distress experienced by sufferers of depression directs attention away from meaningful thoughts and actions to the passage of time, which makes it appear to be passing more slowly" (Ahmadi et al. 2019, 672). Repeated throughout von Trier's "Depression Trilogy" (Antichrist, Melancholia and Nymphomaniac Vol. I and Vol. II), and in this film in particular, slow-motion and desaturated color serves to put the viewer in the same mental state as its melancholic main characters. In fact, what Antichrist's She recalls to the viewer is no less than a 
dark inversion of Michelangelo's famous sculpture Pietà, in which the lifeless body of Jesus is limply draped over his mother Mary's lap after his crucifixion. But whereas Mary is depicted as the very embodiment of serene beauty in the wake of her child's death, calmly looking down on him with a transcendent half-smile, She is warped in her grief over the loss of her own son, thrashing wildly against the world. While Mary appears to be brought closer to God in her mourning, She is implacably dragged downward in her distress, nearer to the devil.

In Antichrist, this confluence of techniques is introduced in the Prologue to "[produce] the stasis of extreme melancholia: sorrow, fear, paranoia" (Badley 2010, 144). But whereas this first section of the film contains what is presumed to be the inciting incident of She's depression (it certainly is assumed to be such from the perspective of $\mathrm{He}$ ), the fact that the film opens in this manner prior to the child Nic's death indicates that her depression predates the supposed opening tragedy of the film: a fact that is later confirmed when She recounts her traumatic experiences in Eden with Nic the previous summer. Time is already distorted, color has already drained from the world and Handel's sonorous lament already echoes throughout the scene. She's constant self-treatment for her depression seen throughout the film - sex - is already present, and indeed is the very reason why the couple was ignorant of Nic's waking. Some of these melancholic techniques (the use of slow motion in particular) are echoed in She's imagined return to Eden near the end of Chapter 1 and also by "fragmented by degraded close-ups (a pulsing throat, trembling hands) to express anxiety in haptic terms" (Badley 210, 144) throughout She's therapy sessions. And then, in the Epilogue, all of these techniques return again as He burn's She's body, leaves Eden and is implicitly killed by the coven of resurrected witches.

It is fitting that the film is dedicated to Andrei Tarkovsky, as the Russian director, "whose metaphysical bent, meditative style, and vividly textured imagery marked [von] Trier's 
earliest films and shaped his career" (Badley 2010, 145), was deeply invested in the idea of refrains, both lyrical and narrative. In his acclaimed book Sculpting in Time, Tarkovsky reveals that:

When we come across a refrain in poetry we return, already in possession of what we have read, to the first cause which prompted the poet to write the lines originally. The refrain brings us back to our first experience of entering that poetic world, making it immediate and at the same time renewing it. We return, as it were, to its sources. (Tarkovsky 1986, 158)

The aesthetic function of the Epilogue, then, is to call back to the Prologue, to repeat that initial tragedy and bring it forward into the present moment: to effectively act as its refrain. It presents us with a cyclical world, one that ends as it begins and, implicitly, one that is doomed to repeat itself just like an ouroboros eternally eating its own tail. And, waltz-like, these three beats of tragedy, oppression and death endlessly repeat themselves across this infinite recurrence.

As the film transitions from a "psychological thriller [...] into a horror film" (Badley $2010,141)$, more indexical signs begin to appear: more suggestions of and associations with witchcraft and outright horror before their more literal inclusions later in the narrative. After $\mathrm{He}$ and She leave the train, they enter the woods surrounding Eden: an earie, primordial forest wrapped in smoke-like trails of mist and viewed through a swirling distortion in the lens, whereby trees swirl and shift and spin like an illusory eddy. All the while, She becomes for visibly disturbed, more reluctant to move forward and more instinctively resistant to He's commands to press on toward Eden. The sign of the haunted or enchanted woods is strongly evocative of the witches that traditionally dwell there: a dark, all-consuming labyrinth of primitive horrors, a natural sanctum of the supernatural and the place furthest removed from 
settled, 'civilized' land. After all, it is in the woods that Hansel and Gretel meet the witch in her delectable home; it is in the woods that Betty Parris and the other girls of Salem meet with Tituba to hold their communion with the devil; it is in the woods that Suzy Bannion must venture to find the Freiburg Dance Academy in Dario Argento's film Suspiria (1977). Simply put, the woods are where witches dwell, and that is as true of her older incarnations as it is of those that figure into Antichrist, The Witch, Maleficent (2014), The Love Witch (2016) and Gretel \& Hansel (2020). It is no surprise, then, that a couple alone in the dark woods (i.e., in nature) begins to warp into something horrific and unexpected, as seen in the three beggars (starting with the deer at the end of Chapter 1) and with the dead chick in Chapter 2, the dead arms under the tree in Chapter 3 and eventually, the coven of witches in the words of the Epilogue.

Similarly, He and She's Edenic cabin in the woods is another indexical sign which signifies the witch, for just as the woods house the witch, so too does her hovel serve as visual evidence of her presence. An isolated cabin in a remote wooded area is perhaps best remembered as the setting of Sam Raimi's Evil Dead series, wherein the profane book the Necronomicon resides (a book of the dead based on a fictional grimoire invented by H. P. Lovecraft, itself not unlike the devil's book allegedly signed by witches). The secluded cabin has become so emblematic of horror movie monsters at large that the very description leant itself to the title of the later film The Cabin in the Woods (2012), within which all manner of disruptive evils were housed. And in Antichrist's rustic forest cabin - from its bare, utilitarian furnishings, to the thunderous acorns that, like hail, rain down on it nightly, to the swollen ticks exsanguinating $\mathrm{He}$ overnight and to the literal embodiment of She's psychosis tucked away in the attic - there is no mistaking their secluded home as anything short of a witch's den, further upending the 'natural' order of the world. 
This isolated cabin in Eden, which is the sight of so many past traumas - including She's inculcation of medieval misogynist propaganda, the abandonment of her thesis, Nic's phantom cries that bring She to a fever-pitched panic in the woods, her accidental disfigurement of her child through her constant, compounding mistakes in dressing him by mixing up his left and right shoes - takes on additional significance in the horror genre. Those familiar with the trappings of slasher cinema, which also notably intersect with final girl Thomasin in The Witch (Borer and Lang 2017; Stanley 2020), recognize both Eden in general and the cabin in particular as the film's terrible place, which Carol Clover identifies as one of the core syntactic elements in film theory, elements which "[stress] the genre's building blocks" such as the "common traits, attitudes, characters, shots, locations, sets, and the like" (Altman 1984, 556) which comprise the recognizable components of this or that genre - of the slasher film. "The Terrible Place," Clover explains, is the location, oftentimes a house, "in which victims [like He] sooner or later find themselves" and is terrible precisely because of "the terrible families - murderous, incestuous, cannibalistic - that occupy them" (Clover 1992, 30). And just as He slowly learns of the depths of his wife's depressive malady and the disturbing events that took place there previously, "it is the conventional task of the genre to register in close detail the victims' dawning understanding, as they survey the visible evidence, of the human crimes and perversions that transpired there" and it is that horrific "perception [that] leads directly to the perception of their own immediate peril" (Clover 1992, 30-31).

Antichrist precisely follows the horrific convention of Clover's "Terrible Place:" the location the victim believes to be a sanctuary ultimately becomes a trap that imperils him. Although, as the name Eden implies, it "at first seem[s to be] a safe haven[ ... but] once the killer" or, more accurately, She's psychotic episodes, "penetrates them, the walls [...] hold the 
victim in" (Clover 1992, 31). Thus, over the course of the film, He brings She to this terrible place, the place that He has identified She fearing most, which at first promises to be a heavenly refuge that will help heal the pair.

Underneath its seemingly idyllic appearance, however, the forested cabin is actually the site of great traumatic pain and bodily horror, which becomes evident as He "survey[s] the visible evidence of the human crimes and perversions that transpired there" (Clover 1992, 3031), including the coroner's report (that details Nic's foot "deformity"), the Polaroids of Nic wearing his shoes on the wrong feet (that demonstrate the cause of his "cloven hoof"), She's abandoned research (that reveals the depths of her psychosis) and the innumerable disruptions in nature, great and small, that portend the pair's doom (the acorns, the ticks, the dead chick, the three beggars). This, in turn "leads directly to the perception of [his] own immediate peril" (Clover 1992, 30-31), most evident in his revelations about Nic causing She to attack He, castrating and "hobbling" his leg. And when She's violent nature fully penetrates the promised sanctuary of Eden, He is varyingly trapped within its verdant borders, within the earthen foxhole and within the cabin itself. It is additionally notable that the splayed-out remnants of She's research and thesis is appropriately stored in the cabin's attic, above the "body" of the home, buried like a repressed memory in the part of the cabin that most directly corresponds with the human mind; and it is discovered in a sequence that is syntactically and semantically apt for a gothic or horror narrative. This sequence is reminiscent of the horrific reveal of Bertha Mason, first wife of Edward Rochester in Jayne Eyre (1847), who has been trapped in the attic of Thornfield Hall since their marriage began, as well as the unveiling of Jack Torrence's madness in The Shining (1980), where his wife Wendy reads the manuscript that he had been writing for 
months, which is nothing but the sentence "all work and no play makes Jack a dull boy" for hundreds of pages. In Antichrist, the combination of these various:

genre tropes (the isolated cabin and [the] haunted forest) [were able to] merge with Bergmanesque drama, shift into Lynchian sadomasochism, and from thence into Boschian grotesque and supernatural revenge, all the while playing off Freudian/Jungian archetypes to the extent that Antichrist [...] imparts "the most undulated surge of emotion and mystical/mythical implication to be found in all [of von Trier's] work." (Badley 2010, 145-146)

By wedding his aesthetic sensibilities to the established narrative conventions of the horror genre, Lars von Trier is able to more viscerally evoke the terrifying implications of deeply embodied gender paradigms and better leverage these events for their dramatic heft and thematic significance.

She's various castrations - both of He and of herself - also indexically signify her as a witch, who were noted femme castratrices both historically and cinematically. She crushing He's testicles and then bringing him to a profane climax after he passes out hearkens back to the popular image of witches in the Malleus Maleficarum who would steal men's penises and keep them 'alive' in jars so as to continue to torment their now-sexless former owners (Oldridge 2008). Additionally, She's self-castration (and consequent genital bleeding) evokes the monstrous-feminine, who is simultaneously "woman and menstrual monster" and "foreground[s] her essentially sexual nature" as a "monstrous figure with supernatural powers and a desire for evil” (Creed 1993, 76). Like Sissy Spacek’s Carrie White, perhaps the horror genre's most iconic witch and menstrual monster, "the symbolic function of women's menstrual blood is of crucial importance" (Creed 1993, 77), as it the source of her sexual power over her male partner. In 
Antichrist, She is, after all, able to convince her nominally resistant therapist-husband to sleep with her on any number of occasions as well as to command him to violence against her during coitus.

Prior von Trier films like Medea (1988) and Dogville (2003) had already played with the idea of the monstrous-feminine, in which "gifted wom[e]n struggl[e] against a repressive culture epitomized in a male antagonist [and avenge] the crimes against [them] - with the revenge being as unimaginable and apocalyptic as [the degree to which their] powers have been suppressed" (Badley 2010, 146). Drawing on his obsession with Japanese ghost stories and J-horror films featuring "wraithlike wom[e]n with long dark hair associated with both female oppression and [...] the destructive aspect of primeval nature" (Badley 2010, 146), Antichrist's She varyingly resembles these horror antagonists. She at once possesses “the oceanic chaos[ of Sadako's] female power [that] takes virally proliferating forms and destroys indiscriminately" in Ring (1998) as well as the gruesome wiles of Asami, "a beautiful, melancholy woman [who] seduces and renders men maimed, doglike wretches[ by] cutting off their feet to avenge the abuse she suffered as a child and to keep them from leaving" (Badley 2010, 147) in Audition (1999). In von Trier's She, castration, dismemberment, immobilization and annihilation combine into a singular threat against the symbolically patriarchal order.

The three beggars of Antichrist - varyingly a deer, a fox and a crow - double as both indexical signs and symbolic signs. In their indexical functions, they represent a witch's familiars: animal companions gifted by the devil that would do her dark bidding. Although more typically presented as cats, a wide swath of animal forms were possible, and other recent films have made use of rabbits (The Witch), crows (The Witch) and ravens (Maleficent). Their presence throughout the film represents an inversion of the Godly order, each introduced via some 
grotesque deformity (a stillborn fawn dangling from the deer's birth canal, an auto-cannibalizing fox and a seemingly dead crow that forever rises from the earth). Furthermore, each serves to psychically menace He (and, in the crow's case, alert She to his otherwise perfect hiding place in the foxhole) and represents a delirious escalation in the danger He finds himself in while in Eden. When the three beggars gather in Chapter 4, they curl companionately around She and, after She is killed, return in the Epilogue to act as harbingers of She's avengement.

At the same time, the three beggars also serve as symbolic signs. More abstract than either iconic or indexical signs, these represent "a conventionalized but clearly arbitrary relation between signifier and signified" (Rose 2016, 120). Unlike Antichrist's other symbolic signs, however, the relationships that the three beggars represent are plainly labeled in She's abandoned research. Each represents a worsening stage of her depression - the deer, grief; the fox, pain; the crow, despair - and is introduced at calculated intervals that correspond with that stage of her psychic descent. Each's malady, similarly, corresponds with their symbolic meaning. The deer's stillborn offspring is a clear representation of the grief She feels (most recently and acutely to her own dead child, the fox's self-ingestion corresponds with the physiological pain that She feels while deprived of her medication and the dauntless, resurrecting crow depicts the relentless doggedness of her own toxic and destructive thoughts toward both man and womankind. Combined, they represent no less than total annihilation: the death of all humankind. Most central to the film, however, are the symbolic signs of the characters He and She and the setting of Eden (itself distinct from the broader cabin and woods settings of the film). That is because Antichrist, which is “populated by the archetypical 'He' and 'She,' who simultaneously represent spouse, parent, and masculine and feminine aspects of the self, [von] Trier's psychodrama similarly returns to the repressed and therefore mystical, space of Eden" 
(Badley 2010, 145). As their deconstructed names suggest, He, like the biblical Adam, signifies men, masculinity and the patriarchy. She, like biblical Eve, signifies women, femininity and motherhood. And, like the medieval witch, from a certain patriarchal perspective She signifies the corruption of these concepts: the bad woman, bad femininity and bad motherhood specifically. Eden, as the biblical reference imparts, represents an otherwise utopic site of sin, degradation and deviance. With these relationships thusly constructed, the interactions between the characters and their environment, which are at first obfuscated by the layers of representational meaning, can be better understood by way of how "nature (external and internal) conspires in her (and increasingly his) derangement as the border between reality and unconsciousness collapses, and [the ways in which] they [ultimately] tear each other apart" (Badley 2010, 144). In other words, Antichrist posits that the interrelation between these signs and what they signify is so inherently antagonistic that the only logical outcome from their interaction is mutually assured self-destruction.

These multivariate relationships (between each of the characters, between the characters and their environments and between the different signs and their signifieds) are evident throughout the film. They are evident in how the responsibilities of childrearing was predominantly shunted to She; after all, She cared for Nic alone in Eden for months and She blames herself for Nic's death because, unlike her husband, She knew about Nic's newfound tendency to wake early from his nap and escape his room. They are evident in the how She's education and career came secondary to He's, to the point that He is a practicing therapist; She was forced to care for their child alone while working on her thesis and She abandoned her thesis without He so much as realizing it. These relationships are evident in the clear power differential between them (even aside from the aforementioned educational and socio-economic components 
of their power dynamics), in which He forcibly recruits She as a patient (an act whose murky ethics are addressed in the film, both in dialog and in character actions), forces her off of her prescribed medication (despite being beyond the scope of his training), assumes a dual role as both She's husband and therapist, isolates her from other relational support networks during her therapy in Eden (such as friends or family) and withholds vital information from her out of a paternalistic sense of responsibility (such as the coroner's report). They are evident in the way that He dismisses She's every concern or conviction, ranging from her protestations against $\mathrm{He}$ becoming her therapist ("but you're not a doctor"), his dismissal of her thesis subject as "glib" ("and all of a sudden it was glib... or worse, some kind of a lie"), his constant need to rationalize her feelings (“can't I just be afraid without a rational object [causing it]?"), his insistence on using immersion therapy when she is deeply and vocally against the practice ("we never should have come here. You were just so damned arrogant") and his varying attempts of bullying her into a state of acceptable mental health ("yeah, well, you don't have to understand me, just trust me"). Moreover, the architecture of gendered violence as a multivalent force in these relationships is evident even in the ways which He defends himself from the increasingly violent She, as in Chapter 4, after the three beggars' arrival, when He grabs a half-naked She by the throat, throws her against the wall and slowly strangles her to death, placing their relationship, like other witch narratives, "in conversation with male [sexual] violence[ $\ldots$ and is pointedly evocative of] rape culture" (Wilson 2020). And, finally, the multivariate nature of wife abuse is evident in the way that He ultimately rids himself of She by burning her in a makeshift pyre, fully positioning himself as the modern-day extension of the witch's hammer and thus the historic persecution and gynocidal destruction of women. 
Like the biblical Eden, Antichrist's Eden is the site of original sin: She's original sin of being an unfit mother to Nic, whose parenting resulting first in his foot "deformity" and then in his death. Nic, in turn, is yet another symbolic sign: the witch's victim - stolen away into the woods by the film's witch, mangled in her malice and ultimately killed due to her malevolent nature.

Antichrist, however, of all the films that occupy this witchy moment alongside the initial push of the \#MeToo movement and the pull of post-9/11 America, is unique in that it is a largely transitory, even experimental film: not yet fully committed to the witch as a feminist icon, but still clearly sympathetic to longstanding traditions of misogyny and persecution that birthed her. It is actively transitioning out of the witch-as-villain paradigm and into the witch-as-hero (or, alternatively, witch-as-anti-hero) paradigm that has largely defined her function in 2010s popular culture. So while it leans more heavily into the tradition of horrific female-coding in cinema and elsewhere - particularly in its connections to the monstrous-feminine and the woman-ascastrator, concepts that other recent films, such as Hard Candy (2005) and Teeth (2007), were able to mine for female empowerment by way of evoking the myth of vagina dentata - it represents a breaking point from the most typical cinematic uses of the witch. While arguably just as monstrous as ever, she is equally a victim of male machinations to control her and undercut her autonomy (not only by way of her sexual autonomy, but her sexual, educational and motherly autonomies as well). For all the extremities of violence that is varyingly inflicted on and by her, She is nevertheless presented sympathetically, if not outright as one of Carol Clover's female victim-heroes, avenging the wrongs He has done to her (and, post-mortem, by way of her Edenic sisters). Antichrist, just like "the art-house films which began [the] conversation [surrounding the New French Extremity ...] began the horrific narratives" that 
experimented with the idea of a "theatre of cruelty" tormenting present-day witches (West 2016, 9). But as more and more witch films, with increasingly commercial ambitions, were released throughout the 2010s, "the latter half of the movement[ ...] continue[d] many of those same conversations but within a genre that has a die-hard fan base that is always hungry for that next scare" (West 2016, 9), especially in the scares that were necessarily informed by "the knowledge that the events depicted in the filmed is all somehow real and present within our Western societies may be the most frightening of all" (West 2016, 9), and therefore secure in the precept that "the movie is an expression of $[\ldots]$ truth, $[\ldots]$ experience, $[$ and $]$ the experiences of $[\ldots$ a]nyone who feels like the other” (Kohn 2017, $₫ 6$ ). This particular understanding of how a more art-oriented class of films can transition into a more commercial-oriented class of films after its continued, proven success, and how the competing motivations that guide films of those different orientations can produce more seemingly traditional and conservative narratives that more easily fall into the familiar tropes and genre pitfalls inherent to horror films, can go a long way in explaining the continued struggles that face "the witch as a figure $[\ldots]$ to $[\mathrm{be}]$ reclaim[ed because of] the precise reason [that] witches are primarily coded female" (Wilson 2020, 14). Thus, owing to decades of genre tradition, the witch continues to be essentially monstrous despite attempts to reframe "the kidnapping of babies, killing of innocents, and the hexing of the living [as being the result of] the oppressive contexts in which these witches reside rather than in any natural wickedness" (Wilson 2020, 14). So just as von Trier can draw power from the conventionality of the horror genre, so too are his attempts to reframe the witch constrained by those very same genre conventions.

And yet, Antichrist is also acknowledged "as a celebration of women's primal energies" (Badley 2010, 148) that posits that She (and ultimately the larger coven) "as not only monstrous, 
but also powerful, as able to kill the patriarchal beast" (Wilson 2020, 2) represented by He. In this fashion, She is less interested in "shoring up inequitable systems of power as [She is in] destabilizing them" (Wilson 2020, 11), although many of the films that follow are just as capable and just as interested in doing both. One might even say that Antichrist is a "queer" narrative, exploring She's queer way of experiencing time; how gendered trauma can rupture, destabilize and threaten heteronormative bliss to the extent of no future for the film's couple eclipsed by their death drive; or providing the "viewer... with a vision of queer dark ecology" from a queerer ecocritical perspective (Thomsen 2018, 123). From such perspectives, then, Antichrist can be understood not simply as a misogynist film, as many critics contend, but as a feministic observation of preexisting misogyny. Better understood as being "more misanthropic than misogynistic," the film scorns men's "heartlessness of rationality" that "patronizingly [...] sneers at $[\ldots]$ wom[e]n's research [and] bullies [women] into exposing [their] inner demons" (Brooks 2009, 99). In this way, Antichrist "sees the world in full masochistic flower [and] refuses to look

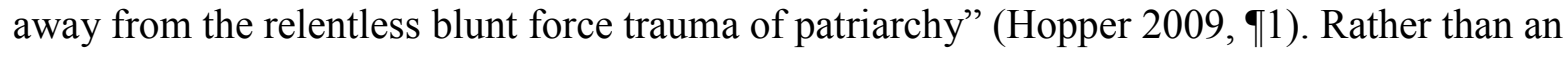
attack on women, it can be seen as a desperate clarion call against those who would do women harm.

Even though She is monstrous, She is monstrous purely as a consequence of the monstrous machinations of men (e.g., He repeatedly forcing her into the ill-fitting role of the ideal wife and mother, He forcing her off of her prescribed medications, He forcing her to return to Eden for his own regiment of therapy). Despite the myriad of pornographic sexual activity and striking violence interwoven throughout the film, "it is not designer violence, intended to appall and titillate in the same breath" (Brooks 2009, $\uparrow 10$ ) and thus resists adopting a male gaze with which to view this narrative of sexual violence and oppression. Just as the film itself does, von 
Trier has "always [identified with] the female character[s] in all of [his] films [because] the men tend to be stupid, to have theories about things and to destroy everything" (Aftab 2009, $\llbracket 11$ ). Or, put another way:

if Lars [von Trier] is horrified when he gazes into the vagina dentata of the real chthonic nature ([w]here 'chaos reigns'), at least he's not afraid to point his camera and shoot it. A true misogynist would just hide it in tight spandex and shoot it out of a wet t-shirt canon, . .. film[ing] it after the threat has been 'subdued,' i.e. objectified. ... Expressing cleareyed cognizance of masculine fear of women cures misogyny not creates it, that's the point of art and therapy. It's only when you need to prove you're not afraid, via sexual violence, winky objectification or smug condescension, that misogyny does its true damage (Badley 2010, 149).

By directly grappling with the nature of misogyny and the multifaceted ways in which it violently spills out into the world, Antichrist depicts the world as it exists, at least from von Trier's perspective: a hateful, repressive violation of the human spirit, where men and women do each other grievous harm (both physical and psychological) and the sins of past transgressions will always manifest in the world once more.

Emerging at the end of the 2000s, Lars von Trier's Antichrist bridges the narrative, thematic and aesthetic concerns of the cresting wave of "extreme" European cinema (typified by movies like Xavier Gens's Frontier(s) in France and Pedro Almodóvar's The Skin I Live In in Spain) with those of the emergent wave of recontextualized witch films in English-language cinema (typified by movies like Robert Eggers's The Witch and André Øvredal's The Autopsy of Jane Doe). By delving into the historical reality of how Christian doctrines were propagandistically coopted in order to legally and morally justify the persecution of witches, 
Antichrist delivers an unblinking portrait of the modern-day misogyny that directly descended from the European witch hunts. The film's emphasized importance on the presence of symbolic signs not only allows its audience to create more abstract associations between its pornographic subject matter (Badley 2010,147) and its high-art aesthetic, but also allows for them to experience a greater sense of abjection, what Julia Kristeva identifies as the duplicitous, subjective, corporeal horror that is, by nature, "immoral, sinister, scheming, and shady" (Kristeva $1982,4)$, to inform those associations. Although von Trier's decision to center the male perspective of He in the unfolding narrative resulted in the film's mixed success at evoking sympathy for the wronged She (as evidenced by its precarious standing as a "feminist" film in the critical discourse), Antichrist represents the genesis of a new portrayal of witchcraft in film: one that is increasingly decoupled from the traditional malevolence of the character and more closely aligned with her oppositional perspective. 


\section{CHAPTER III: ROBERT EGGERS'S ‘THE WITCH’ (2015)}

Owing perhaps to writer-director Robert Eggers's willingness to directly present an “aggressively accurate portrait of the [American colonies during the] time period [of the film's narrative] and the fears it contained," a considerable amount of the scholarship on The Witch

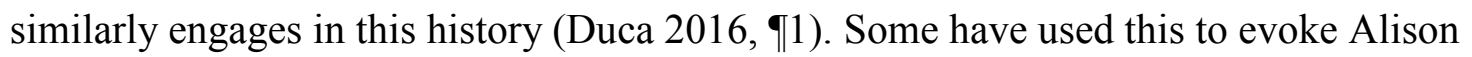
Landsberg's assertion that "historical films can [...] provide audiences with "prosthetic memories," in which a "person does not simply apprehend a historical narrative but takes on a more personal, deeply felt memory of a past event through which he or she did not live"" (Briefel $2019,4)$. Frequently praised for being the latest development of the on-screen image of the witch, and a decisively feminist one as well, The Witch is seen as emblematic of the recent variations on the witch archetype that have "reiterated social constructs surrounding gender and often reinforced witchcraft as a signifier of the femme fatale” (Carroll 2020, 14 ) or, alternatively, of the "final girl" (Borer and Lang 2017; Madden 2020, Stanley 2020). Adopting a queer lens, some scholars view the film as representative of the recent approach of films employing "camp [...] as a coping mechanism and an affective relation to and between objects[ that] can resonate powerfully with the recent turn in disability studies toward mad feminism, new materialism, and biopolitics [... thus] champion[ing] a reparative approach to paranoid sensibilities that takes seriously camp's status as a therapeutic gesture" (Barounis 2018, 213). Others, however, have taken the bleak historical realities of the Euro-American witch trials as proof that "the feminist vision [that the film] represents, while a critique of literal patriarchy, is not one of hope" because the "anachronistic conflation of witchcraft and feminist agency[ is] a construct [that is] at odds with the early modern world otherwise so faithfully portrayed in the film" (Zwissler 2018, 1). Even positive takes on the film often make note of how the "deeply ambiguous figure [of the 
witch] proves problematic for feminism and its project to subvert or otherwise destabilize misogynist symbols" (Buckley 2019, 22). Thus, while the general tenor of the literature surrounding The Witch is not only positive, but often names it the best film of its recent type, there is considerably less consensus concerning the degree to which it can be said to be successful in its feminist aims.

Having already left England in order to experience "the pure and faithful dispensation of the gospels and the kingdom of God," Calvinists William, Kate and their children Thomasin, Caleb, the twins Jonah and Mercy and baby Samuel are now banished from the colonial plantation in which they live as a consequence of the irreconcilable theological differences between them and their neighbors. They trek out into the surrounding wilderness, eventually raising a farm where they can continue to practice their puritanical faith in peace. Samuel, however, is taken by a witch from the nearby woods while in Thomasin's care. He is slit open, mashed into a paste and spread gorily onto the witch's naked body, granting the witch the newfound power of flight. And, in Samuel's absence, the heretofore outwardly functional bonds that tie the family together rapidly begin to collapse.

Desperate for money and unable to yield an unblighted harvest from the earth, father William secretly sells his wife's silver cup in order to buy traps to catch wild game, which nevertheless fail to yield any victims. Caleb lies to his mother about their father-son venture into the woods to check the empty traps in the in order to protect his father's secret divestment from the family's one treasure, saying instead that they were inspecting an apple tree he had previously found for fruit. Caleb is soon thereafter taken by the witch of the wood and returned naked and delirious and seemingly possessed by the devil. Twins Jonah and Mercy continuously make trouble for their older sister, Thomasin, and sing songs about their goat Black Phillip, who 
they claim speaks to them in a human voice. In order to get them to behave, Thomasin scares them by saying that she is in fact the witch of the wood, that she signed the devil's black book and brought him the missing baby Samuel at his command. Meanwhile, mother Kate blames Thomasin for both Samuel's abduction and the disappearance of her silver cup and convinces her husband to send Thomasin away to foster with another family as soon as possible. After briefly appearing to get better, Caleb dies. Jonah and Mercy accuse Thomasin of witchcraft, who in turn accuses them of conspiring with the devil in the guise of Black Phillip. Not knowing who to believe, William locks all three of them in the barn overnight and commits to moving back to the plantation in the morning, where a formal witch trial will suss out the truth of the matter.

That night, witches from the woods invade the barn, killing the twins. Kate envisions her cup returned to her and Caleb and infant Samuel alive again, but when she breastfeeds Samuel, he is instead revealed to be a crow that is pecking hungrily at her breast. When William wakes to find two of the three remaining children dead and the barn scorched and blown apart, Black Phillip rams into him, goring him with its horns and killing him. Kate, freshly accusing Thomasin of witchcraft, attacks her daughter, only for Thomasin to kill her after a protracted fight between them. In shock, Thomasin goes inside and falls asleep, waking at night and bidding Black Phillip to speak to her as he did to the twins. Appearing now in the guise of a man, he offers her power, luxury and freedom ("Wouldst thou like the taste of butter? A pretty dress? Wouldst thou like to live deliciously?") in exchange for signing his book. She does so and, naked, goes into the woods to find a witch's sabbath. Upon completing their ritual, the sisters of the coven ascend into the night sky and then so too does Thomasin.

Set sixty years prior to the infamous Salem Witch trials, The Witch enjoyed a considerably more uniform reception compared to Antichrist. Although some lamented that the 
film "keeps the jump scares to a minimum and requires a fair amount of patience before the body count starts rising” (Stanley 2020, $\mid 3$ ), it was widely praised for being “a high-minded feminist liberation tale" (Subissati and West 2018) due as much to how director Robert Eggers depicted "the gender of [its] oppressed protagonist[ as it is to] the historically gendered implications of witchcraft[,] the witch's reappropriation as a feminist symbol[ ...] and because the narrative involves 80 minutes of patriarchal dysfunction followed by an ecstatic post-patriarchal conclusion” (Halperin 2016, \5). Deeply researched and based on a synthesis of firsthand accounts of colonial witchcraft, The Witch, like director Jordan Peele would later insist of Get Out (2017), "is a tale that seems part documentary, part scary movie" (Wilson 2020, 169), combining primary source narratives, period dialog (some lifted directly from diary entries, trial transcripts and other firsthand accounts), natural lighting and historically accurate beliefs in witchcraft. As a result, "witchery is put in conversation with religious doctrine and early American colonialism" in ways that popular depictions of that practice rarely do, and, consequently it "depict[s] each as having the capacity to do great harm" (Wilson 2020, 169). Robert Eggers himself proclaimed that "feminism is bursting out of all the primary source material, it burst out of the script and it bursts off the screen" (Halperin 2016, $\uparrow 5$ ), a sentiment echoed by national spokesperson for the Satanic Temple, Jex Blackmore, who "declared that [The Witch] 'departs from the [more popular] victim narrative' of witchcraft and stands as a 'declaration of feminine independence"” (Sollèe 2017, 47).

Although it nevertheless holds true that the "documentation of witch-hunts comes from the persecutors, not the accused[ $\ldots$ and that] there are no primary sources penned by women (let al.one women accused of witchcraft)" (Wilson 2020, 134), authors, artists and activists have been subverting sacrosanct theology and reinterpreting biblical stories and witch narratives 
through feminist lenses (or at least with a great deal more sympathy for its female characters than was traditionally afforded to them) for hundreds of years. Although John Milton's stated intention in writing Paradise Lost (1667) was to "'justify the ways of God to men,' and not at all to glorify Lucifer" (Faxneld 2017, 75), his ambiguous portrayal of both his chief antagonist (Satan) and his unwitting disciple (Eve) left much room for counter-authorial interpretations of his work, which oftentimes framed both Lucifer and Eve as counter-cultural heroes who champion scientific advancement, individualism and an intrinsic authority over one's own trajectory in life. Ada Langworthy Collier's epic poem Lilith: The Legend of the First Woman (1885), like John Gardner's monster advocacy in Grendel (1971) and Gregory Maguire's revisionist Wizard of $\mathrm{Oz}$ retelling Wicked (1995), retells the events of Genesis from the perspective of its other antagonist, Lilith, who when confronted with the extent of Adam's chauvinism, asks "must I, my Adam, mutely follow thee? / Run at thy bidding, crouch beside thy knee? / Lift up (when thou dost bid me) timid eyes? / Not so will Lilith dwell in Paradise" (Faxneld 2017, 62-63). Jules Michelet's La Sorcière (1862), whose stated intent was to explore real-world witchcraft, starting "not from the devil[ ...] but from a living reality, the Sorceress, a warm, breathing reality, rich in results and possibilities" (Michelet 1863, 326), acknowledges that "the devil allows for certain things that we have taken away from women" (Subissati and West 2018) and is ultimately a deeply sympathetic account of historic witchcraft that is ideologically opposed to texts like the Malleus Maleficarum. Benjamin Christensen's film Häxan (1922), which directly draws on the dark legacy of the Malleus Maleficarum, posits that accused witches were actually suffering from a variety of mental illnesses, such as somnambulism and kleptomania, rather than performing malicious deeds at the behest of the devil, and were subsequently the victims of religious hysteria and persecution. Also notable is the fact that 
"Glinda is one of the first explicitly 'good' witches to be depicted in popular media," and certainly the most recognizable, “first in L. Frank Baum's 1900 book, The Wonderful Wizard of $\mathrm{Oz}$, and later in the 1939 MGM film adaptation, The Wizard of Oz" (Sollèe 2017, 48).

Thus, Robert Eggers and "The Witch largely let history speak for itself $[\ldots]$ and $[\ldots]$ reif[y] the witch as an evergreen symbol of feminist freedom" by extension (Sollèe 2017, 116). Indeed, one of the starkest departures between Antichrist and The Witch is the increased prevalence and narrative importance of the iconic sign of the witch. Although barely present in von Trier's film (and, even then, only at the very end), the various witches of Eggers's film are frequent and active participants in the destruction of the pious and patriarchal family unit. It is the witch that kidnaps, kills and converts Samuel into the necessary material components of her sorcery, thus exposing the inherent fragility and toxicity of the family (and, by extension, the patriarchal order under which they live). It is the witch that lures Caleb deeper into the woods that strips, bewitches and then returns him - which further plunges the family into existential chaos. It is the witches that invade the farm at night, killing Jonah and Mercy and framing Thomasin for the crime, launching her headlong into a conflict that ends in matricide. It is the witches that Thomasin joins in the woods, performing their sabbath and ascending viciously into the heavens. Thus it is the witch, Thomasin, that relays the events of the film to the audience and comes into her own as a woman before them. No longer posturing like the "nudes in Renaissance art [who] are portrayed as sexual objects to be viewed by a presumed male spectator outside the painting" and who preen and pose for the male gaze of "a stranger [who still has] his clothes [...] on" and for whom "the figures have assumed their nudity" (Sollèe 2017, 64), witches are now both the subject moving within the narrative and the lens through which their own story is viewed. 
Recent scholarship on the subject teaches us that "the witch is reviled, as many texts suggest, because she flouts societal norms, because she threatens male control of family and industry, [and] because she claims her body as her own" (Wilson 2020,134), all of which are prevalently depicted in Eggers's iconic sorceresses. Over time, a certain monstrous image of witchcraft has calcified in the Euro-American imagination, much like obscenity, most people seem to "know it when [they] see it" (Stewart 1964), whether it is a Greek goddess (e.g., Hecate), a Jewish demoness (e.g., Lilith), a Slavic hag (e.g., Baba Yaga), a Japanese crone (e.g., Yamauba), a French martyr (e.g., Joan of Arc), a Voodoo priestess (e.g., Marie Laveau), a lusty vamp (e.g., Elvira) or a Pakistani teen (e.g., Malala Yousafzai) (Sollèe 2017, 14-15). She is a faceless shapeshifter who can slip between the guises of a dazzling enchantress (e.g., Circe), a stoic stateswoman (Morgan le Fay) and a grim specter of stolen beauty (e.g., Kuchisake-onna). And, appropriately, a similar range in iconographic representations populate The Witch.

The first witch that the film presents is the red-caped 'witch of the wood' who, like a supernatural polymorph, is seemingly able to "[transform] from vixen to hag, healer to hellion, adversary to advocate based on who seeks her" (Sollèe 2017, 14). The version that we most clearly see in the film - especially as encountered by the coming-of-age Caleb - is that of a voluptuous young woman. She is fitted in a tight corset, full breasts overflowing from the fabric, waist-length raven-black hair spilling over in a rivulet of wavy curls, plump lips pouting sultrily, curvaceous frame loosely wrapped in a scarlet cloak (itself a sign replete with sexual symbolism, not just of historical and biblical prostitution, but indexically signifying women in general and witches in particular as menstrual monsters). Hearkening back to the witch as an inherently sexual (as opposed to merely sexed) creature - who, like the prototypical Lilith, is constructed as the bride of Satan, the mother of demons and the commander of the devil's legions (Faxneld 
2017, 55-61) - the red-caped 'witch of the wood' bears all the classical trappings of a sexually vivacious movie monster and knowingly plays with "the 'invisible' ideological effects" (Hole et al. 2017, 2) that inform the male gaze. At the same time, the witch actively uses her comely appearance, which conforms to a White normative standard of beauty, to draw in vulnerable young men like Caleb, putting them at ease before junking them for parts. Understanding that the female is traditionally "coded for strong visual and erotic impact so that they can be said to connote to-be-looked-at-ness" (Mulvey 1975, 716), the film both consciously and literally employs the male gaze: approaching the trope of the beautiful/hag witch head-on in a nearlyminute-long, drawn-out, point-of-view shot from Caleb's perspective. He watches as the witch saunters out from the darkened confines of her pointed cabin, pulls up her skirt at the knee, teasingly leans down so as to center her chest in the frame, slyly smiles as he nears, strokes the side of his cheek and kisses him passionately on the mouth before clutching the back of his head with her gnarled, taloned hand and bewitching him off-screen. Additionally, the low wailing of music, a light cacophony of women chanting that grows louder and more discordant as it cuts between the alluring witch and the visibly recoiling child whose face has warped into a mask of unmitigated terror, seems to enchant and compel the witch's victim despite his better judgment, evoking "the long-standing Western suspicions of music that conflate[s] its supposed[ly] abstract and non-referential nature and lack of fixed meanings with fears of (feminine) disorder, and emotional and sexual excess" (Vernon 48). Thus, the film situates this witch "as not only monstrous, but also powerful" (Wilson 2020, 2), capable of both great harm to the patriarchal order around her and also as an active, capable and actualized subject within the narrative in ways that have not classically been afforded to women in the medium. 
The other witches of the coven provide a great range of differing appearances relative to the singular witch of the wood. Some, especially those seen in the coven in the final scene, appear as ultimately ordinary: neither sexualized (even in their nakedness) nor grotesque. The combination of dim fire-and-moonlight, their shifting dance around these light sources, the medium and long shots that capture their presence and the increased narrative weight on Thomasin's (non-sexual) gaze and their ascending flight offers a stark contrast to the manner in which Caleb became entranced and seduced by the red-caped witch of the wood. Only in the assault on the farm - when a haggard old witch attacks Thomasin and the twins - do we see a classically monstrous witch (naked, twisted and seemingly feral), and even that can be read as an alternate form of the witch of the wood (given that her had that clutched Caleb's skull belied her otherwise comely appearance).

The film's final witch, of course, is Thomasin. Although initially presented as an ideal of puritanical virtue - hard-working, obedient, humble, loving, pious and repentant - the thin veneer of her patriarchally constructed femininity cracks and eventually shatters over the course of the narrative. After the prologue-esque segments that depict the family's banishment and exodus from the plantation for their moral offenses - which, in keeping with Max Weber, results "economically, [in] loss of credit and, socially, [in] being declassed" (Weber 1946, 306) - we are introduced to the family's new status-quo on the farm via Thomasin's earnest prayer. Intercut with her obediently doing her chores, helping her parents, working in the field, and eventually interrupted by her mother telling her to watch baby Samuel (which, true to the expectations of her sex, she does exuberantly), she humbly prays:

O most merciful father: I here confess I have lived in sin. I have been idle of my work, disobedient of mine parents, neglectful of my prayer. I have, in secret, played upon thy 
sabbath and broken every one of thy commandments in thought... followed the desires of my own will, and not the holy Spirit. I know I deserve all shame and misery in this life, and everlasting hell-fire. But I beg thee, for the sake of thy Son, forgive me. Show me mercy. Show me thy light. I thank thee that thou hast defended me this night, and brought me safe unto this day. These and all other graces, I beg at thy hands in that prayer which Christ himself hath taught me.

In so doing, Thomasin conforms to the expectations of her age (deference to her parents), her gender (childrearing) and her faith (earnest prayer, which includes both the confession of and repentance for her past wrongs).

Indeed, over the course of the film, Thomasin is the only productive worker among her family. After Samuel's disappearance, Kate is emotionally distraught, sleepless and absorbed only in her prayers. William is unable to yield a viable crop from the earth, as all the corn he harvests is stricken with ergotism, and his attempts at catching wild game likewise prove to be unsuccessful. Jonah and Mercy idly sing and play all day, to Thomasin's eternal annoyance, getting in the way of the farm work and heaping praise onto the goat Black Phillip. Caleb is earnest in his attempts to productively labor, but his trip into the woods with his father is fruitless and his later trip with Thomasin, although it does result in some reclaimed game, is ultimately marred by his abduction by the witch of the wood. Meanwhile, Thomasin does all that is asked of her and constantly tries to win back her mother's lost affection. In fact, it was her volunteering to bed the goats down in the storm despite her mother's indifference which lead to Caleb's discovery back at the farm.

Despite her earnest adherence to their theologically draconian and patriarchally restrictive way of life, however, her "womanhood is the target of paranoia and the subject of shame" 
(Stanley 2020, \5). When tending to her chores throughout the film, various natural disruptions (not unlike the presence of the three beggars in Antichrist) occur throughout the farm: not just the mysterious disappearance of baby Samuel, but also the goat spraying blood when Thomasin milks it and a dropped egg reveals a dead, bloodied chick. In fact, even by conforming to the various patriarchal expectations placed on her by her faith and family, Thomasin slyly, if unknowingly, retraces behaviors commonly associated with witches. Like the ur-witch Lilith, Thomasin appears to be varyingly responsible (least in the eyes of her parents) for the abduction of an infant (Samuel) and the sickening of a child (Caleb) and the death of innocents (Jonah and Mercy). And, "much like the bloodied chick" or the bloody spray from the goat, "the eviscerated dog," who was killed by the witch, "evokes the family itself, which is being ripped apart and gutted by the fear their religion fosters and the barren environment exacerbates" (Wilson 2020, 171). In other words, the oppressive patriarchal system that the entire family finds itself in is itself directly responsible for the antithetical and ruinous arcs that the characters take throughout the film's narrative.

So, counter to her constant attempts at doing good, Thomasin is the one who ultimately loses her baby brother to the witch of the wood, torments the twins, kills her mother, converses with Black Phillip (who symbolically signifies the devil in his beast form), conscripts with the devil by signing his black book, ventures naked into the forest and takes up with a coven of witches during their black sabbath. Not only does she "[turn her] back on [her] church and [start] over anew, [she commits to] burning it down and starting over actually anew" (Subissati and West 2018). Through her narrative, The Witch serves as "a condemnation and a rejection of a religion [and] a way of life that sought to not only oppress women but, as we see through this film, oppress everyone" (Subissati and West 2018). But while the different family members all 
"have different ages, different wants, different desires and they are all so trapped" (Subissati and West 2018) by the narrowly drawn confines of patriarchal Christianity, none suffer more so than Thomasin.

It is, in part, for these reasons that many have begun to associate, either explicitly or implicitly, Thomasin with the horror archetype of the final girl (Borer and Lang 2017; Stanley 2020). Introduced in Carol Creed's seminal Men, Women, and Chainsaws as the female victimhero, the final girl is an archetype that "combine[s] the functions of suffering victim and avenging hero" (Clover 1992, 17) into a single character, one that exists simultaneously as the film's "monster [...] victim [and] hero" (Clover 1992, 4). Although the final girl is really only a small aspect of Clover's larger work on the female victim-hero, one which specifically applies to slasher films, the two concepts have, in the decades since their introduction, become effectively synonymous in both the popular and scholarly discourse of the horror genre and has varyingly become associated with androgynous slasher heroines (e.g., Laurie Strode in Halloween, 1978), fiery rape-revenge murderesses (e.g., Jennifer Hills in I Spit on Your Grave, 1978) and preternaturally monstrous females (e.g., Carrie White in Carrie).

As conceived of by Clover, however, the final girl is the feminine reconstituted within the masculine. She "is boyish [... and] not fully feminine" (Clover 1992, 40), characteristics that become more pronounced as the film progresses and she becomes phallicized through performing violent, male-coded actions and arming herself with phallic melee weapons. Unique among the film's other characters, she is chaste, sober, “intelligent, watchful, levelheaded; the first character to sense something amiss and the only one to deduce from the accumulating evidence the pattern and the extent of the threat" (Clover 1992, 44). It is she who, horrified, "stumbles on the corpses of her friends [and who is] momentar[ily] paraly[zed] in the face of 
death" (Clover 1992, 44). She is the one who "tentatively[, but] aggressively[ ...] looks for the killer, even tracking him to his forest hut or his underground labyrinth, and then [looks] at him," which will either result in a punishment or a battle for her exercising her "active investigating gaze" (Clover 1992, 48). By the film's denouement, "she stops screaming, faces the killer, and reaches for the knife [to violently address] the monster on his own terms" (Clover 1992, 48). Thus, "when she drowns the killer, we are triumphant[, because] she is by any measure the $[\ldots]$ film's hero" (Clover 1992, 46). And because "abject terror," like abject horror, "is gendered feminine $[\ldots]$ prolonged struggles [ensue between a film's hero and monster], in which the victim has time to contemplate her imminent destruction" (Clover 1992, 51). Or, as the film Cabin in the Woods (2012) glibly surmised, "the virgin's death is optional, as long as it's last. [The m] ain thing is that she, you know, suffers" (Goddard 2012), either psychologically (by witnessing the gruesome death of her friends) or physically. Indeed, the final girl simultaneously functions as both a martyr and a bloody-knuckled fighter.

More recent scholars, like Anthony Hayt, have noted that recent slasher films (which, notably, are comprised of many remakes of the films that Clover discusses in the original slasher cycle) have featured numerous ideological shifts between the genre's transgressive forebears and their more conservative retreads, which now focus on "way[s] of understanding and processing the trauma of the [September 11] terrorist attacks that forever changed the cultural landscape of America, and of the world" (Hayt 2017, 131). And while these films have "allow[ed] us to map our social fears concerning gender, foreign policy, and domestic anxieties onto the bodies of individuals" (Hayt 2017, 135), they have done so by reconstructing a version of "the masculinecoded women as seen in the character of the Final Girl [as ...] heroes for whom we can [no longer] cheer" (Hayt 2017, 133). Rather, as a function of "post-feminist social anxieties [that] 
obsess over concerns that men have gone soft, and to help allay this fear [... recent films] place men in the position of the hero" that would ordinarily have been reserved for the final girl, thus "reasserting a tenuous hold on the ever-precarious dominance of white masculinity" (Hayt 2017, 133) and, in so doing, bringing "all forms of femininity [...] back in line with a more traditional standard" (Hayt 2017, 135). Horror in Post-9/11 American cinema became bleaker, rousing nationalism and a retreat to gender traditionalism wherein the hope of any final girl defeating the monster became deflated.

Consequently, these Post-9/11 horror films have largely "focus[ed] on [the] ways in which men attempt to reclaim a sense of power and superiority over their situations while repositioning women [...] into traditional, family-oriented roles" (Hayt 2017, 135). This patriarchal gender repositioning is typically coupled with "a heterosexual pairing [between the male and female leads] (in contrast to a lone woman standing in defiance to patriarchal heterosexuality)" (Hayt 2017, 135). In addition, even female characters who are presented as strong, capable or independent are invariably "undercut by constant aesthetic choices that highlight her sexuality" (Hayt 2017, 135), such as "pair[ing] down [the female lead's wardrobe] to nothing but skin-tight jeans and a midriff-bearing undershirt, while lighting is constantly used to highlight her stomach and breasts" (Hayt 2017, 135). Playing into the most conservative readings of the male gaze, these recent slasher films "sexualiz[e] the violence done to [women] in a way that was specifically avoided in the original film” (Hayt 2017, 136). Thus, film "feminism" underwent a "remake" at the same time these classic films were reimagined for the 2000s, wherein regressive gender roles normalized sexual violence or depicted male companions or sexual confidence as a woman's pathway to power. 
Although "the feminism of the 1970s did not cause the final girl per se [...] looking back through the lens of the recent remakes" like The Texas Chainsaw Massacre (2003), Friday the $13^{\text {th }}$ (2009), Halloween (2009) and A Nightmare on Elm Street (2010), "it is clear that these strong female leads were [once] influenced by a social world in which feminism was a prominent political movement" (Hayt 2017, 135). It is notable, then, how the original socio-political context that informed the development of the final girl so closely mirrors the socio-political context of \#MeToo (especially since 2017) that has given rise to vengeful, subversive and explicitly feminist witch narratives in film. The recent influx of witch-centered horror movies emerged in a post-9/11 "neo-conservative, post-feminist social milieu in which powerful female leads [were] considered unneeded and/or unwanted" (Hayt 2017, 135), in which traditional examples of these final girls were being actively erased from the genre and during a time in which concerns over male-perpetrated sexual violence was emerging as a dominant social and safety issue in the larger public discourse. And among the films that have emerged in the current witchcraft cycle, Robert Eggers's The Witch (2015), and Thomasin as its central protagonist, has received particular notoriety for continuing the earlier tradition of the final girl (Borer and Lang 2017; Madden 2020, Stanley 2020). Yet, in the \#MeToo era reactions to gender violence, it also seems relevant to consider how the presence of white privilege alters the lens through which we view The Witch. The film conveys the coming-of-age story about a white child who is centered as the film's final girl, who confronts her oppressors, who conscripts with the devil guised in the form of a man of color and who is ultimately the only one left alive to tell the story of what happened (even the film's subtitle, A New England Folk Tale, suggests something less than factual about the version of events we are presented with). All of these necessitate a deeper discussion, one 
which is beyond the scope of this thesis, in order to tease out the parallels to how the media coopted the \#MeToo movement from Black women and made it about white women in Hollywood.

Although The Witch could hardly be misconstrued as a slasher film, Thomasin nevertheless meets the criteria for Clover's female victim-hero over the course of the film. Like more classically conceived final girls, Thomasin "is boyish [... and] not fully feminine" (Clover 1992, 40), evidenced even in her name, a trait shared by fellow classic final girls like "Stevie, Marti, Terry, Laurie, Stretch, Will, Joey, [and] Max" (Clover 1992, 40). She is, like them, chaste, sober, "intelligent, watchful, levelheaded; the first character to sense something amiss [when Samuel disappeared] and the only one to deduce from the accumulating evidence the pattern and the extent of the threat [when she confronted Black Phillip and conscripted with him as a witch]" (Clover 1992, 44). Over the course of the film, which "is so deeply about the powerless" (Subissati and West 2018), we watch Thomasin go from a meek and pious girl to someone who ventures boldly into the forest with her brother, who calls her father out on his innumerable failings as head of household and who fights, to the death, her own mother with, appropriately for a final girl, a phallic melee weapon (in this case, a cleaver). And by the denouement, when she has suffered, endured and, ultimately, triumphed. Drenched in her mother's blood, standing amidst the carnage wrought upon her family and sluffing off her shift, she gains agency over her own life and brokered that agency into power. She is the last one standing, and now able to reap all the rewards of what that entails.

Writer-director Robert Eggers, however, goes out of his way to play with one of the most central aspect of the final girl archetype within The Witch's narrative: that is, the character's virginity or apparent sexlessness. Although "the white female child has a historical association in Western culture with a state of being sexless, the physiological capability for conception has 
paradoxically signified the female body as corruptible" (Willis 2008, 242). Therefore, young white femininity has historically been conceptualized as the same kind of ideological construct that mother Kate attributes to daughter Thomasin, one that "the Devil is in $[\ldots]$ and hath had $[\ldots$ that is $]$ smeared of his $\sin [\ldots$ and possessed by the $]$ proud slut $[\ldots$ who] bewitch[ed Caleb's] eye as any whore." This last comment in particular recalls the numerous fleeting moments glimpsed throughout the film where Caleb be seen leering curiously at Thomasin's breasts and Thomasin's outwardly physical affections for her brother Caleb. Rather than the androgyny expressed by other final girls, in which the female character would phallicize herself with a long-bladed weapon, Thomasin's story ends with her stripping naked: unquestionably displaying her young, nubile body as conforming to the White normative standard of beauty. When Thomasin calls out to Black Phillip in the barn after committing matricide, he appears to her in the form of a man: specifically a man of color, who Eggers describes as "a beautiful bearded man with a dark complexion" in the film's script (Wilson 2020, 173). In so doing, the film perpetuates a longrunning, deeply problematic and heavily raced tradition in film - horror film in particular - that traces back to the notoriously racist film The Birth of a Nation (1915), which was "the movie that really solidifie[d] that there's this odd Black lust on the behalf of Black men towards White women. You see it time and time again throughout the horror genre, from King Kong [in 1933] to Candyman [in 1992]" (Burgin 2019). Although seeming to stem more from Eggers's failing to "interrogate [the] racialized underpinnings of [The Witch's] horror nearly as well as it engages with gender, religious practice, and the nuclear family (Wilson 2020,173), the resulting scene, in which a domineering Black man encircles a naked, tremulous White woman, darkly asking her "Wouldst thou like the taste of butter? A pretty dress? Wouldst thou like to live deliciously," Eggers recapitulates the image of a "black boogeyman [lustily] in pursuit of [a] blonde White 
woman" (Burgin 2019). This is subsequently followed by Thomasin nakedly joining the other witches during their sabbath, during which the naked women taken flight and Thomasin's face is jubilant with unbridled ecstasy. The witches of the wood, then - which, indeed, now includes Thomasin - are thus constructed as the buxom temptresses that mother Kate feared earlier, a clear departure from the tradition of the final girl to which Thomasin otherwise belongs.

These iconically signified witches in the film, further, are indexically constructed with a number of other signs and proxies that, in effect, offer visual evidence of their presence. The rabbit that stalks William and Caleb in the woods with seemingly preternatural intelligence and the crow that feasts on the hallucinating Kate's breast are clearly made to be witch's familiars that varyingly spy on, guide and torment the witch's victims on her behalf. And, in keeping with a socio-historical understanding of these bestial servants, the crow pecking at Kate's breast when she believes she is feeding her young child aligns with a witch suckling her familiar from an extra teat (Sollèe 2017, 37). The devil's black book, which witches would sign in exchange for their sorcerous powers, makes several appearances throughout the film, from the tales of Jonah and Mercy to the illusory Caleb asking his mother to sign it to Black Phillip "guid[ing Thomasin's] hand" across it in enlisting with his coven. Additionally, the witch's sabbath and the missing children (which, starting with Lilith, were referred victims of witches) help construct the witches as such.

One of the most fascinating and frequently discussed aspects of the film is the various flights taken by the witches of the coven throughout the narrative; this is first done after the redcaped witch of the wood washes in Samuel's viscera and is later accomplished by the entire coven after they dance at the witch's sabbath. There is great indexical significance tying witches to flight. However, this supernatural feat has traditionally been accomplished via an enchanted 
broomstick, a deliberate inversion of "proper" domesticized femininity and another instance of the witch evoking "a 'hurlyburly' with its suggestion of misrule and topsyturveydom" (Clark 1980, 129). Like the sorcery performed by Samantha Stephens in the television series Bewitched (1964-1972), this appropriation of "appropriate" female iconography and domestic servitude for magical ends "thus functions as an apt metaphor for feminism - knowledge with the potential for personal empowerment and transformation that is feared and forbidden by the patriarchs" (Sollèe 2017, 113). By this tradition, the radicalized femininity of the witch is constructed in direct opposition to so-called "proper" femininity by transforming the tools of female subservience into weapons against male dominance. While oppositional, it still exists as an easily delineated offshoot of traditional Western womanhood.

In The Witch, however, no such domestic apparatus is necessary. Through the witches' own cunning, craft and satanic connections, they are able to propel themselves into the air of their own accord. They are liberated not just from the laws of men, but the laws of God and gravity as well. In a darkly celebratory inversion of centuries of Christian art, mythology and theological constructs like the Great Chain of Being - with God at the head of creation looking down on humanity and, beneath them, on Satan housed in Hell - the film ends with clearly constructed witches, "but they're also ascending, not descending. They're not hopping on their broomsticks and flying around everywhere. It is this kind of gorgeously shot ascension" (Subissati and West 2018) that "overturns Christian perceptions of hell/damnation" (Wilson 2020,173 ) and counters "even the idea that you have to die to ascend" (Subissati and West 2018). These women are living "deliciously" on Earth, not endlessly toiling in fields and farms and families and wrestling with the Christian anxiety of their unknowable, predestined place in the afterlife. These female "monsters negate the charge of the general will much as [when] 
Frankenstein's creature reject[s] the charge of his creator" (Wilson 2020, 11). And although "the price for such willfulness is often rejection [...] or annihilation" (Wilson 2020, 11), like Thomasin, these women:

made a choice. And it's a choice that [they] never would have thought that [they would] make, that [their] famil[ies] would never even conceive of making, but [their families] hadn't suffered the way [they] did. [Their] ordeal was unique and it was [theirs] and [they] took it and took it and took it, [were] persecuted and persecuted, and then [they] chose to live deliciously (Subissati and West 2018).

Indeed, the goat Black Phillip's seductive question, "wouldst thou like to live deliciously," is a pleasurable, satanic, counterhegemonic and arguably feminist subversion of the Christian eschewment of earthly pleasures in favor of deferred gratification in Heaven.

Although not as symbolically invested as Antichrist, The Witch does prominently feature three symbolic signs of central import to the narrative. The first is Black Phillip, the family's contentious goat, whose centrality to the supernatural goings-on, transformations between animal and human forms, gift of speech, associations with the coven of witches and the black book they sign and Thomasin's concluding deference to him (darkly mirroring her opening prayer), all serve to construct him not as another familiar, but as the devil himself.

The second bewitching sign is the bloody apple that Caleb chokes up and spits out while bewitched. While a fitting visualization for Caleb literally choking on his lies from earlier (when he deceived his mother into thinking that he and his father were out picking apples instead of them actually checking the animal traps that his father had purchased from the sale of her stolen silver cup), its true significance is in embodying original sin: the eating of the forbidden fruit that resulted in Adam and Eve's expulsion from Eden. Indeed, the fact that the film itself opens with 
the family being expelled from the plantation where they live for their religious transgressions and being forced into the wilderness to suffer in ways strongly reminiscent of the biblical couple reinforces this association. Like Eve, Kate was forced to be ruled over by her husband, whose multitudinous inequities brought ruin to their family (e.g., his inability to grow or catch food, his inability to keep his children safe, his theft of her silver cup).

William, meanwhile, suffers even more directly the punishments of Adam, for whom God decreed:

Cursed is the ground because of you; through painful toil you will eat food from it all the days of your life. It will produce thorns and thistles for you, and you will eat the plants of the field. By the sweat of your brow you will eat your food until you return to the ground, since from it you were taken; for dust you are and to dust you will return. (Genesis 3:16$3: 19)$.

This, in turn, leads to the third symbolic sign of the film: ergotism. The rot and blight that has ruined the family's crops is not merely some unfortunate happenstance, but a specific malady that has specific meanings within the history of witch persecution, particularly in the United States. Occurring periodically throughout Europe and the Pre-Salem colonies, ergot is a "fungus [that] may dangerously [and intermittently] parasitize" grains, such as the family's corn, in "warm, damp, rainy springs and summers," such as the family experienced in the woods, and has "has deleterious effects on cattle as well as on humans" (Caporael 1976, 23), which can be seen with Caleb's bewitchment, Kate's hallucinations, the twins (and, later, Thomasin) conversing with Black Phillip and the general breakdown of the rest of the family. Long-term exposure to Ergot, known as ergotism, is a condition that "children and pregnant women are most likely to be affected by" (Caporael 1976, 23) and could result in symptoms that included "crawling 
sensations in the skin, tingling in the fingers, vertigo, tinnitus aurium, headaches, disturbances in sensation, hallucination, painful muscular contractions leading to epileptiform convulsions, vomiting $[\ldots]$ diarrhea $[\ldots$ and $]$ mental disturbances such as mania, melancholia, psychosis, and delirium" (Caporael 1976, 23), most of which are on display within the family (most notably by Kate and Caleb) and would go a long way in secularly explaining the supernaturally charged narrative of the film. Notably, "all of these symptoms are alluded to in the Salem witchcraft records" (Caporael 1976, 23) and has, for decades, led to speculation of ergot-tainted rye as a cause of the hysteria surrounding the Salem witch trials. The symbolic relationship between ergot (and ergotism) and witchcraft is thus firmly established and used, in the film, as something that is both predictive and representative of the family's own hysteria regarding and persecutorial actions against perceived witchcraft.

More so than any other film produced in this current cycle of witch cinema, The Witch directly contends with the long and complex history of witchcraft, gendered oppression and female persecution. Whereas Lar von Trier used Antichrist to shock its audience with the extremities of misogyny and gender-directed violence, Robert Eggers uses The Witch to examine the complex matrices of patriarchal oppression and the various ways that they have historically manifested themselves within Western, specifically American, society. And in The Witch's subversively ascendant ending, Eggers illustrates a potential path forward that serves as a radical departure from the ways in which that society through the present.

Arriving years after Antichrist's then-novel treatment of the witch She and in a more decidedly American context, Roger Eggers's The Witch has proven to be the most successfully transformative treatment of the cinematic witch to date. By fully centering its female protagonist within its narrative, strategically adopting conventions of disparate film sub-genres and 
emphasizing the importance of iconic signs, The Witch both clearly and directly addresses the ways in which patriarchal religious ideologies were weaponized against women historically and maps out a radical path forward for women outside of those sacrosanct epistemologies. Although the idea of witches and witchcraft have calcified in Western culture over centuries of rigid depictions in religion and art, coalescing into a particularly powerful and enduring monstrous legacy, Eggers's sympathetic portrayal of the witch continues to decouple the character from its traditional malevolence in art while also more closely aligning the witch in film with the more successful attempts at rehabilitating the character in other mediums. 


\section{CHAPTER IV: ANDRÉ ØVREDAL’S ‘THE AUTOPSY OF JANE DOE’ (2016)}

Unlike the previous two films examined in this thesis, relatively little scholarship has been written on The Autopsy of Jane Doe. Perhaps due to it being the most recently released of the three films (Antichrist premiered at the Cannes Film Festival in 2009, while The Witch premiered at the Sundance Film Festival in 2015), or perhaps due to its comparatively commercial aspirations (it employs the most recognizably horrific aesthetics and features the most discernably mainstream narrative of the three films), it has thus far not made for an attractive subject for scholarly analysis. What does exist, however, comments on how "morguebased films hold up death for our deeper contemplation (and our pleasure)" (Kern 2017, 20), connecting it to both the dreamlike Phantasm (1979) and the stark The Corpse of Anna Fritz (2015). More recent writing connects André Øvredal's film to “[t]he term wound culture [which] implies that modern audiences have become obsessed not just with the figure of the dead body, but with the idea of seeing within it" (Harris 2020, 160). Others note how the film "represents the current status of female representation while simultaneously providing passive commentary on progression being held in stasis “ (Salazar 2018, 1 ). Thus, the film has mostly been filtered through the lenses of sociology of death, dying, the body and white "wounded attachments" (Brown 1995) of public sexual violence feminisms" (Phipps 2019, 1), with comparatively little focus on the direct associations with and history of witchcraft itself. Amusingly, this means that its narrative status as a "secret witch film" (Subissati and West 2018) is mostly maintained by the very scholarship that grapples with it.

Within a seemingly idyllic suburban home, police investigate a grisly crime scene. With no signs of forcible entry - and numerous clues suggesting that the inhabitants were desperately trying to break out of the home when they were brutally murdered - the only substantive lead 
that they have is the half-buried and apparently untouched body of an unidentified woman (Jane Doe). In order to determine her cause of death, the police transfer the body to the father-son coroner team of Tommy and Austin Tilden. Although Austin has plans with his girlfriend Emma and secretly does not want to continue in the family business following his mother's suicide, he agrees to stay and help his father with this last-minute case, promising Emma that they will meet up later that evening.

Although they start their examination in the clear and cloudless light of day, as the autopsy stretches on, the radio informs them of the increasingly stormy weather outside, an unnerving hymnal, "Open Up Your Heart (And Let the Sunshine In)," plays intermittently on the radio and they become menaced by the animated corpses of other autopsies that they had previously performed. Their investigation of Jane Doe's body reveals a number of details that at first make no logical sense: shattered wrists and ankles with no external signs of trauma, clouded-over eyes (suggesting that she has been dead for days) on an otherwise fresh and pliable body, tongue cut out, a paralytic plant in her system that is not native to their region of the country, a missing molar that is found wrapped in a mysterious cloth diagram in her stomach, scorched lungs and badly scarred-over organs without the expected corresponding entry wounds, arcane symbols written inside of her skin and inexplicably active and living brain cells despite surely being dead. Although it belies the cold logic of their profession, their conclusion is that Jane Doe was an innocent woman condemned to torture and execution during the Salem Witch Trials, whose suffering had somehow transformed her into a witch, prolonged her life past her body's expiration and allowed her to wreak her savage, post-mortem vengeance on the living embodiment of her past tormentors. And, because of her inexplicably continued brain activity, 
Jane Doe felt every stage of her own autopsy, thus restaging and recreating the torturous process that transformed her into a witch.

After accidentally killing Austin's girlfriend Emma with an axe that was intended for one of the menacing corpses animated in the autopsy room, and failing to kill Jane Doe by immolation, patriarch Tommy offers Jane a trade: his life so that his son Austin may live. Jane inflicts every torture she had endured onto Tommy, who Austin then mercifully stabs to end his suffering. Although Tommy believes that his father's sacrifice has saved him and hears the Sheriff outside of their subterranean examination room, it is revealed to be a hallucination conjured by Jane Doe, whose animated corpses attack Austin and send him plummeting to his death. The next morning, the police remove Tommy and Austin's bodies from the new crime scene (the presence of just their two bodies suggesting that Emma's death was merely another torturous illusion). Jane Doe's body is sent to another coroner, on route to which it is revealed that she is still living and soon to continue this vicious cycle.

Intended to "to shine a light on extraordinary screenwriting, some of which may have been overlooked more broadly" (The Black List 2020), the annual Hollywood Black List is a list which compiles the best-liked unproduced screenplays circulating the desks of Hollywood studio executives. Ranked among them are eventual critical darlings, popular favorites and awardwinning classics. The Autopsy of Jane Doe appeared on the 2013 edition of the Black List alongside future Oscar nominees A Beautiful Day in the Neighborhood (2019), American Sniper (2014) and Spotlight (2015). Coming off of the international success that was Trollhunter (2011), Norwegian filmmaker André Øvredal "wanted to prove something[, that he could be a] very controlled [storyteller]” (Rife and Dowd 2016, $\uparrow 4$ ) like the filmmakers that he grew up watching, and he chose The Autopsy of Jane Doe script primarily because it had "such a classical horror 
movie [appeal at] a time where all these movies had tried to do all kinds of different stuff [and this allowed him to go] back to the basics" (Gorman 2016, $₫ 7$ ). It was perhaps this paired down, back-to-basics, deliberately non-flashy approach to filmmaking - its more conventional approach to the genre and its willingness to straight-forwardly engage with familiar tropes and conventions of terror - that resulted in The Autopsy of Jane Doe's much cooler reception compared to other witch movies like Antichrist and The Witch. Although a wide critical consensus praised it for being "a smart, suggestively creepy thriller" (Rotten Tomatoes 2016), others complained that film "revolve[s] around [a female] who [is] not imbued with identifiable character traits or personalit[y]" (Wilson 2020, 164); even though audience members are "initially encouraged to empathize with Jane, she is [ultimately] villainized" in its climax, and while the male characters may "sympathize with the horrors [Jane Doe] has undergone, the camera shows no such sentiment" the film is shot "like a relentless scalpel[ ...] hon[ing] in on gory details of dissection and excavation. Each cut, each layer of skin, each removed organ is disassociated from human suffering" (Wilson 2020, 166). Counter to that is the assessment that The Autopsy of Jane Doe "has a really uplifting narrative [...] similar to The Witch," one that tracks "feminism's grand trajectory and where we are with it right now $[\ldots$ and emphasizes its $]$ retributive aspect[s], where we're fed up [with ...] sexual predators, we want them to pay [and] to suffer the social stigma that the victims of their crimes suffered" (Subissati and West 2018). The majority of The Autopsy of Jane Doe's critical analysis, however - especially at the moment of its release - largely dismissed the film with back-handed praise like:

it does the job without overstaying its welcome $[\ldots]$ if you're looking for a message or a bigger point or some kind of underlying "theme," you're not really going to find it, but not every solid genre exercise needs to be straining for some extra level of subversive 
intent to be worth watching [and ...] it's gotta be more worth your time than Rings is (Chipman 2017).

This profound reluctance to consider The Autopsy of Jane Doe as anything other than a kind of haunted house story with a twist, bereft of theme or deeper meaning, despite the literal text of the film imploring us that "every body has a secret, some just hide it better than others" and revealing that deepening layers of meaning can be drawn out under careful examination, is testament to the enduring legacy of the original witch imagery. To an even greater extent than either Antichrist or The Witch, The Autopsy of Jane Doe proves that while "horror cinema can subvert older ideas about witches[ ...] it also reveals their continued power" (Buckley 2019, 22). When the witch is presented in the context of a more commercial film that is admittedly more concerned with constructing memorable horror set pieces and delivering shocking scares than the kind of prestigious film that premiers at Cannes (Antichrist) or Sundance (The Witch), the cultural memory of the monster proves to be remarkably resistant to reexamination and recontextualization.

Arguably more so than Lars von Trier's and Robert Egger's witch films, André Øvredal's film attempts to reframe "the kidnapping of babies, killing of innocents, and the hexing of the living [as being the result of] the oppressive contexts in which these witches reside rather than in any natural wickedness" (Wilson 2020, 14). Like the estimated 40,000-60,000 women who were persecuted on the pretense of practicing witchcraft between 1400 and 1700, Jane Doe was an innocent: in truth, guilty only of everyday womanhood. She was poisoned, pulled apart, mutilated, stabbed, burnt and buried, and is only made monstrous by the traumatic scars (physical and psychic) that were inflicted on her without just cause. It is the predatory actions of men, not the promises of devils, that propel individuals headlong into monstrosity and viciously 
resign themselves to say "sure, if you insist, it's a witch hunt. I'm a witch, and I'm hunting you" (West 2017, ๆ6).

Because the film "focus[es] on the body of the witch in ways that proffer [a] metaphoric 'every [witch]' - [one] whose experiences stand in for the general abominations done to women assumed to be witches" (Wilson 2020, 164), Jane Doe (a name which is, appropriately, given to a woman without a specific and known identity) can signify every woman "who walks around bearing this weight" (Subissati and West 2018). A crucial feature of rape culture is that the woman is never believed, that her word is never good enough, that her lived experiences are somehow distinct from legal evidence., that her testimony is naturally suspect. This is why it took at least 100 accusations of sexual assault against Harvey Weinstein before he was convicted of rape (Schonbek 2020 -1) and why Brett Kavanaugh, who had only one accuser, is currently serving on the Supreme Court. But so many of women's experiences are not evidentiary in that way. Rather, like Jane Doe, “the evidence is inside of [them]. You can't see it. [They] need to die and be cut open before you can actually unpack everything that [they have] been through" (Subissati and West 2018). Thus, it stands that "the body of a naked woman, a dead naked woman $[. .$.$] it doesn't tell a story at all. It's only when they cut into it that they're able to glean$ all this history, all this trauma, all this past" (Subissati and West 2018). On the surface, she just could have been someone young who died yesterday, who was not subjected to such historically specific cruelties (Subissati and West 2018). As a result, she can be "viewed as a symbol of female power, but she is equally a symbol of female persecution [as] thousands of women have suffered and died because of their perceived association with witchcraft" (Sollèe 2017, 13). While many critics of the film took issue with the inherent broadness of Jane Doe's everywomanhood - complaining that she lacked an interior voice and means of expressing her 
own story in her own words - that broadness is, in many ways, the very point that the film is trying to make. Jane Doe is not remarkable: she could be any woman walking down the street right in front of you and you would never give her a second look.

Just as Jane Doe symbolically signifies every woman or every witch, Tommy and Austin symbolically signify her opposite: every man or the patriarchy at large. Coroners, after all, were agents of king and country, originally formed to "protect the financial interests of the crown in criminal proceedings" (Subissati and West 2018). So too are Tommy and Austin (along with the male police officers, whose profession carries similar patriarchal connotations) the only male characters in the film.

In many ways, the comparative conventionality of The Autopsy of Jane Doe allows it to act as a transition away from the art-house aesthetics and relatively niche appeal of Antichrist and The Witch, both of which were slower, more ponderous and less explicit examinations of women's, and especially witches', persecution. The Autopsy of Jane Doe, however, is an unquestionably commercial film. Drawn from a well-received script, starring two recognizable actors and shot in an evocative funhouse horror style - with genre hooks like zombies, tinkling bells, distorted mirrors, subterranean laboratories and other conventional tropes in addition to witches - it was built from the ground up to be a wider-reaching and more readily accepted horror narrative, more akin to an R-rated version of the kinds of mainstream (and typically televisual) co-options of various other monsters (Hayt 2017).

It is perhaps in this conventionality that many of the recognizable signs of the witch become muddled within the narrative. Several indexical signs that are usually indicative of the witch and witchcraft, for instance, are instead connected with Tommy and Austin, her victims. For instance, stored in a fridge in their laboratory is a jar of severed penises, which ordinarily 
would be replete with associations of the monstrous-feminine castrator and witch's historic theft of men's genitalia in the Malleus Maleficarum, but here merely act as (admittedly unsettling) visuals associated with modern-day science and criminology. Likewise, Tommy has a pet cat, Stanley, leftover from his wife which, like the three beggars in Antichrist or the rabbit and crow from The Witch would suggest a witch's familiar. But the cat is in no way connected to the titular witch and in fact serves as her first victim as she begins to exercise her supernatural powers.

Similarly muddled is the way in which the film adopts and withholds the male gaze. In many ways, Jane Doe epitomizes the "to-be-looked-at-ness" (Mulvey 1975, 716) of classic Hollywood females. She is a passive, pliant subject who never moves unless a male character moves her, never speaks except through her increasingly traumatized anatomy (indeed, lacking a tongue, she could not even speak if she wanted to) and although her vengeance is the central subject of the narrative, it progresses only when Tommy or Austin cut into her as part of their investigation. Jane Doe is thus passive, reactionary and exists predominantly as a visual object for men to look at and manipulate, without a voice or discernable personality aside from scattershot revenge. She is literally "the terrain on which [the] patriarchy [depicted in the film] is erected" (Rich 1976, 55) and her body exists as "a specific construction of such terrain, one that sowed seeds of distrust within families and communities while promoting a distrust of women even amongst women themselves" (Wilson 2020, 133). Presented as a puzzle for the male characters to solve, her very presence on the corner's slab invites the audience to lean forward in their seats and "solve" her for themselves.

At the same time, however, the film seems to prefer "the clinical gaze of medicine, psychoanalysis and science $[\ldots]$ the investigative gazes of the police state $[\ldots$ and $]$ the informational gaze of news reportage" (Denzin 1995, 5). Despite her nakedness, Jane Doe is 
often shot from the collar up throughout the film, centering her face in the frame and cutting out her breasts entirely. When she is brought to Tommy and Austin, although her body bag is unzipped, creating a plunging " $v$ " that exposes her chest, her breasts are nevertheless covered by the bag and the opening stops short of exposing her vagina. Shots that do encompass her sexual anatomy are frequently distant, off-center or out-of-focus, with the ultimate effect being that she exists as a non-sexualized body within the film.

Despite the admittedly extreme divergences between their subject matters and critical receptions, comparisons between André Øvredal's horror film and Spanish director Pedro Almodóvar's film Talk to Her (2002) are particularly revealing in the ways that even maledirected films that are deeply interested in and sympathetic toward their female characters can nevertheless fail to narratively center and do justice by those same female characters. Talk to Her, for which Almodóvar was nominated for two Oscars (winning Best Original Screenplay), is an ambiguous and controversial tale of love and obsession that follows two men (one a travel writer, the other a nurse) who care for two comatose women (one a gored bullfighter, the other a ballerina who was hit by a car); later, it is revealed that the male nurse rapes and impregnates the incapacitated woman that he was hired to care for, deeply complicating a character that we had heretofore been engendered to sympathize, and even identify, with. In both The Autopsy of Jane Doe and Talk to Her, narratives that are ostensibly about the tragedies that befall and the wrongs done to women nevertheless center on the men in those women's lives. In both cases, the cataleptic women characters are presented overwhelmingly as pliant, voiceless and obedient bodies that have no choice but to comply to whatever actions are done to them by the men who oversee them, whether those actions take the form of sexual assault (as in Talk to Her) or dissection (as in The Autopsy of Jane Doe). In both cases, the films' narratives progress only in 
as much as the men looking over women's unconscious bodies "paradoxically com[e] to know [them] better as [they] atten[d to them] at [their] bedside" (Ebert 2002, $\uparrow 4$ ). And, just as "there is something selfless in [the] dedication [of both film's male characters, there is also] something selfish, too, because what they are doing is for their own benefit" (Ebert 2002, ๆ7). After all, it is only by unspooling Jane Doe's anatomy, piece by bloody piece, that coroners Tommy and Austin can uncover the truth of Jane's death, which they do despite the apparent agony it causes the still-cognizant Jane in the process, therefore recapitulating the trauma done to her in life (up to and including her immolation). The women of these films seem to share much of the same narrative purpose that the "Manic Pixie Dream Girl" character archetype does in other genres, in as much as they exist:

solely in the fevered imaginations of sensitive writer-directors to teach broodingly soulful young men to embrace life and its infinite mysteries and adventures. [...] Audiences either want to marry her instantly $[\ldots]$ or they want to commit grievous bodily harm against them. (Rabin 2007, $\uparrow 7$ ).

In other words, despite Øvredal's best intentions and deepest sympathies, Jane Doe narratively exists only to serve the edification and character development of male leads Tommy and Austin. And, even less so than the women of Talk to Her (where those women at least are granted some establishing scenes prior to their accidents), Jane Doe lacks any discernable semblance of an interior life. In a particularly dark twist on the character type, even in her vengeance, she seeks only to teach the witless men surrounding her important life lessons.

The Autopsy of Jane Doe, with its unreactive and stone-faced title character, recalls another foundational concept of film theory: that is, the Kuleshov Effect. Pioneered by Russian filmmaker Lev Kuleshov in the early twentieth century, this principle of filmmaking dictates that 
the way in which a film is edited "is not merely a method of the junction of separate scenes or [shots], but is a method that controls the 'psychological guidance' of [a film's] spectator" (Pudovkin 1926, 11). This means that the ways in which a filmmaker arranges and juxtaposes different shots together in sequence creates a complex web of associations in the viewer that would otherwise be absent had these shots not been arranged together in that exact way. In other words, the context in which different shots are presented creates new meanings and associations in the viewer independent of the individual meanings of the shots themselves. Kuleshov illustrated this principle with his now-famous film experiment, in which we first see a shot of an expressionless man, followed by a shot of a bowl of soup, ending on the same shot of the expressionless man. Although these shots have nothing to do with each other in principle, the effect is that the audience reads into the overall shot sequence that the man is hungry. He repeated this sequence again, replacing the bowl of soup with a girl in a casket (viewers now understood that the man was sad) and again with a beautiful woman (viewers now understood that the man was aroused). Although the image of the man never changed (only the contrasting images differed in any way), audiences read his expression differently based on what images were intercut with his. Or, as British director Alfred Hitchcock rakishly explained in a 1964 interview with Canadian filmmaker Fletcher Markle:

now we have a close-up [of a man], then we show what he sees. Let's assume that he saw a woman holding a baby in her arms. Now we cut back to his reaction to what he sees, and he smiles. Now what is he as a character? He's a kindly man. He's sympathetic. Now, let's take the middle piece of film away, the woman with the child, but leave his two pieces of film as they were. Now we're putting a piece of film of a girl in a bikini. He 
looks, a girl in a bikini, he smiles. What is he now? A dirty old man. He's no longer the benign gentleman who loves babies. That's what film can do for you. (Markle 1964) Regardless of the content of subsequent images, the principle remains consistent: given a set of contrasting images, the audience will connect the images together into a compounding idea that combines the entire series together.

The Kuleshov Effect is similarly employed to great effect in The Autopsy of Jane Doe, only here she is the blank-faced individual that the audience projects meaning onto and the revelations made about her, or the carnage she wreaks, are the contrasting images. Nothing about her expression fundamentally changes throughout the film, save for the occasional adjustment of her head by Tommy and Austin or the resulting trickle of blood from their investigative probing. Even though she is possessed of a malevolent will that lashes out at the men around her, she has no external means of expressing her interior thoughts or reactions. Every cut back to her when something supernatural happens should, in theory, be no different from cutting to any other inanimate object in that examination room. But that is not the case, because the Kuleshov Effect dictates that we will read into her still recognizably human face some kind of reaction, emotion or other association: how she appears to sadden when the unhappy story of her death begins to unfold, how she becomes wrathful as they continue to carve into her flesh, how she thoroughly relishes in the torment that she causes her examiners over the course of the night or, when she kills son Austin after father Tommy impotently trades his life to try to secure his son's survival, she grows dark with malice, as if to assure us, like Lindy West, that "sure, if you insist, it's a witch hunt. I'm a witch, and I'm hunting you" (West 2017, $₫ 6$ ). So while the film fails to imbue Jane Doe with a distinctive voice, she is not truly expressionless. Through Øvredal's conscious collaboration with the film's audience, he forces the viewer to empathically consider Jane's 
point-of-view and embodied reaction to the havoc she causes. Thus, without telling us a thing, Jane Doe forces us to understand these events from her perspective: to, in effect, internalize her story within us.

If The Witch operated primarily on the level of the iconic sign and Antichrist operated primarily on the level of the symbolic sign, then The Autopsy of Jane Doe primarily operates on the level of the indexical sign: deeply delving into all of the visual evidence, drawn from the body of Jane Doe, that signifies the "inherent relationship[s] between the signified[s] and the signifier[s]" (Rose 2016, 120). All of the evidence that Tommy and Austin are able to quite literally pull out of her signifies her as a victim of historical witch persecution. These signs include the internal disfigurations (scarred organs, blackened lungs, missing teeth and tongue) that signify the external trauma that she experienced near the end of her life, the regionallyspecific plant she ingested that signifies her life in Salem and the biblical passage (Leviticus 20:27, which condemns witches), the dated cloth (which lists 1693, the year in which the Salem Witch Trials took place) and the arcane runes carved inside of her body (intimating the supernatural more specifically).

Jane Doe herself is an iconic sign of witchcraft, yes, but as The Autopsy of Jane Doe primarily functions as a "secret witch film" (Subissati and West 2018) - in which Jane Doe's identity as a witch is obfuscated until near the end of its narrative - that sign is constructed slowly over the course of the film (and titular autopsy) rather than being readily apparent from her porcelain, doll-like body and expressionless features. Even then, despite her undeniable and malevolent powers utilized throughout the film, her associations are more closely tied with historic witchcraft (e.g., her direct association with Salem, her status as a martyred woman who became a witch after her execution, the film's initial grounding in the realistic world of police 
procedural narratives). "Every body has its secrets," Tommy tells us, and so Jane Doe's secret status as a witch and arcane revenger is established through the various indexical features which suggest the traumas inflicted on her individually and, taken as a collective whole, bring the oppressive history of women's patriarchal persecution to the fore.

Of the current cycle of sympathetic witch films, André Øvredal's The Autopsy of Jane Doe is perhaps the least successful at rehabilitating the character of the cinematic witch, even compared to the far more contentious Antichrist. Like von Trier's witch film, The Autopsy of Jane Doe is only sometimes-successful at eliciting its audience's sympathies for the vengeful Jane Doe because the narrative directly centers and adopts the perspective of her male victims. Its emphasized use of indexical signs, although they more directly construct Jane Doe as the victim of religious persecution and patriarchal retribution than Antichrist's accentuated use of symbolic signs, nevertheless keeps the audience at a greater emotional distance to her than The Witch's more direct treatment of iconic signs. Likewise, the film's greater commercial aspirations (relative to von Trier's and Eggers's features) confound the relationship between many of the film's signifiers and their signifieds and foreground its horrific set pieces at the expense of clearer meaning-making and more concrete sympathies toward its witch. The end result is a film whose content is indeed sympathetic toward the female victims of patriarchal oppression and religious persecution, but whose narrative and aesthetic conventionality nevertheless fails to satisfactorily convey those sympathies. 


\section{CONCLUSION}

Even the most cursory examination of the subject reveals that "the first two decades of the $21^{\text {st }}$ century $[\ldots]$ brims with phenomenal horror texts[ and that m]any place not only female characters - but also many feminist ones - front and center" (Wilson 2020, 3). These films,

particularly ones that prominently feature the figure of the witch, "are [...] way[s to diverge from the] traditional narratives around female characters where they are expected to fall in love, where they are expected to understand something other than them" (Subissati and West 2018). In the realm of horror, they are allowed to be powerful, independent and "gloriously selfish" (Subissati and West 2018). And while the fact "that horror is doing political work is by no means new, what is new $[\ldots]$ is the embrace of the progressive politics horror is currently proffering" by being a-characteristically "being heaped with praise, winning awards, [and] changing minds" (Wilson 2020, 3): films like Antichrist (2009), The Witch (2015), The Autopsy of Jane Doe (2016) and more.

Just as many scholars have questioned why the horrific popularity of cults in the 1970 s, slashers in the 1980 s and zombies in the 2000 s, so too must we ponder why witches, and why now? How do these monsters uniquely speak to this moment in time? Pondering these very questions herself, Natalie Wilson posits that "part of the answer certainly lies in the fact that we are experiencing two contradictory impulses in relation to the gender" (Wilson 2020,131) in the present moment. The first, she claims, is "a profound anti-woman, anti-feminist backlash" and the second is "a heightened popularity and embrace of feminism and other social justice movements" (Wilson 2020, 131), chief among them being \#MeToo. Given the witch's sordid history in religion, history and popular culture - that it has been "deployed to denigrate women as well as to celebrate female empowerment and agency" (Wilson 2020,131) - it has emerged as 
an emblematic figure of the $21^{\text {st }}$ century: embraced across all manner of political and gendered strata as the ultimate enemy of the established patriarchal order. Though whether this makes her a hero or a villain in her own story, or something else besides - neither "good or evil[, but] wicked good" (Wilson 2020,130) - is a much more complicated matter in the popular discourse. What these recent witch films, and especially the three deeply examined witch films, indicate is that “this moment isn't just about sex" (West 2019, 16). Really:

it's about who feels at home in the workplace and who feels like an outsider - which, by extension, dictates who gets to thrive and ascend, who gets to hire their replacements, who gets to set their children up for success, who gets credit and glory, and who gets forgotten. It's about who feels safe in public spaces and who doesn't. Which is to say, it's about everything (West 2019, 16-17).

These films, in this moment, reveal not only that "we have a lot to figure out" (West 2019, 17) about gender's enduring place in history, film and society, but that "the very foundation of our culture is marbled with violence, exploitation, and exclusion - the work of brilliant abusers (and mediocre ones), the institutional scaffolding that enabled them, and the invisible absence of their victims" (West 2019, 17). In the coming decades, "separating art from artist [...] may not be a choice" and, as much as we may wish to otherwise, "we can't un-Michael Jackson music or deAlfred Hitchcock film - nor, necessarily, should we" (West 2019, 17). What is needed is not "neutrality; we don't need 'nice"” (West 2019,73), it is not enough to simply reign in the rankest sexual offenders and the most ardent defenders of the patriarchy because "it's [simply] not enough to just stop being terrible" (West 2019, 73). Like these recent witch movies, "we need new work that actively challenges old assumptions, that offers radical models for how to conceive of ourselves and how to treat each other. We need artists and studios fighting for 
diversity because it's the right thing to do" (West 2019, 73). To this end, there are a number of different approaches that can be taken within the film industry as pertains to film production, film distribution and film criticism.

Author Lindy West described the kind sea-change that needs to happen when talking about, of all things, noise-cancelling headphones, which work by using:

a built-in microphone that measures the ambient noise around you, then generates an inversion of that sound wave and adds it to the mix in your headphones. When a frequency meets its opposite - when the peaks of one mirror and coincide with the valleys of another - the result is called phase cancellation. The two waves cancel each other out. Silence.

What we really need from Hollywood is about a hundred years of phase cancelation. (West 2019, 73)

There needs to be a radical, top-down overhaul of the power structures in and surrounding the film industry in order to properly correct for more than a century of such structures systemically empowering men and marginalizing women. According to the Times Up movement's intersectional initiative 50/50 by 2020, the gender disparity in Hollywood power structures are utterly staggering. 78 percent of the parent media corporations senior leadership (that is to say, the corporations that own the film studios) is male, as is 81 percent of Hollywood board membership, 96 percent of film directors and 78 percent of writers across all platforms (5050 by 2020). This means that men have grossly disproportionate power in terms of setting film studios' agendas, greenlighting and budgeting films, hiring the producers / directors / writers who dictate the direction that a film's production takes and actually producing / directing / writing content that involves (let alone centers) female perspectives and experiences. Because it reasons that "if 
more women are in decision-making roles in the creation and production of mass media content, then portrayals will change" (Chattoo 2018, 374), women need to be included equally at every level of film production in order to address the imbalance of women's stories, perspective and even presence in film today. As the data bear out that. "given two otherwise equivalent movies with the same budget, audiences do not appear to penalize those with a female presence" (Lindner et al. 2015, 423), producing more films with a female presence, "both on screen as characters and behind the scenes in decision-making creative positions," will combat the deeplyingrained and oppressively dominant male ideology that "perpetuat[es] long-standing patterns of inequity in media industries, as well as audience understanding of [what] cultural voices and [what critical] lens[es are] worthy of consideration. (Chattoo 2018, 374). By radically restructuring these old, unequitable systems of power, it changes the kinds of people who are able to express their artistic visions, the kinds of stories that are available to audiences and the ways in which both are encouraged to approach film analysis.

But, of course, "the people who review films need to be as diverse as the people who watch them" (CherryPicks). A similar gender-based power restructuring needs to occur in media outlets that promote, review, analyze and otherwise discuss the films coming out of Hollywood studios. By changing the composition of media outlet board rooms, news rooms and writers' rooms to equitably represent the broader gender composition of the general population, films that demonstrate a female presence, both behind and in front of the camera, will be given more and better consideration than under the current gender-exclusive model. Media outlets like Cherry Picks, a review aggregator that operates like a gender-inverted counterpart of the website Rotten Tomatoes, "highlight[s] reviews and write[s] original stories exclusively from female-identifying and non-binary writers[ in an industry where] most film critics are overwhelmingly male" 
(CherryPicks). Such gender-based reframing of film criticism would do much to unhinge the enduring legacy of the original witch imagery, which has proven to be remarkably resistant to reexamination and recontextualization throughout the preceding decade (as evidenced in the reluctant and surface-level praise earned by The Autopsy of Jane Doe). The crucial first-step taken by organizations like Cherry Picks toward the more comprehensive work that still needs to be done, giving credence to non-hegemonic voices in film criticism, is merely just that: the first of many steps that need to be taken to correct more than a century of gender-imbalanced film criticism.

As it relates to witch horror films particularly, new films need to continue to "actively challeng[e] old assumptions[ and] offe[r] radical models for how to conceive of ourselves and how to treat each other" (West 2019, 73). The three films that acted as the central focus of this thesis - Lars von Trier's Antichrist, Robert Eggers's The Witch and André Øvredal's The Autopsy of Jane Doe - are merely three prominent examples among a surge of films that have been released over the last decade, all of which can be used as narrative and aesthetic models for future films and fertile subjects for future film criticism. Director Robert Stromberg's Maleficent (2014), a Disney-produced deconstruction of that studio's animated film Sleeping Beauty (1959), combines its iconic title sorceress with syntactic and semantic elements from not just from witch films, but from rape-revenge films as well. Anna Biller's The Love Witch (2016), notably the only woman-directed film of this production cycle, complicatedly negotiates between traditional depictions of femininity and radical depictions of witchcraft while purposively adopting a displaced timelessness in its aesthetic that makes this modern-set story appear to be both set in and produced during the mid-1960s. Luca Guadagnino's Suspiria (2018) remakes Dario Argento's lean and nightmarish 1977 film of the same name by synthesizing the already 
contentious associations of witcheraft with the social, historical and political contexts of postWorld War II Berlin (including, but not limited to the Holocaust, denazification, the Berlin Wall, the Lufansa hijacking, the Baader-Meinhof gang, Jungian psychotherapy and Mary Wigman's Hexentanz); additionally, Suspiria attempts to subvert the expectations of the film possessing a major masculine presence on-screen by having actress Tilda Swinton play the film's only significant male role under heavy prosthetic makeup. Most recently, Oz Perkins' Gretel \& Hansel (2020) reimagines the classic German fairy tale as a mentorship between an older witch and a magically-adept girl who has been abandoned by the patriarchy. While these films, like those presented in this thesis, are sometimes narratively confused and only partially-successful at their feminist aims, they collectively seek to reframe the witch from its historical status as an ancient villainess to a radically new conception as a keeper of female knowledge, possessor of female power and dispenser of female justice. 


\section{REFERENCES}

2020. 5050 by 2020. “About.” Retrieved July 9, 2020. (https://site.5050by2020.com/).

Aftab, Kaleem. 2009. "Lars von Trier - 'It's Good that People Boo."” Independent. Retrieved April 10, 2020. (https://www.independent.co.uk/arts-entertainment/films/features/larsvon-trier-its-good-that-people-boo-1692406.html).

Ahmadi, Maryam, Ali Reza Moradi, Azizollah Tajik Esmaeili, Vida Mirabolfathi and Laura Jobson. 2019. “A Preliminary Study Investigating Time Perception in Adolescents With Posttraumatic Stress Disorder and Major Depressive Disorder.” Psychological Trauma: Theory, Research, Practice, and Policy. 11 (6): 671- 676.

2015. 'Interview with Laura Mulvey and Anna Backman Rogers, Co-Editor of 'Feminisms,' Amsterdam University Press. Retrieved July 22, 2015). (http://en.aup.nl/nieuws/191interview-with-laura-mulvey-and-anna-backman-rogers-co-editors-of-feminisms.html).

Badley, Linda. 2010. Lars von Trier. Urbana, IL: University of Illinois Press.

Bal, Mieke. 1991. Reading Rembrandt: Beyond the World-Image Opposition. Cambridge, MA: Cambridge University Press.

Barounis, Cynthia. 2018. "Witches, Terrorists, and the Biopolitics of Camp." GLQ: A Journal of Lesbian and Gay Studies. 24 (2-3): 213-238.

Barthes, Roland. 1957. “The Face of Garbo.” Pp. 471-473 in Film Theory

\& Criticism: Introductory Readings. $7^{\text {th }}$ ed, edited by Leo Braudy and Marshall Cohen. Oxford, England: Oxford University Press.

Bechdel, Alison. 1985. "The Rule.” Dykes to Watch Out For.

Bergesen, Albert. 2016. "How to Sociologically Read a Movie." The Sociological Quarterly. 57 (4): 585-596. 
2020. The Black List. Retrieved April 14, 2020. (https://blcklst.com/).

Borer, Simon and Alison Lang. 2017. "Black Museum Debate: Final Girl Face-off.” The Black Museum.

Bourdieu, Pierre. 1992. The Rules of Art: Genesis and Structures of the Literary Field. Stanford, NJ: Stanford University Press.

Briefel, Aviva. 2019. "Devil in the Details: The Uncanny History of The Witch (2015)." Film \& History: An Interdisciplinary Journal. 49 (1): 4-20.

Brooks, Xan. 2009. "Antichrist: a work of genius or the sickest film in the history of cinema?" The Guardian. Retrieved April 2, 2020. (https://www.theguardian.com/film/2009/jul/16/antichrist-lars-von-trier-feminism).

Buch-Hansen, Gitte. 2011. "Lar's von Trier's Antichrist, the Bible, and Docetic Masculinity." Relegere: Studies in Religion and Reception. 1 (1): 115-144.

Buckley, Chloe Germaine. 2019. “Witches, ‘bitches' or feminist trailblazers? The Witch in Folk Horror Cinema." Revenant. 4: 22-42,

Bucholz, Robert and Newton Key. 2009. Early Modern England 1485-1714: A Narrative History. Boston, MA: Wiley-Blackwell.

Buhler, James. 2014. "Gender, Sexuality, and the Soundtrack." Pp 367-382 in The Oxford Handbook of Film Music Studies. Edited by David Neumeyer. Oxford: Oxford University Press.

Burgin, Xavier. 2019. "Horror Noire: A History of Black Horror.” Shudder. Retrieved July 7, 2020. (https://www.shudder.com/movies/watch/horror-noire-a-history-of-blackhorror/e650978256281a67). Philadelphia, PA: Stage 3 Productions. 
Butler, Judith. 1990. Gender Trouble: Feminism and the Subversion of Identity. London: Routledge.

Caporael, Linnda. R. 1976. “Ergotism: The Satan Loosed in Salem?” Science. 192 (4234): $21-26$

Carroll, Chloe. 2020. ““Wouldst thou like to live deliciously?': Female Persecution and Redemption in The Witch." Frames Cinema Journal. Retrieved July 11, 2020. (https://framescinemajournal.com/article/wouldst-thou-like-to-live-deliciously-femalepersecution-and-redemption-in-the-witch/).

Chattoo, Caty Borum. 2018. "Oscars So White: Gender, Racial, and Ethnic Diversity and Social Issues in U.S. Documentary Films (2008-2017)." Mass Communication and Society. 21 (3): 368-394.

2020. CherryPicks. Retrieved July 9, 2020. (https://www.thecherrypicks.com/about).

Chiu, Allyson. 2018. “'It is a scary time,' Trump backer Amy Kremer tells MSNBC. Witches ‘are placing a hex on Brett Kavanaugh.”' Washington Post. Retrieved July 3, 2020. (https://www.washingtonpost.com/news/morning-mix/wp/2018/10/15/a-scary-time trump-backer-amy-kremer-tells-msnbc-witches-are-placing-a-hex-on-brett-kavanaugh/).

Chipman, Bob. 2017. “MovieBob Reviews: The Autopsy of Jane Doe.” Geek.com. Retrieved April 14, 2020. (https://www.geek.com/movies/moviebob-reviews-the-autopsy-of-janedoe-1687443/).

Clark, Stuart. 1980. "Inversion, Misrule and the Meaning of Witchcraft." Pp. 136-147 in The Witchcraft Reader. $2^{\text {nd }}$ ed, edited by Darren Oldridge. New York, NY: Routledge.

Clark, Stuart. 1997. "Protestant Witchcraft, Catholic Witchcraft." Pp. 136-147 in The Witchcraft Reader. $2^{\text {nd }}$ ed, edited by Darren Oldridge. New York, NY: Routledge. 
Clover, Carol. 1992. Men, Women, and Chainsaws: Gender in the Modern Horror Film. Princeton, NJ: Princeton University Press.

Cole, Kai. 2017. “Joss Whedon Is a 'Hypocrite Preaching Feminist Ideals,' Ex-Wife Kai Cole Says (Guest Blog)." The Wrap. Retrieved July 11, 2020. (https://www.thewrap.com/josswhedon-feminist-hypocrite-infidelity-affairs-ex-wife-kai-cole-says/amp/).

Creed, Barbara. 1993. The Monstrous Feminine: Film, Feminism, Psychoanalysis. London, England: Routledge.

Curry, Timothy. J. 1984. "Sociological Films." Contemporary Sociology. 13: 42-44.

Dalton, Andrew. 2018. "Chicago Comic Hannibal Buress, Who Called Cosby a Rapist in 2014 Standup Act, Now Credited After His Conviction.” Chicago Tribune. Retrieved September 15, 2020. (https://www.chicagotribune.com/entertainment/ct-hannibal-buresscosby-conviction-20180427-story.html).

Davidson, J. P. 1995. "The Myth of the Persecuted Female Healer.” Pp. 257-260 in The Witchcraft Reader. $2^{\text {nd }}$ ed, edited by Darren Oldridge. New York, NY: Routledge.

De Beauvoir, Simone. 1949. The Second Sex. Paris: Gallimard.

Demerath, Nicholas, J. III. 1981. “Through a Double-Crossed Eye.” Teaching Sociology. 9: 69-82.

Denzin, Norman. K. 1995. The Cinematic Society: The Voyeur's Gaze. London, England: Sage Publications.

Douglas, Mary. 1966. Purity and Danger: An Analysis of Concepts of Pollution and Taboo. New York, NY: Frederick A. Praeger. 
Dowd, Maureen. 2018. “This Is Why Uma Thurman Is Angry: The Actress Is Finally Ready to Talk About Harvey Weinstein.” The New York Times. Retrieved March 25, 2020. (https://www.nytimes.com/2018/02/03/opinion/sunday/this-is-why-uma-thurman-isangry.html).

Duca, Lauren. 2016. "How Robert Eggers Wove the Nightmares of The Witch Out of Historical Documents.” Vulture. Retrieved July 11, 2020. (https://www.vulture.com/2016/02/howrobert-eggers-researched-the-witch.html).

Ebert, Roger. 2002. “Talk to Her.” RogerEbert.com. Retrieved July 5, 2020. (https://www.rogerebert.com/reviews/talk-to-her-2002).

Ebert, Roger. 2009. "The Embodiment of Unalloyed Evil in a Parable without Mercy." RogerEbert.com. Retrieved April 6, 2020. (https://www.rogerebert.com/ reviews/antichrist-2009).

Eisenstein, Sergei, Vsevolod Pudovkin and Grigori Alexandrov. 1928. "Statement on Sound." Pp. 315-317 in Film Theory \& Criticism: Introductory Readings. $7^{\text {th }}$ ed, edited by Leo Braudy and Marshall Cohen. Oxford, England: Oxford University Press.

Fahrenthold, David. A. 2016. "Trump Recorded Having Extremely Lewd Conversation About Women in 2005." The Washington Post. Retrieved March 25, 2020. (https://www.washingtonpost.com/politics/trump-recorded-having-extremely-lewdconversation-about-women-in-2005/2016/10/07/3b9ce776-8cb4-11e6-bf8a3d26847eeed4_story.html).

Faxneld, Per. 2017. Satanic Feminism: Lucifer as the Liberator of Woman in NineteenthCentury Culture. New York, NY: Oxford University Press. 
Federici, Silvia. 2004. "The Great Caliban: The Struggle Against the Rebel Body." Capitalism, Nature, Socialism. 15 (2): 7-16.

Feinberg, Scott. 2020. “Brutally Honest Oscar Ballot: '1917' Is 'Gimmicky,' Renée Zellweger 'Nailed It." Hollywood Reporter. (https://www.hollywoodreporter.com/lists/brutallyhonest-oscar-ballot-1917-gimmicky-renee-zellweger-nailed-it-1276607).

Freeland, Cynthia A. 1996. "Feminist Frameworks for Horror Films." Pp. 627-648 in Film Theory \& Criticism: Introductory Readings. $7^{\text {th }}$ ed, edited by Leo Braudy and Marshall Cohen. Oxford, England: Oxford University Press.

Gerould, Alexander L. 2002. "Eve's Seed: Biology, the Sexes, and the Course of History (Book)." Journal of the History of Sexuality. 11 (4): 689-692.

Gorbman, Claudia. 1987. Unheard Melodies: Narrative Film Music. Bloomington, IN: Indiana University Press.

Gorbman, Claudia. 2007. “Auteur Music.” Pp 149-162 in Beyond the Soundtrack: Representing Music in Cinema. Edited by Daniel Goldmark, Laurence Kramer, and Richard Leppert. Berkeley, CA: University of California Press.

Gorman, Howard. 2016. "Interview: André Øvredal Dissects The autopsy of Jane Doe." Dread Central. Retrieved April 14, 2020. (https://www.dreadcentral.com/news/202607/ interview-andre-ovredal-dissects-autopsy-jane-doe/).

Halperin, Moze. 2016. "Feminism, Radicalization, and Injustice: The Enduring Power of the Witch Narrative." Flavorwire. Retrieved April 12, 2020. (https://www.flavorwire.com /571723/not-just-feminist-what-todays-puritan-witch-horror-stories-have-to-say-aboutmore-insidious-forms-of-radicalization). 
Harris, Rachel. 2020. "Wound Culture on Film: The Autopsy of Jane Doe.” Pp 160-161 in Photography and Death: Framing Death throughout History. Bingley, UK: Emerald Group Pub Ltd.

Hole, Kristin Lenè. 2017. "Fantasy Echoes and the Future Anterior of Cinema and Gender." Pp. 458-467 in The Routledge Companion to Cinema and Gender. Edited by Kristin Lenè Hole, Dijana Jelača, E. Ann Kaplan and Patrice Petro. New York, NY: Routledge. Hole, Kristin Lenè, Dijana Jelača, E. Ann Kaplan and Patrice Petro. 2017. "Introduction." Pp. 1-12 in The Routledge Companion to Cinema and Gender. Edited by Kristin Lenè Hole, Dijana Jelača, E. Ann Kaplan and Patrice Petro. New York, NY: Routledge. 2004. The Holy Bible: King James Version. Dallas, TX: Brown Books Publishing Group. Hopper, Jessica. 2009. “In Which Nature Is Lars Von Trier's Satanic Church.” This Recording. Retrieved April 11, 2020. (http://thisrecording.com/today/2009/10/27/in-which-natureis-lars-von-triers-satanic-church.html).

Hurwitz, Siegmund. 1992. Lilith - The First Eve: Historical and Psychological Aspects of the Dark Feminine. Einsiedeln, Switzerland: Daimon Verlag AG.

Iversen, Margaret. 1986. "Saussure v. Pierce: Models for a Semiotics of Visual Art." The New Art Historian. London, England: Camden Press, 134-147.

Jones, G. W. 1967. Sunday Night at the Movies. Atlanta, GA: John Knox. Jones, Steve. 2011. "Porn of the Dead: Necrophelia, Feminism, and Gendering the Undead." Pp. 40-61 in Zombies Are Us: Essays on the Humanity of the Walking Dead. Edited by Christopher Moreman and Corey Rushton. Jefferson, NC: McFarland.

Kaes, Anton. 2009. Shell Shock Cinema: Weimar Culture and the Wounds of War. Princeton, NJ: Princeton University Press. 
Kantor, Jodi. 2017. “Tarantino on Weinstein: 'I Knew Enough to Do More than I Did'”. The New York Times. Retrieved December 17, 2019. (https://www.nytimes.com/2017/10/19/movies/tarantino-weinstein.html).

Kantor, Jodi and Megan Twohey. 2017. "Harvey Weinstein Paid Off Sexual Harassment Accusers for Decades.” The New York Times. Retrieved November 25, 2019. (https://www.nytimes.com/2017/10/05/us/harvey-weinstein-harassment-allegations.html). Kaylan, Melik. 2019. "China Has a Soft-Power Problem.” The Wall Street Journal. Retrieved July 5, 2020. (https://www.wsj.com/articles/china-has-a-soft-power-problem11567696212).

Kern, Laura. 2017. "Back on the Slab.” Film Comment. 53 (1): 20-21.

King, Stephen. 1981. Danse Macabre. New York, NY: Gallery Books.

Kohn, Eric. 2017. “Jordan Peele Challenges Golden Globes Classifying 'Get Out' As a Comedy: "What Are You Laughing At?"” Indiewire. (https://www.indiewire.com/ 2017/11/jordan-peele-response-get-out-golden-globes-comedy-1201897841/).

Kracauer, Siegfried. 2019. From Caligari to Hitler: A Psychological History of the German Film. Princeton, NJ: Princeton University Press.

Kvam, Kristen E., Linda S. Schearing and Valarie H. Ziegler. 1999. Eve \& Adam: Jewish, Christian, and Muslim Readings on Genesis and Gender. Bloomington, IN: Indiana University Press.

Lachs, Samuel Tobias. 1974. “The Pandora-Eve Motif in Rabbinic Literature.” The Harvard Theological Review. 67 (3): 341-345.

Laing, Heather. 2007. The Gendered Score: Music in 1940s Melodrama and the Woman's Film. Hampshire: Ashgate. 
Langill, Molly. 2014. "Issues of Gender in the Horror Genre, Part 1." Off Screen. 18 (6).

Retrieved December 26, 2019. (https://offscreen.com/issues/view/volume-18-issues-67).

Larner, Christina. 1994. “Was Witch-Hunting Woman-Hunting?” Pp. 253-256 in The

Witchcraft Reader. $2^{\text {nd }}$ ed, edited by Darren Oldridge. New York, NY: Routledge.

Lindner, Andrew, M., Melissa Lindquist and Julie Arnold. 2015. "Million Dollar Maybe? The Effect of Female Presence in Movies on Box Office Returns." Sociological Inquiry. 85 (3): 407-428.

Lorber, Judith. 1994. “'Night to His Day' - The Social Construction of Gender.” Paradoxes of Gender. New Haven, CT: Yale University Press.

Madden, Victoria. 2020. “'Wouldst Thou Like to Live Deliciously?': Gothic Feminism and the Final Girl in Robert Eggers' The Witch.” Pp 135-151 in Final Girls, Feminism and Popular Culture. Edited by Katarzyna Paszkiewicz and Stacy Rusnak. London, England: Palgrave Macmillan.

Markle, Fletcher. 1964. "'Hitchcock Explains the Kuleshov Effect to Fletcher Marckle. 1964." YouTube. Retrieved July 8, 2020. (https://www.youtube.com/watch?v=96xx3831pil).

Mayer, J. P. 1948. Sociology of Film: Studies and Documents. London, England: Faber and Faber Limited.

Merck, Mandy. 2007. Mulvey’s Manifesto. Camera Obscura. 66 (3). pp. 1-23.

Michelet, Jules. 1862. La Sorcière: The Witch of the Middle Ages. London, England.

Miles, Margaret R. 2008. A Complex Delight: The Secularization of the Breast 1350-1750. Los Angeles, CA: University of California Press. 
Mulvey, Laura. 1975. "Visual Pleasure and Narrative Cinema.” Pp. 711-722 in Film Theory

\& Criticism: Introductory Readings. $7^{\text {th }}$ ed, edited by Leo Braudy and Marshall Cohen. Oxford, England: Oxford University Press.

Mulvey, Laura. 1981. “Afterthoughts on 'Visual Pleasure and Narrative Cinema' Inspired by 'Duel in the Sun' (King Vidor, 1946)." Framework: The Journal of Cinema and Media, 15 (17): $12-15$.

Mulvey, Laura. 2004. "Looking at the Past from the Present: Rethinking Feminist Film Theory of the 1970s." Signs: Journal of Women in Culture and Society. 30 (1). pp. 1286-1292.

Mumford, Gwilym. 2018. "Michael Haneke: \#MeToo has led to a witch hunt 'coloured by a hatred of men.'” The Guardian. Retrieved July 4, 2020. (https://www.theguardian.com/ film/2018/feb/12/michael-haneke-metoo-witch-hunt-coloured-hatred-men).

Murrey, Amber. 2017. "Decolonising the Imagined Geographies of 'Witchcraft."” Third World Thematics: A TWQ Journal. 2 (2-3): 157-179.

Nietzsche, Friedrich. 2020. Beyond Good and Evil: The Philosophy Classic. Chichester, England: John Wiley \& Sons Ltd.

Nye, Joseph, S, Jr.. 2012. "China’s Soft Power Deficit” The Wall Street Journal. Retrieved July 5, 2020. (https://www.wsj.com/articles/ SB100014240527023044511045773899230 98678842).

Pajaczkowska, Claire. 2017. "Psychoanalysis Beyond the Gaze: From Celluloid to New Media.” Pp. 301-310 in The Routledge Companion to Cinema and Gender. Edited by Kristin Lenè Hole, Dijana Jelača, E. Ann Kaplan and Patrice Petro. New York, NY: Routledge. 
Pasquini, Maria. 2018. "Liam Neeson Says Sexual Misconduct Allegations Have Turned into 'a Bit of a Witch-Hunt."' People. Retrieved July 4, 2020. (https://people.com/movies/liamneeson-sexual-misconduct-allegations-witch-hunt/).

2020. The People Pill. Retrieved July 1, 2020. (https://peoplepill.com/).

Petro, Patrice. 2017. "Classical Feminist Theory: Then and (Mostly).” Pp. 15-24 in The Routledge Companion to Cinema and Gender. Edited by Kristin Lenè Hole, Dijana Jelača, E. Ann Kaplan and Patrice Petro. New York, NY: Routledge.

Pettibone, Justin. 2013. "Horror Films and Misogyny as a Critique of Western Hegemonic Patriarchy: Lars von Trier." Grand Valley State University.

Phipps, Alison. 2019. "Every Woman Knows a Weinstein": Political Whiteness and White Woundedness in \#MeToo and Public Feminisms around Sexual Violence.” Feminist Formations. 31 (2): 1-25.

Pinedo, Isabela Cristina. 1997. Recreational Terror: Women and the Pleasures of Horror Film Viewing. New York, NY: SUNY Press.

Poe, Edgar. A. 2004. “The Philosophy of Composition." Great Short Works of Edgar Allen Poe: Poems, Tales, Criticisms. 528-541. New York, NY: Literary Classics of the United States.

Prendergast, Christopher. 1986. "Cinema Sociology: Cultivating the Sociological Imagination through Popular Films." Teaching Sociology 14: 243-248.

Pudovkin, Vsevolod. 1926. “[On Editing].” Pp. 7-12 in Film Theory \& Criticism: Introductory Readings. $7^{\text {th }}$ ed, edited by Leo Braudy and Marshall Cohen. Oxford, England: Oxford University Press. 
Pulver, Andrew. 2018. "Lars von Trier Producer: 'I'll Stop Slapping Asses' in Wake of \#MeToo.” The Guardian. Retrieved July 11, 2020. (https://www.theguardian.com/film/2018/may/ 10/lars-von-trier-producer-peter-aalbaek-jensen-stop-slapping-asses).

Rabin, Nathan. 2007. “The Bataan Death March of Whimsy Case File \#1: Elizabethtown.” AV Club. Retrieved July 6, 2020. (https://film.avclub.com/the-bataan-death-march-ofwhimsy-case-file-1-elizabet-1798210595).

Rahman, Khaleda. 2020. “Director Terry Gilliam Sparks Outrage After Calling \#MeToo Movement A 'Witch Hunt."' Newsweek. Retrieved July 4, 2020. (https://www.newsweek .com/terry-gilliam-sparks-outrage-metoo-witch-hunt-1480445).

Rife, Katie and Dowd, A. A. 2016. “Director André Øvredal on performing The Autopsy Of Jane Doe.”AV Vlub. Retrieved April 14, 2020. (https://film.avclub.com/director-andreovredal-on-performing-the-autopsy-of-jan-1798255626).

Romer, Knud. 2009. “A Hearse Heading Home.” Danish Film Institute. Retrieved April 6, 2020. (https://www.dfi.dk/en/english/hearse-heading-home).

Rose, Gillian. 2016. Visual Methodologies: An Introduction to Researching with Visual Materials. Los Angeles, CA: Sage Publications Inc.

2016. "The Autopsy of Jane Doe." Rotten Tomatoes. Retrieved April 14, 2020. (https://www.rottentomatoes.com/m/the_autopsy_of_jane_doe).

Rowlands, Alison. 1996. "A Lutheran Response to Witchcraft and Magic." Pp. 148-153 in The Witchcraft Reader. $2^{\text {nd }}$ ed, edited by Darren Oldridge. New York, NY: Routledge. Salazar, Jeff. 2018. "A Beast in the Pews: The Autopsy of Jane Doe - A Contextual Analysis." Interdisciplinary Journal of Student Research and Scholarship. 2 (1): 1-19. 
Schatz, Thomas. 1981. Hollywood Genre: Formulas, Filmmaking, and the Studio System. New York, NY: McGraw-Hill.

Schiff, Stacy. 2015. The Witches: Suspicion, Betrayal, and Hysteria in 1692 Salem. New York,: Little, Brown \& Co.

Schoell, William. 1985. Stay Out of the Shower: Twenty-Five Years of Shocker Films Beginning with Psycho. New York, NY: Dembner.

Schonbek, Amelia. 2020. "The Complete List of Allegations Against Harvey Weinstein.” The Cut. Retrieved April 15, 2020. (https://www.thecut.com/2020/01/harvey-weinsteincomplete-list-allegations.html).

Sharf, Zack. 2018. "Lars von Trier Says He 'Hugged’ Björk and Did Not Sexually Harass Her, Thinks \#MeToo Is ‘Brilliant’ If Used Correctly.” Indiewire. Retrieved on July 11, 2020. (https://www.indiewire.com/2018/05/lars-von-trier-hugged-bjork-not-harassed-dancer-inthe-dark-1201966799/).

Shiel, Mark and Tony Fitzmaurice. 2003. Screening the City. New York, NY: Verso.

Silverman, Kaja. 1988. The Acoustic Mirror: The Female Voice in Psychoanalysis and Cinema. Bloomington, IN: University of Indiana Press.

Soskice, Janet Martin. 2001. “God's Mother, Eve's Advocate (Book Review).” Theology \& Sexuality: The Journal of the Institute for the Study of Christianity \& Sexuality. 7 (14): $119-122$.

Spoto, Donald. 1983. The Dark Side of Genius: The Life of Alfred Hitchcock. New York, NY: Ballantine. 
Stanley, Anya. 2020. "Why Criticism: The Race to Problematize Bittersweet Horror Endings." Vague Visages. Retrieved April 10, 2020. (https://vaguevisages.com/2020/03/20/whycriticism-the-race-to-problematize-bittersweet-horror-endings/).

Stenger, Mary Ann. 2006. "The Coming of Lilith: Essays on Feminism, Judaism, and Sexual Ethics, 1972-2003/Divided Houses: Religion and Gender in Modern France/Jesus in Our Wombs: Embodying Modernity in a Mexican Convent...." Signs: Journal of Women in Culture \& Society. 32 (1): 288-295.

Stewart, Potter. 1964. Jacobellis v. Ohio.

Subissati, Andrea. 2010. When There's No More Room in Hell: The Sociology of the Living Dead. USA: Lambert Academic Publishing.

Subissati, Andrea and Alexandra West. 2014. "Episode 16. Toil and Trouble: Witches in Film.” The Faculty of Horror. Retrieved January 30, 2020. (https://www.podbean.com/ media/share/dir-e5fzg-37cb6d6?utm_campaign=w_share_ep\&utm_medium=dlink\&utm _ source=w_share).

Subissati, Andrea and Alexandra West. 2015. "Episode 27. Bewitched: Witches in Film Part 2, with The Witchfinder General (1968), The Crucible (1996) and Inferno (1980)." The Faculty of Horror. Retrieved January 30, 2020. (https://www.podbean. com/media/share/dir-grdqs-37cb6ca?utm_campaign $=w_{-}$share_ep\&utm_medium $=$ dlink\&utm_source=w_share).

Subissati, Andrea and Alexandra West. 2018. "Episode 60. Season of the Witch: Witches in Film Part 3, The Witch (2015) and The Autopsy of Jane Doe (2016).” The Faculty of Horror. Retrieved January 30, 2020. (https://www.podbean.com/media/share/dir-j5qnk3c4657c?utm_campaign $=\mathrm{w} \_$share_ep\&utm_medium $=\mathrm{dlink} \& u t m \_s o u r c e=\mathrm{w} \_$share $)$. 
Tarkovsky, Andrei. 1986. Sculpting in Time. Austin, TX: University of Texas Press.

Tasker, Yvonne. 1993. Spectacular Bodies: Gender, Genre and the Action Cinema. New York, NY: Routledge.

Tasker, Yvonne. 2015. The Hollywood Action and Adventure Film. Boston, MA: Wiley-Blackwell.

Thomsen, Bodil Marie Stavning. 2009. "Antichrist — Chaos Reigns: The Event of Violence and the Haptic Image in Lars von Trier's Film." Journal of Aesthetics \& Culture. 1 (1): $1-10$.

Thomsen, Torsten Bøgh. 2018. "Foggy Signs: Dark Ecological Queerings in Lars von Triers “Antichrist."' Journal of Scandinavian Cinema. 8 (2): 123-134.

Tuchman, Gaye. 1978. "The Symbolic Annihilation of Women in Mass Media." Pp. 150-172 in Culture and Politics: A Reader. Edited by Lane Crothers and Charles Lockhart. New York, NY: St. Martin's Press.

Tudor, Andrew. 1974. Image and Influence: Studies in the Sociology of Film. New York, NY: St. Martin's Press.

Tudor, Andrew. 1989. Monsters and Mad Scientists: A Cultural History of the Horror Movie. Oxford: Basil Blackwell.

Vale, V. and Andrew Juno. 1986. RE/Search No. 10: Incredibly Strange Films. San Francisco, CA: RE/Search Publications.

Vernon, Kathleen M. 2017. "Sound and Gender." Pp. 47-56 in The Routledge Companion to Cinema and Gender. Edited by Kristin Lenè Hole, Dijana Jelača, E. Ann Kaplan and Patrice Petro. New York, NY: Routledge. 
Waite, Gary. K. 1999. “Anabaptists and the Devil.” Pp. 154-163 in The Witchcraft Reader. $2^{\text {nd }}$ ed, edited by Darren Oldridge. New York, NY: Routledge.

Weber, Max. 1946. "The Protestant Sects and the Spirit of Capitalism.” Pp. 302-322 in From Max Weber: Essays in Sociology. Edited by Darren Oldridge. New York, NY: Oxford University Press.

Wells, Jeffrey. 2009. “Antichrist = Fartbomb." Hollywood Elsewhere . Retrieved April 2, 2020. (http://hollywood-elsewhere.com/2009/05/antichrist-fart/).

West, Alexandra. 2016. Film of the New French Extremity: Visceral Horror and National Identity. Jefferson, NC: McFarland \& Company, Inc.

West, Candace and Don Zimmerman. 1987. "Doing gender." Gender and Society. 1 (2): $125-151$.

West, Lindy. 2017. “Yes, This Is a Witch Hunt. I'm a Witch and I'm Hunting You.” The New York Times. Retrieved November 25, 2019. (https://www.nytimes.com/2017/10/17/ opinion/columnists/weinstein-harassment-witchunt.html).

West, Lindy. 2019. The Witches Are Coming. New York, NY: Hatchette Books.

Williams, Gerhild. S. 1999. "Pierre de Lancre and the Basque Witch-Hunt." Pp. 180-184 in The Witchcraft Reader. $2^{\text {nd }}$ ed, edited by Darren Oldridge. New York, NY: Routledge.

Williamson, Judith. E. 1978. Decoding Advertisements: Ideology and Meaning in Advertising.

Willis, Jessica, L. 2008. "Sexual Subjectivity: A Semiotic Analysis of Girlhood, Sex, and Sexuality in the Film Juno." Sexuality \& Culture 12: 240-256.

Wingfield, Adia. H. 2019. “'Reclaiming Our Time’: Black Women, Resistance, and Rising Inequality." Gender \& Society. 33 (3): 345-362.

Wood, Robin. 1978. "Return of the Repressed." Film Comment. 14 (4): 25-32. 
Zinoman, Jason. 2011. Shock Value: How a Few Eccentric Outsiders Gave Us Nightmares, Conquered Hollywood, and Invented Modern Horror. New York, NY: The Penguin Press.

Zolkos, Magdalena. 2011. "Violent Affects: Nature and the Feminine in Lars von Trier's Antichrist." Parrhesia. 13: 177-189.

Zwissler, Laurel. 2018. "'I am That Very Witch': On The Witch, Feminism, and Not Surviving Patriarchy," Journal of Religion \& Film. 22 (3): 1-33. 